Instituto de

Relaciones

Internacionales

\title{
Diplomacia de las Naciones sin estado y de los estados sin nación.
}

Argentina e Irlanda: una visión comparativa.

Maria Eugenia Cruset 



\section{Agradecimientos}

Quiero agradecer a mi tutor, el Dr.. Alejandro Simonoff, por su ayuda, consejo y concienzuda guía en la elaboración de esta tesis. Del mismo modo quiero hacerlo con mi co-tutor Edmundo Murray. De todos modos no debería responsabilizárseles por lo que en ella aparece.

También quiero dejar plasmada mi gratitud a la Embajada de Irlanda en Argentina y, en particular, a su Secretario Derek Lamber por hacerme traer material imprescindible para poder realizar mi trabajo.

Al Irish Institut, de la Queen`s University, en Belfast (Reino Unido), a su Director el Dr. Dominic Ryan y a todo su personal, por facilitarme acceder a sus cursos y tener así una visión más amplia de la historia y política de Irlanda.

A la Dra. Gloria Totoricaguena de la Universidad de Reno, EEUU, por brindarme material y darme su asesoramiento en el tema que ella trabaja que es el de las Diásporas.

Debo expresar mi agradecimiento a la Dra. Nancy Cardinaux, por haber leído la tesis completa y hacer útiles comentarios tanto de forma como e fondo.

Muchas de las ideas aquí expuestas fueron previamente discutidas y analizadas en distintos ámbitos como el IRI de la UNLP, la Universidad de Chile, la Universidad de Santiago (Chile) y la Universidad de Sevilla. Todas estas instituciones me ayudaron de alguna manera para que fuera posible por eso mi agradecimiento hacia ellas.

Al Dr. Raúl Zerbino, por acercarme bibliografía que no estaba a mi alcance. Pero más aún por su apoyo constante y su visión critica desde las ciencias exactas.

Mi gratitud a la Dra. Lucrecia Enriquez por su apoyo constante y su amistad.

A mis padres por inculcarme desde muy chica el amor al conocimiento y darme las herramientas para poder conseguir mis objetivos.

Finalmente deseo agradecer muy especialmente a mis tres hijos, Maria Paz, Maria Eugenia y José Francisco, por permitirme demostrarles que en el esfuerzo también hay satisfacciones y que valen la pena. 

Prólogo a cargo de la Sra. Philomena Murnaghan, Embajadora de Irlanda en Argentina

Introducción

Marco teórico

\section{CAPITULO I:}

\section{LA NACION Y EL NACIONALISMO}

Karl Marx: Nacionalismo y Burguesia

\section{CAPITULO II:}

LA DIPLOMACIA CIVILISTA: EL CASO ARGENTINO 29

El nacionalismo fundacional

\section{CAPITULO III:}

\section{IRLANDA: NACIONALISMO ROMANTICO}

\section{CAPITULO IV:}

\section{POLÍTICA EXTERIOR DE ARGENTINA E IRLANDA:}

\section{COMPARACIÓN}

1.a. Relación con Inglaterra:

b. Relaciones bilaterales/multilaterales:

c. Relación con Estados Unidos de América:

2. Los objetivos:

3. el estilo 
CONCLUSION

Aquí estudiamos principalmente la relación bilateral de los dos países con Inglaterra y con los Estados Unidos. 68

2. Los objetivos:

3. el estilo

Identidad Nacional 71

El caso argentino 75

APENDICE DOCUMENTAL 75 DOCTRINA DRAGO

Declaration of independence

Message to the Free Nations of the World 


\section{Prólogo a cargo de la Sra. Philomena Murnaghan, Embajadora de Irlanda en Argentina}

Estoy muy contenta por haber sido invitada a escribir un preámbulo a la tesis finalizada por la Sra. María Eugenia Cruset, en la cual se comparan la política exterior de Argentina e de Irlanda. Argentina e Irlanda comparten muchos lazos históricos, culturales y humanos. Existe mucho material sobre este y otros temas relacionados. Debemos felicitar a la Sra. Cruset por haber encontrado un ángulo tan novedoso para mirar a estos dos países la influencia en la política exterior del desarrollo político interno de cada país, y la interacción entre ambos. De esto, ella desarrolló una teoría de las influencias potenciales que los orígenes de un país podrían tener sobre el desarrollo de su política exterior, dependiendo si emergió como "una nación sin estado" (Irlanda) o "un estado sin nación" (Argentina). En este estudio, la Sra. Cruset consideró un número de temas interesantes que ofrecen un valioso material para un estudio más profundo que espero que ella u otros se sientan alentados a seguir. Me gustaría tomar esta oportunidad para desearle a la Sra. Cruset todo lo mejor en sus futuros emprendimientos.

Philomena Murnaghan

Embajadora de Irlanda Buenos Aires, 4 de mayo de 2007 



\section{Introducción}

El nacionalismo como objeto de estudio es nuevo. Sin embargo, muchos de los hechos sociales del presente o del pasado pueden ser mejor comprendidos a partir de él. En términos generales se puede hablar de dos grandes vías que conducen a la formación de los estados nacionales: A partir del concepto civilista de nación o a partir de la idea romántica. No todas las nacionalidades logran cruzar ese umbral que les permite convertirse en estados nacionales. Eso no significa que no exista en ellas el afán reivindicatorio.

La relación entre la política interna de los estados y su diplomacia es un tema bastante novedoso de estudio. Hay autores que tratan de analizarlo usando como método la teoría de los juegos y todo el andamiaje teórico que brindan las teorías de toma de decisiones. En este contexto es que el nacionalismo como ideología o, al menos, el imaginario que se tenga de la propia nación, constituye una variable de suma importancia a la hora de definir las políticas exteriores de los estados. ${ }^{1}$

Hay pocos temas tan sensitivos para el estudio como el nacionalismo. Pocos despiertan tan encontradas pasiones. Y en un mundo que parece desconocer las utopías es difícil encontrar una razón para matar o para morir. Sin embargo, un hecho tan abstracto y azaroso al mismo tiempo, como es el lugar donde uno nace parecería que sí las da plenamente.

A nadie escapa, principalmente a ningún argentino, el carácter peculiar de nuestro nacionalismo. Frases como "crisol de razas", " descendiente de los barcos" forman parte de nuestro acerbo cultural más profundo. Por otro lado parecería que lo más propio del ser nacional brotara solamente en los mundiales de fútbol o cuando se escucha el tango "La Cumparsita" estando en el exterior. Parecería en el arco opuesto los irlandeses. Aparentemente homogéneamente constituidos, genética y culturalmente. Luchando durante siglos por su derecho a un estado-nación.

Las Relaciones Internacionales de los estados se han estudiado por lo general des de la sola perspectiva exterior olvidándose de las políticas internas y de cómo influyen estas. Un nuevo acercamiento al tema se basa en esta interrelación dando una riqueza de análisis mayor.

Es en este contexto que el "imaginario" del negociador sobre su propia identidad y capacidades cobra una importancia central. Lo que pueda lograr y cómo lo consigue depende de lo que él piensa que puede conseguir a partir de sus atributos. En el caso de las nacionalidades su viabilidad y éxito en las negociaciones está íntimamente relacionado con el concepto de identidad nacional. Un estudio serio sobre los nacionalismos debe ser tenido en cuenta si se quiere hacer un análisis completo.

Entender como es el nacionalismo argentino o el nacionalismo irlandés, nos ayudará a descubrir las razones que los llevaron a tomar ciertas decisiones de política exterior,

\footnotetext{
$1 \mathrm{El}$ concepto de "imaginario" se toma aquí como el conjunto de representaciones y referentes a partir de los cuales una sociedad o una cultura alcanza a percibirse, a pensarse, a sentirse e, incluso, a soñarse a sí misma. Es por eso que "imaginario nacional" es un concepto profundamente enraizado en el de "identidad nacional".
} 
a actuar de determinada manera. Si nos acercamos al qué es (su esencia), podremos entender el cómo y el porqué.

\section{Marco teórico}

En esta tesis buscamos usar las teorías sobre el Nacionalismo como marco teórico a partir del cual entender la profunda relación que existe entre la política doméstica de los Estado-nación y sus relaciones internacionales. Esta relación es un tema bastante novedoso de estudio. Hay autores que tratan de analizarlo usando como método la teoría de los juegos y todo el andamiaje teórico que brindan las teorías de toma de decisiones. En este contexto es que el nacionalismo como ideología o, al menos, el imaginario que se tenga de la propia nación, se constituye en una variable de suma importancia a la hora de definir las políticas exteriores de los estados.

Dentro de este marco es que proponemos la tipificación de modelos de estudio (Paradigmas) a partir de los cuales se pueda analizar y comparar distintos contextos internacionales.

Una de las mayores dificultades que vamos a enfrentar es la de resolver que es una Nación y como se conforma. Qué hace que un grupo de personas se diferencie de otras hasta el punto de formar una comunidad distinta .Es evidente que a la hora de buscar esta diferenciación elementos como la lengua, la religión, el origen étnico, la historia en común son variables determinantes. No es un elemento solo lo que marca la diferencia es, más bien, la combinación original que cada pueblo realiza entre ellos. Hobsbawm en la introducción a su libro Naciones y Nacionalismo desde 1780, plantea de forma muy gráfica y, hay que decirlo también, con una buena dosis de fino humor, las enormes dificultades que existen para descubrir la esencia de las nacionalidades.

Supongamos que un día, después de una guerra nuclear, un historiador intergaláctico aterriza en un planeta muerto con el propósito de investigar la causa de la lejana y pequeña catástrofe que han registrado los sensores de su galaxia...Nuestro observador, después de estudiar un poco, sacará la conclusión de que los últimos dos siglos de historia humana del planeta Tierra son incomprensibles si no se entiende un poco el término "nación"...Este término parece expresar algo importante en los asuntos humanos. Pero, ¿exactamente qué?. Ahí radica el misterio. ${ }^{2}$

Teniendo en mente esta gran dificultad debemos seguir avanzando para tratar de comprender como es que se forman esas naciones. Es decir, dejamos paso al tema sobre la esencia de una nación para avanzar hacia el modo de su formación. Nosotros creemos que existen dos grandes vías las cuales se pueden dar en estado puro pero también en diferentes combinaciones:

Por un lado está lo que algunos autores llaman el "nacionalismo genealógico"3 y que nosotros llamamos "nacionalismo romántico". Es el concepto surgido a partir de este movimiento filosófico-cultural en Europa en la década de 1830. Para estos intelectuales es la vuelta a los sentimientos, a las raíces más puras del ser nacional. La esencia del Romanticismo era la exaltación de los instintos y emociones en oposición al racionalismo exagera-

2 HOBSBAWM, ERIC. Naciones y Nacionalismo desde 1780. Barcelona, Ed. Crítica, 1995. Pag.9.

3 PALTI, Elías. La nación como problema. Argentina, Fondo de Cultura Económica, 2002. 
do de la Ilustración. En Alemania el fenómeno se transforma en el Idealismo Romántico de filósofos como Hegel y Kant y presentó el contexto ideológico para las reivindicaciones nacionales.

El Idealismo Romántico debe su nombre a la combinación de la teoría romántica con la concepción idealista del universo. Creían que el hombre carece de importancia si no forma parte de un grupo social y de un espacio (real o imaginario). Por lo tanto, se debía procurar el bien del grupo primero y así el individuo podrá alcanzar también beneficios. La sociedad y el estado son organismos sociales, producto de la evolución natural. Surge de la idea herderiana de Volksgeist o "espíritu del pueblo". Concibe a la nación como una entidad objetiva independiente de la voluntad de sus miembros.

Por el otro lado tenemos el "nacionalismo civilista" o "nacionalismo jacobino" Este concepto correspondería a la Ilustración y tendría un carácter artificial basado en un vínculo contractual. Según este concepto todos los nacionales de un país son ciudadanos. La ciudadanía iguala y unifica. Todos son iguales ante la ley sin importar su procedencia, lengua materna o religión. El estado se compromete a tratar a todos por igual: les brinda un sistema educativo en la lengua nacional (por lo general es un sistema escolar obligatorio en los primeros años), separa la Iglesia del Estado y tiende a ser laico.

Por un lado vemos un nacionalismo "de abajo", es el pueblo que toma conciencia de su ser nacional y reclama- con éxito a veces-, su hogar nacional. Son naciones sin estado que buscan un sitio, generalmente el pedido es sobre la tierra de sus ancestros, donde poder desarrollar sus originalidades religiosas, lingüísticas, etc. Por el otro lado tenemos los "estados sin nación", donde el movimiento es de arriba hacia abajo. El Estado cumple la función de unificar e igualar. Generalmente se ve en los estados plurinacionales como el francés, o en aquellos con una importante inmigración como es el caso de Argentina.

Cómo influye "un nacionalismo de arriba", con un estado fuerte e integrador, laico y civilista, en sus políticas diplomáticas? Qué papel tiene la diplomacia de carrera? Qué idea geopolítica tiene la dirigencia política? Del mismo modo: para un "nacionalismo de abajo" que necesita con ansias la aprobación del resto de las naciones, que papel juega la diplomacia formal junto a las redes de vínculos que se forman entre los que habitan el país y los que han emigrado ${ }^{4}$ ? Estos interrogantes serán las líneas directrices del trabajo y para responderlas es que compararemos las diplomacias de los estados sin nación y de las naciones sin estado a partir del estudio del caso argentino e irlandés, durante sus etapas fundacionales. Las diferencias y similitudes en sus objetivos de política exterior, sus métodos para alcanzarlos y sus resultados,- exitosos o no-, en el contexto de la época y en el nuestro actual.

\section{Metodología}

El carácter pasado de los hechos que se estudian obliga una in vestigación de carácter histórica basada en el estudio hermenéutico de fuentes de esta naturaleza. La palabra hermenéutica, del griego hermeneutiqué --que equivale en latín a interpretâri--, define el

\footnotetext{
4 En el caso irlandés es prioritario analizar los vínculos existentes entre los irlandeses de Irlanda y los irlandeses de la diáspora (en modo principal los que emigraron a EEUU).
} 
"arte de interpretar los textos, especialmente los sagrados, para fijar su verdadero sentido", según señala el Diccionario de la Academia.

Tanto para el caso argentino como para el irlandés nos centraremos en documentos emanados del gobierno (memorias ministeriales, principalmente del área de política ext erior, sesiones del Congreso, correspondencia oficial, partes de guerra), como de aquellas que nacen del sector civil de la población : periódicos, correspondencia privada, etc.

Por último, y como un complemento que ayude a tener una visión amplia del problema es que agregamos un anexo que estudia la creación de la conciencia nacional en los estados en general y en Argentina en particular. Además se incluyen dos apéndices: uno documental transcribe textual e íntegramente información contemporánea . El otro tiene un carácter estadístico y trata mayormente de explicar gráficamente el proceso migratorio en Argentina. El mismo, como se verá, forma parte de la quintaesencia del nacionalismo argentino como lo entendemos. 


\section{CAPITULO I \\ LA NACION Y EL NACIONALISMO}

\section{La Nación}

Los estudios sobre la nación y el nacionalismo son relativamente nuevos. Surgen como objeto en el período de entreguerras y toman fuerza después de la segunda. Durante el siglo XIX y comienzo del XX lo que existían eran narrativas contando el origen, -real o ficticio-, de cada nación.

Por nacionalismo algunos autores entienden la fórmula política o la doctrina que propone el desarrollo autónomo, autodeterminado, de una colectividad definida según características externas precisas y homogéneas, y considerada como depositaria de valores exclusivos e imperecederos (nación).

Es difícil una definición unívoca. El significado que se le ha dado a la palabra varía en cada idioma, con cada nacionalista, en cada período de tiempo. Shafer cataloga por lo menos cinco categorías distintas.

El amor por el suelo, la raza, la lengua y la cultura histórica común.

La aspiración a la independencia política, a la seguridad, al prestigio de la nación.

Una devoción mística a la nación o Volk, que es algo más que la suma de las partes. mis mo.

El dogma de que el individuo vive solo para la nación y la nación es un fin en sí

La nación propia debería dominar sobre las demás naciones y con ese fin emprender una acción agresiva.

Las definiciones más completas ponen el acento en dos factores: la autodeterminación y el autogobierno. Su origen se encuentra en Europa en el siglo XIX como respaldo ideológico que justificase los primeros movimientos nacionalistas. Raramente se presenta en "estado puro" y, en ocasiones se mezcla con conceptos similares pero distintos como son el patriotismo, el chauvinismo o el imperialismo.

¿Qué es pues una Nación?. Para algunos autores corresponde con un recuerdo histórico remoto, con una identidad lingüística o racial, con un espacio territorial y con una visión común de futuro. Pero en esencia la nación corresponde a un acto de voluntad que crea el hecho nacional y cesa cuando esa voluntad se extingue

Puede que lo mejor sea empezar por el concepto de la "nación" que resulta menos satisfactorio, a saber: el sentido en que Adam Smith utiliza la palabra en el título de su gran obra. Porque en ese contexto significa claramente nada más que un estado territorial.

Una buena definición es la que la ve como un grupo humano consciente de formar una comunidad, que comparte una cultura, se siente ligado a un territorio claramente delimitado, tiene un pasado en común y un proyecto para el futuro, y reivindica el derecho a gobernarse a sí mismo. Es necesario distinguir entre nación y grupo étnico pues este último no plantea la autodeterminación del grupo como demanda política.

Se pueden distinguir cuatro situaciones diferentes. ${ }^{6}$

\footnotetext{
5 BOBBIO, Norberto y METTEUCCI, Nicola. Diccionario de Política. México,Siglo XXI, 1997. Décima edición. 6 GUIBERNAU, Montserrat. Los nacionalismos. España, Ariel, 1996
} 
Reconocimiento cultural: Un estado-nación puede reconocer las "diferencias culturales" de su minoría o minorías permitiéndole el cultivo de su cultura.

Autonomía parcial: Disfrutan de cierto grado de autonomía política. Pueden contar con órganos de gobierno y pueden decidir sobre un gran número de cuestiones que les ha trasferido el gobierno central.

Federación: Es el nivel más avanzado de autodeterminación. Gozan de plenos poderes políticos que les permite decidir sobre la vida social, económica y política, sin ser realmente independientes.

Represión: En una categoría distinta se encuentran aquellas naciones que carecen completamente de reconocimiento por parte del estado que las contiene. La violencia es utilizada a menudo para su control.

Hay una diferencia entre nación y estado,- aunque en el habla coloquial se usan como sinónimos-. La primera es la comunidad que aspira a autodeterminarse políticamente y el segundo es el conjunto de instituciones políticas que aspiran poseer. El territorio es el nexo entre ambos.

Así, finalmente, encontramos estos cuatro elementos distintivos:

- constituida por una creencia compartida y un compromiso mutuo,

- que se extiende en la historia,

- ligada a un territorio particular,

- distinta de otras comunidades por una cultura pública distintiva- sirve para distinguir la nacionalidad de otras fuentes colectivas de identidad personal.

Sobre la antigüedad del concepto de nacionalidad los autores no se ponen de acuerdo. Para algunos es tan primitivo como la diferencia entre uno y los otros,- la idea griega de griegos y bárbaros-, la relación con un territorio, la idea que el servicio a la nación es una virtud. Para otros es un concepto fruto de la modernidad. Para Hobsbawm, por ejemplo, nace con la Revolución francesa. Para Geller su origen se asocia con la Revolución Industrial. Sin embargo parece que aquellos que lo ven solo como un fenómeno moderno y aquellos que lo hacen como continuación de un viejo tribalismo sólo están en lo cierto a medias.

Ahora bien, ¿Por qué es importante para una nación autodeterminarse?. Siguiendo a David Miller la mayor justificación para la autodeterminación es la justicia social ya que el estado es el redistribuidor de las riquezas. Otra es la protección de la cultura nacional, no es que el estado sea imprescindible para eso pero ayuda. Las culturas nacionales pueden decaer y lo único que se puede hacer es usar el poder del Estado para proteger aquellos aspectos que se juzgue como relevantes?

Por último, debemos considerar la defensa de la autodeterminación nacional como expresión de la autonomía colectiva. Supone que la gente tiene interés en modelar el mundo en asociación con otros con los que se identifica. La asociación histórica entre democracia y 
autodeterminación nacional no son arbitrarias. Sólo en un estado democrático puede garantizarse que la autodeterminación sea auténticamente nacional, opuesta a una clase o grupo gobernante. Siempre será más fácil lograr la justicia social en los estados con fuertes identidades nacionales y sin divisiones comunales internas. Lo ideal para los estados multinacionales es el federalismo y la descentralización que aseguran que cada comunidad tenga protegidos sus intereses frente a los del resto.

Resumiendo los principales argumentos a favor de la autodeterminación: un mejor esquema de justicia social, mejor protección y desarrollo de la cultura común, y mayor posibilidad de determinar el destino compartido de la colectividad. Esto forma un argumento poderoso para tratar que los límites de las naciones y los estados los cuales deberían coincidir en la medida de lo posible.

La afirmación de Gellner sobre el hecho que no todos los nacionalismos pueden ser satisfechos por la simple razón de que no hay "suficientes estados potenciales" que pudieran llegar a ser viables, es tan dañino como pensar que el sistema telefónico se bloquearía si todos los abonados decidieran llamar al mismo tiempo. Parte de una premisa errónea porque no contempla la posibilidad de estados multiculturales. ${ }^{8}$

El liberalismo ha generado dos doctrinas radicalmente distintas acerca de las fronteras de los estados. Una subordina la cuestión a consideraciones sobre derechos individuales y justicia. El Estado tiene determinadas obligaciones hacia sus ciudadanos y si este las satisface de manera adecuada, ningún grupo tiene derecho a reclamar la secesión. Por el contrario, si un Estado fracasa en esto explotando y oprimiendo a un grupo particular es probable que este grupo pueda proteger mejor sus intereses creando un estado propio y quedará justificado por ello. Birch, por ejemplo, establece cuatro condiciones en las que un grupo regional podría justificar su demanda de secesión: la previa inclusión a la fuerza de la región en el estado; fallos graves en la protección de los derechos y seguridad de los habitantes; fallo grave en la protección de los intereses políticos y económicos de la región; incumplimiento de una negociación implícita o explícita diseñada para salvaguardar los intereses esenciales de la región (por ejemplo un cambio constitucional). El punto dominante entre los políticos de la comunidad internacional se restringe al segundo supuesto.

En contraste con estas dos perspectivas liberales, el principio de nacionalidad no centra su atención ni en los intereses materiales ni en las preferencias individuales sobre fronteras, sino en las condiciones políticas que aseguran las identidades nacionales. El principio nos dice que desarrollemos la causa de autodeterminación donde sea posible.

El nuevo estado necesita ser viable en el sentido que pudiera atender a su seguridad territorial.

Parece haber tres razones que justifiquen casos de autodeterminación parcial en vez de la secesión:

Primero: cuando el territorio al que aspira una nacionalidad es tan pequeño que no es realista su funcionamiento.

Segundo: cuando coexiste otro grupo minoritario numeroso que está afiliado al estado nacional más grande.

Tercero: Cuando los habitantes se ven a sí mismos como poseedores de una doble identidad, por ejemplo: catalanes/españoles, escoceses/británicos. 
Avanzando sobre el tema es importante descubrir cuales son los criterios que definen a una nación. En la práctica pueden distinguirse tres:

- La asociación a un estado (actual o reciente).

- La lengua.

- La etnicidad.

El elemento de la lengua es el más importante. Naciones enteras pueden ser definidas como tales sólo por este criterio. Es casi imposible que personas que convivan usando lenguajes mutuamente incomprensibles puedan llegar a ser una comunidad. Las lenguas nacionales son casi siempre conceptos semiartificiales o incluso inventados. Son lo contrario de lo que la mitología nacionalista suponen que son, los cimientos primordiales de la cultura nacional y las matrices de la mente nacional. ${ }^{9}$

Excepto para los gobernantes y los alfabetizados la lengua no era un criterio de nación, e incluso para estos era necesario escoger una lengua vernácula nacional por encima de otras lenguas. De hecho la identificación casi mística de la lengua con la nacionalidad es más cercana a los ideólogos del nacionalismo como Herder que a las masas que utilizaban el idioma.

La lengua en el sentido herderiano,de la lengua hablada por el volk, no era un elemento central en la formación del protonacionalismo. Sin embargo, indirectamente llegaría a ser central para la definición moderna de la nacionalidad y para su percepción popular. Porque donde existe una lengua literaria o administrativa de elite, por pequeño que sea el número de personas que lo usa, puede convertirse en un elemento importante de cohesión protonacional por tres razones que Benedict Anderson indica acertadamente. En primer lugar crea una comunidad de esta elite, que si coincide o puede hacerse coincidir con determinada zona, puede ser modelo o experiencia piloto para la "nación" que todavía no existe. Hasta este punto los idiomas hablados no son ajenos a la nacionalidad futura.

La lengua oficial o de cultura de los gobernantes y la elite llegó a ser la lengua real de los estados mediante la educación pública y otros mecanismos administrativos.

En pocas palabras, salvo casos especiales, no hay razón para suponer que la lengua fuese más que uno entre varios criterios por medio de los cuales se indicaba la pertenencia a una colectividad humana. Las lenguas se multiplican con los estados y no éstos con aquéllas.

En relación con la etnicidad, el "parentesco". y la "sangre" tienen ventajas obvias para unir a los miembros de un grupo y excluir a los que son ajenos a él y, por consiguiente, ocupan un lugar central en el nacionalismo étnico.

La etnicidad en el sentido que le da Heródoto puede ser algo que une a poblaciones que viven en grandes territorios y que carecen de una organización política común, y forma con ellas algo que puede denominarse "protonacionales". Es muy posible que este sea el caso de los kurdos, los judíos, los vascos y otros. Esta etnicidad, sin embargo, no tiene nada que ver con lo que conforma la nación moderna: la formación de un estado-nación.

En realidad muy pocos movimientos nacionales modernos se basan en una fuerte conciencia étnica, aunque a veces inventan una sobre la marcha, bajo la forma de racismo. La etnicidad o la "raza" no son del todo ajenas al estado moderno. Las diferencias físicas son demasiado evidentes como para dejarlas de lado.

9 El caso de Suiza es interesante debido a que es un estado -nación en el que conviven cuatro lenguas nacionales, tres de ellas oficiales y donde el inglés es el idioma más compartido entre todos sus habitantes. Sin embargo, su fuerte estructura federativa nos hace pensar que su ejemplo sirve más para reforzar esta tesis que para refutarla. 
Aunque no la hemos mencionado aún la religión puede ser también un factor importante como es el caso de Irlanda y Polonia. De todos modos aún para estas dos naciones el principio religioso no fue el único y su uso se debió a una necesidad de diferenciación frente a los imperios dominantes,- Anglicano en el caso del Reino Unido, Ortodoxo para Rusia-. Sin embargo hay que reconocer que fue la variable más importante sobre la que se asentaron las reivindicaciones nacionalistas.

Para el caso de Irlanda, el cual trataremos con mayor profundidad en el capítulo 3, siglos de opresión basada en una legislación que forzaba a la conversión no pueden ser olvidados.

\section{El Nacionalismo}

Fundamentalmente, el nacionalismo es un principio político que sostiene que debe haber congruencia entre la unidad nacional y la política. Ya sea como sentimiento, ya como movimiento, la mejor manera de definirlo es teniendo en cuenta este principio. Sentimiento nacionalista es el estado de enojo que suscita la violación del principio o el de satisfacción que acompaña a su realización. Movimiento nacionalista es aquel que obra impulsado por un sentimiento de este tipo.

El nacionalismo es una teoría de legitimidad política que prescribe que los gobernantes de un territorio deben pertenecer étnicamente al mismo grupo que la mayoría de la población.

El problema del nacionalismo no surge en sociedades desestatizadas. No quiere decir que el problema surja en todos y cada uno de los estados. Un homb re sin nación no admite un encuadramiento en las categorías reconocidas y mueve a rechazo. Tener una nacionalidad no es un atributo inherente al ser humano, pero hoy en día ha llegado a parecerlo. Y esto es tan así que el poseer una nacionalidad se ha convertido en uno de los Derechos Humanos de la Carta de San Francisco. Y el no tener una se ha convertido en una tragedia de enormes dimensiones que abarca a los millones de desplazados, migrantes ilegales, despatriados, que existen hoy día en el planeta.

De hecho, las naciones, al igual que los estados, son una contingencia, no una necesidad universal. Ni las naciones ni los estados existen en toda época y circunstancia. Por otra parte, naciones y estado no son una misma contingencia. El nacionalismo sostiene que están hechos el uno para el otro, que el uno sin el otro son algo incompleto y trágico. No cabe duda que el estado ha emergido sin ayuda de la nación.

El nacionalismo concentra la lealtad suprema de la abrumadora mayoría del pueblo en el Estado nacional, realmente existente o deseado. El Estado nacional es considerado no solo como la forma ideal, "natural" o "normal" de organización política, sino también como la infraestructura indispensable de todas las actividades sociales, culturales y económicas.

Ha sido desde el principio un movimiento revolucionario, que ha tratado de transformar o derribar a los gobiernos "legítimos" del pasado cuyo derecho estaba basado en la ordenación divina o en la herencia. En el plazo de cien años ( 1815-1920), el nacionalismo ha transformado por completo el mapa de Europa y, a partir de 1947 ha cumplido la misma función revolucionaria dando una nueva forma a las configuraciones políticas de Asia y Africa.

A mediados del siglo XX, todos los "jóvenes" movimientos nacionalistas se han convertido también en movimientos "socialistas". Mientras que los "jóvenes” movimientos 
nacionalistas de mediados del siglo XIX distinguieron claramente entre socialismo y nacionalis mo.

El nacionalismo, en la segunda mitad del siglo XIX, fue considerado como la doctrina política de las clases superiores, de los derechistas en el espectro político de la época. Se afirmó en una profunda y represiva oposición frente al socialismo, un movimiento internacional que abarcaba a los trabajadores industriales y a los campesinos sin tierras. La primera gran revolución nacionalista, que revistió igualmente un aspecto socialista revolucionario, fue la Revolución mexicana de 1910-1917.

Sólo después de la segunda guerra mundial el socialismo se ha convertido en parte integrante de los movimientos nacionalistas revolucionarios, como en el Egipto de Nasser.

Lo que ha permanecido constante a través de todas sus transformaciones es la exigencia popular de un gobierno de la misma composición étnica que la mayoría. y la autodeterminación política.

Los teóricos del nacionalismo se han sentido a menudo desconcertados, por no decir irritados, ante estas tres paradojas:

La modernidad objetiva de las naciones a la vista del historiador frente a su antigüedad subjetiva a la vista de los nacionalistas.

La universalidad formal de la nacionalidad como un concepto sociocultural- en el mundo moderno todos tienen y "deben" tener una nacionalidad, así como tienen un sexo-, frente a la particularidad irremediable de sus manifestaciones concretas, de modo que por definición, la nacionalidad "griega" es sui géneris

El poder "político" de los nacionalismos, frente a su pobreza y aún incoherencia filosófica. En otras palabras, al revés de lo que ocurre con la mayoría de los "ismos", el nacionalismo no ha producido sus propios grandes pensadores.

Parecería que una idea tan evidente como es la de "cada nación un estado" no necesitara justificación alguna. Esto ha llevado a una cierta pobreza en el terreno de la intelec tualidad nacionalista y a una cierta condescendencia por parte del resto cosmopolita. Así Tom Nair: puede decir :" el "nacionalismo" es la patología de la historia moderna del des arrollo, tan inevitable como la "neurosis" en el individuo, con la misma ambigüedad esencial que ésta, una capacidad semejante intrínseca para llevar a la demencia, arraigada en los dilemas de la impotencia que afectan a la mayor parte del mundo ( el equivalente del infantilismo para la sociedad), y en gran medida incurable". ${ }^{10}$

Un gran estudioso del tema acuña la expresión de la nación como imaginada porque aún los miembros de la nación más pequeña no conocerán jamás a la mayoría de sus compatriotas, no los verán ni oirán siquiera hablar de ellos, pero en la mente de cada uno vive la imagen de su comunión. ${ }^{11}$

No hay emblemas de la cultura moderna del nacionalismo más imponentes que los cenotafios y las tumbas de los Soldados Desconocidos. La reverencia ceremonial pública otorgada a estos monumentos, justo porque están deliberadamente vacíos o nadie sabe quién yace allí, no tiene verdaderos precedentes en épocas anteriores...Por eso tantas naciones tienen tales tumbas sin sentir ninguna necesidad de especificar la nacionalidad de sus ausentes ocupantes. Qué otra cosa podrían ser sino alemanes, norteamericanos, argentinos ...?

10 ANDERSON, Benedict. Comunidades Imaginadas. Argentina, FCE., 1993. 
La significación cultural de estos monumentos se vuelve más clara aun si tratamos de imaginar, por ejemplo, una tumba del Marxista Desconocido o un cenotafio para los Liberales caídos. ${ }^{12}$

Podemos proponer algunas tipologías de nacionalismos:

La más simple es la que plantea Hans Kohn el cual distingue entre nacionalismo "occidental" y nacionalismo "oriental". El primero que floreció en los siglos XVII y XVIII en los países del occidente, del mundo atlántico, es una versión Iluminista nacionalista y pluralista que se amalgama con la revolución burguesa. El segundo nace en el siglo pasado en la Europa central y oriental extendiéndose a Asia.; partiendo de un complejo de inferioridad hacia el hermano mayor "occidental”, está obsesionado por la nostalgia histórica. ${ }^{13}$

Siguiendo una línea similar, pero acentuando el elemento ideológico, Carlton Hayes identifica seis tipos de nacionalismo: el humanitario (Herder), el jacobino, el liberal, el tradicional, el económico proteccionista ( escuela alemana) y el integralista totalitario. ${ }^{14}$

Snyder ofreció en un primer momento un esquema cronológico: Distingue cuatro fases: la integrativa que tuvo lugar desde 1815 hasta 1871, especialmente en la Europa central; la disyuntiva que va desde 1871 hasta 1900 y alcanza la desarticulación de las viejas unidades políticas; la agresiva que va desde 1900 hasta 1945, o sea desde la tentativa hegemónica germánica hasta su frustración; la contemporánea, que va desde 1945 en adelante y que se caracteriza por la difusión del fenómeno a escala mundial.

Trevor Roper distingue entre nacionalismo "histórico" representado por los movimientos alemán e italiano y húngaro, y nacionalismo "secundarios". Sustancialmente los posteriores a estos, comenzando por los movimientos checos y polaco hasta el sionismo. Serían secundarios porque nacen de una emulación o reacción de contagio de los nacionalismos "históricos" 15

Más complejos resultan los esquemas adoptados por Raoul Girardet y Anthony D. Smith. El primero propone seis criterios fundamentales: la situación histórica en razón de la cual se distingue el nacionalismo. Que intenta crear el estado nacional y aquel que se des arrolla en un estado nacional existente; la evolución económica (el retardo o disminución en materia de desarrollo económico puede conferirle tonalidades diversas a los nacionalismos); la motivación doctrinaria e ideológica en base a la cual se puede distinguir un nacionalismo de tipo liberal, un nacionalismo de tipo autoritario y un nacionalismo de tipo socialista; la postura social en función de la cual surgirían o bien un nacionalismo impregnado de complejo de inferioridad y por lo tanto angustiado e inquieto, o bien un nacionalismo satisfecho y eufórico "en un clima de potencia triunfante y de una sensación colectiva de superioridad". ${ }^{16}$

Smith propone un número menor de criterios: la intensidad (nacionalismo primit ivos o desarrollados), el éxito (nacionalismos triunfantes o derrotados, en curso de desarro1lo), el grado de diversificación (nacionalismos étnicos-místicos-territoriales). Tanto para la clasificación de Raoul Girardet como para la de Anthony D. Smith. Un mismo movimiento puede encajar simultáneamente en varias categorías.

11 ANDERSON, Benedict. Comunidades Imaginadas. Op. Cit. Pp.26 y 27

12 ANDERSON, Benedict. Comunidades Imaginadas. Op. Cit. Pp.26 y 27

13 BOBBIO, Norberto y METTEUCCI, Nicola. Diccionario de Política Op. Cit

14 BOBBIO, Norberto y METTEUCCI, Nicola. Op. Cit

15 BOBBIO, Norberto y METTEUCCI, Nicola. Op. Cit

16 BOBBIO, Norberto y METTEUCCI, Nicola. Op.Cit. 
Sobre estas tipologías nosotros optamos por una más simple en apariencia que se basa en el modo de formación de las naciones. Por un lado está lo que algunos autores llaman el "nacionalismo genealógico"17 y que nosotros llamamos "nacionalismo romántico". Es el concepto surgido a partir de este movimiento filosófico-cultural en Europa en la década de 1830. Para estos intelectuales la vuelta a los sentimientos, a las raíces más puras del ser nacional. La esencia del Romanticismo era la exaltación de los instintos y emociones en oposición al racionalismo exagerado de la Ilustración. Incluía otros elementos como el amor a la naturaleza, la informalidad, el amor sentimental. En Alemania el fenómeno se transforma en el Idealismo Romántico de filósofos como Hegel y Kant y presentó el contexto ideológico para las reivindicaciones nacionales.

El Idealismo Romántico debe su nombre a la combinación de la teoría romántica con la concepción idealista del universo. Creían que el hombre carece de importancia si no forma parte de un grupo social. Por lo tanto, se debía procurar el bien del grupo primero y así el individuo podrá alcanzar también beneficios. La sociedad y el estado son organismos sociales, producto de la evolución natural. Surge de la idea herderiana de Volksgeist o "espíritu del pueblo". Concibe a la nación como una entidad objetiva independiente de la voluntad de sus miembros.

El concepto de Volksgeist, es decir, de genio nacional, aparece en 1774 con Herder. Para él todas las naciones de la tierra tienen un modo de ser único e irrepetible y valores universales como el Bien, Verdad o Belleza quedan en segundo plano. Es innegable las potencialidades totalitarias que tiene. El estado y su voluntad están por encima de los individuos. El genio nacional suprime al individuo y a la humanidad. La negación del individuo engendra un poder sin límites. Y así la idea del Volksgeist se transforma en el explosivo de los tie mpos modernos.

Los nacionalismos étnicos se proponen crear naciones a partir de etnias preexistentes. Fundamental para esta concepción era la importancia que se daba a la genealogía. La nación étnica tiene su poder y legitimidad en la voluntad de la mayoría de sus miembros y no sólo de las elites. El objetivo es la comunidad y no el individuo. Se pone énfasis en la cultura del pueblo, su lengua nacional y pasan a ser instrumentos en la lucha contra los opres ores. Son armas de combate y en su nombre se libran las batallas. Esta fue la herencia de Herder y sus seguidores.

Por el otro lado tenemos el "nacionalismo civilista" o "nacionalismo jacobino" Este concepto correspondería a la Ilustración y tendría un carácter artificial basado en un vínculo contractual. Según este concepto todos los nacionales de un país son ciudadanos. La ciudadanía iguala y unifica. Todos son iguales ante la ley sin importar su procedencia, lengua materna o religión. El estado se compromete a tratar a todos por igual: les brinda un sistema educativo en la lengua nacional (por lo general es un sistema escolar obligatorio en los primeros años), separa la Iglesia del Estado y, por lo general, tiende a ser laico.

Es en esta línea que el estado adopta una concepción civilista y amplia de la ciudadanía, otorgándosela a todos los hijos nacidos en territorio nacional. Siguiendo el trabajo clásico de Marshall sobre el tema vemos que esta se puede expresar en tres ámbitos:

civil (libertad personal y de expresión, a la propiedad, acceso a la justicia), político ( derecho a participar en el ejercicio del poder) 


\section{social ( seguridad social, bienestar económico). Por supuesto que la clase d- rigente sólo pensaba en el ámbito ci vil y con restricciones. ${ }^{18}$}

La celebrada declaración de Clermont-Tonnerre realizada en 1789 ante la Asamblea Nacional, por la cual se les concedía la ciudadanía francesa a cambio de que renunciase a su etnicidad judía, ha sido considerada expresión clásica del nacionalismo civil y sigue constituyendo la marca de fábrica del concepto civil de nación. De acuerdo con este punto de vista, todo miembro de una nación quedaba convertido en ciudadano, dotado de todos los derechos y obligaciones que ello lleva aparejado. La nación era una comunidad de ciudadanos

A los judíos como nación no les concedemos nada; a los judíos en tanto individuos se lo concedemos todo. ${ }^{19}$

El estado moderno, que recibió su forma sistemática en la era de la Revolución francesa, se define como un territorio (preferiblemente continuo) sobre el que se gobernaba la población de forma directa y no mediante intermediarios. Y se encontró con que debía tomar nota de la opinión de los súbditos o ciudadanos. En resumen, el estado gobernaba a un "pueblo" definido territorialmente.

El gobierno y el súbdito o ciudadano se veían relacionados en lo cotidiano como nunca antes se había dado. Con el tiempo los estados fueron necesitando de una especie de religión cívica, el "patriotismo" dado que cada vez más requerían de ellos. La nación se convertía en una elección política de sus miembros. Es el concepto francés de la nación como un plebiscito. La nacionalidad francesa era la ciudadanía francesa: la etnicidad, la historia, la lengua que se hablaba en el hogar no tenían nada que ver con la definición de "la nación”.

Los estados usarían la maquinaria para propagar la imagen de la nación. La escuela primaria fue vital en esto. Sin embargo, los mejores resultados se daban cuando se podía manipular un sentimiento nacionalista extraoficial ya existente.

Para los nacionalistas civilistas la condición previa a cualquier nación es el "país". El Estado nacional, que es salvaguarda de la nación, consolida el espacio nacional y regula la vida de los ciudadanos.

Una última característica de las naciones civiles es su empeño en imponer una cultura pública y una "religión civil". Así se explica la importancia de un sistema educativo generalizado, público y unificado. Una educación basada en la lengua común.

Estas dos concepciones "clásicas" de la nación, la civil y la étnica, han dominado los horizontes del nacionalismo y la construcción de los Estados nacionales en todo el mundo. Pero también existe una presencia simultánea.

Para la minoría interior el precio a pagar es muy alto: una total asimilación y la pérdida de la identidad étnica a cambio de los beneficios de la ciudadanía. No es simplemente una ideología de crisol. En la nación cívica el ideal fue la asimilación de la cultura mayoritaria a través de la aculturación. Era algo lógicamente exigido por la igualdad de todos los ciudadanos.

Por un lado vemos un nacionalismo "de abajo", es el pueblo que toma conciencia de su ser nacional y reclama - con éxito a veces -, su estado nacional. Son naciones sin estado que buscan un sitio, generalmente el pedido es sobre la tierra de sus ancestros, donde poder desarrollar sus originalidades religiosas, lingüísticas, etc. Por el otro lado tenemos los

18 MARSHALL, T.H. y BOTTOMORE, Tom. Ciudadanía y clase social. Madrid, Alianza Editorial, 1998. 19 SMITH, Anthony D. Tres conceptos de Nación. En: Revista de Occidente.Madrid, octubre 1994, n 161. 
"estados sin nación", donde el movimiento es de arriba hacia abajo. El Estado cumple la función de unificar e igualar. Generalmente se ve en los estados plurinacionales como el francés, o en aquellos de reciente creación en "territorios vacíos" ${ }^{20}$, con una importante inmigración como es el caso de Argentina.

Para concluir con este capítulo queremos explicar brevemente las concepciones de dos teóricos importantes que darán su visión sobre el nacionalismo. Marx, y Gellner.. El primero por ser opuesto y crítico al nacionalismo y el segundo por ser el iniciador del debate dentro del socialismo inglés y uno de los aportes modernos más significativos.

\section{Karl Marx: Nacionalismo y Burguesia}

Carlos Marx puede inscribirse dentro de la corriente de pensadores socialistas. Sin embargo, su tipo de socialismo llamado "socialismo científico" fue el que mayor influencia ejerció. Nacido en Alemania en 1818 vivió la mayor parte de su vida en Inglaterra por motivos políticos. Allí escribió sus más conocidas obras como son el Manifiesto Comunista (1848) junto a Federico Engels y El Capital (1867).

Los principios fundamentales de su teoría pueden resumirse de la siguiente manera:

1. Interpretación económica de la historia: Todos los movimientos importantes de la historia tanto políticos como sociales, intelectuales e incluso religiosos tienen una causa económica. Esta causa no es la única, ni mucho menos, pero sí es la determinante en última instancia. Todos los sucesos históricos fundamentales se deben a cambios en los medios de producción.

2. Materialismo Dialéctico: Cada sistema económico encierra en sí mismo el germen de la contradicción. Frente a cada modo de producción se va gestando lentamente uno que le es opuesto y que a la larga reemplazará al primero. Es un sistema dinámico dónde la tesis se opone a la antítesis para llegar a la síntesis. Este método lo toman de Hegel y, aunque conservan lo esencial, invierten la base. Para el marxismo será el mundo material y no el de las ideas. Sin embargo, esta inversión no cambia la concepción de la historia como un proceso donde las apariencias históricas están vinculadas por su esencia. ${ }^{21}$

3. Lucha de clases: La historia consiste en la lucha de clases. Una clase oprimida que hace la revolución contra la clase opresora hasta que toma el poder y se vuelve ella misma en opresora. Es lo que pasó con la burguesía que al tomar el poder con la Revolución Francesa perdió su "misión histórica" al no transmitir sus beneficios a las demás clases más desposeídas sino que se quedó con todo para si. Por eso esa misión ahora recae en el proletariado el cual al llegar al poder sí construirá una sociedad justa para todos, la comunista.

4. Doctrina de la plusvalía: El trabajador genera toda la riqueza pero la misma es apropiada por el capital que es el dueño de los medios de producción. Lo que gana el obrero como salario no representa la el total de esa riqueza que produce. La di-

20 Entendemos que este concepto es inexacto y poco feliz. Sin embargo, lo aplicamos con un sentido didáctico para representar una situación geográfica-histórica característica del cono sur de América y que no pretende en lo más mínimo menospreciar la existencia de pueblos pre-existentes con cult uras rícas y originales.

21 Para ampliar este tema:D`HONDT, Jacques. De Hegel a Marx. Buenos Aires, Amorrortu editores, 1974. 
ferencia entre lo que recibe y lo que se queda "indebidamente" el capitalista se llama plusvalía. Esta es a los ojos de Marx lisa y llanamente un robo. La solución es quitar los medios de producción a los burgueses y entregárselos a los proletarios.

5. Teoría de la evolución socialista: Cuando el proletariado gane la revolución morirá el capitalismo y comenzará el socialismo. Este deberá pasar por varias etapas: la dictadura del proletariado, el socialismo y, finalmente, la más elevada de todas, el comunismo.

En líneas generales el Materialismo Histórico es opuesto al Nacionalismo. En el Manifiesto Comunista, Marx describe la historia en términos de lucha de clases. Para él naciones, estados y ciudades deben ser estudiadas y evaluadas dentro del contexto y desde la perspectiva del lugar que ocupan en las relaciones de clases y en la lucha de clases que se desarrolla a escala global. Además, considera al nacionalismo como una expresión de los intereses de la burguesía y como una forma de "distracción" que ejercen sobre el proletariado para que este no "tome conciencia" de su situación y haga la revolución. Para él hay que buscar la liberación de los individuos como individuos y no la liberación de los alemanes como ale manes. Escribe:

La nacionalidad del trabajador no es francesa, inglesa, alemana, es el trabajo, la libre esclavitud, el tráfico de sí mismo. Su gobierno no es francés o inglés ni alemán, es el capital. El aire que respira no es el aire francés ni el inglés ni el alemán, es el aire de las fábricas. ${ }^{22}$

Sin embargo, apoyó junto con Engels algunas causas nacionales como las de Hungría, Polonia y Alemania. Incluso en el caso irlandés Engel llega a decir que el internacionalismo no debe usarse como excusa para justificar y perpetuar el dominio del conquistador. Con esto no pretende ninguna reivindicación de carácter nacionalista. Marx considera a la clase obrera como una clase internacional que debe unirse por encima de las pertenencias nacionales y predijo la abolición del estado.

A la muerte de Marx, a fines del siglo XIX, sus partidarios se dividieron en dos grupos: los Revisionistas, que entendían que había que adecuar sus ideas al nuevo contexto mundial, y los Ortodoxos sostenían que no debía modificarse nada en absoluto. Los primeros buscaban reformas más inmediatas aunque esto significara acceder al poder no por la vía revolucionaria sino de la elección democrática. Esto constituía para los segundos una traición y una claudicación frente al modelo burgués. Asimismo veían con enorme desagrado como los Revisionistas aceptaban reconocer los intereses nacionales, apoyando las ideas de patriotismo e, incluso, apoyando en los parlamentos los incrementos presupuestarios para aumentar los armamentos o extender el servicio militar. Por lo general, los revisionis tas tomaron el control de la mayoría de los partidos socialistas occidentales. El Partido Socialdemócrata de Alemania, el Socialismo Unificado de Francia son un ejemplo. ${ }^{23}$

Aún así, es posible encontrar algunas similitudes entre nacionalismo y marxismo. Estas semejanzas son las que han contribuido a la unión de estas dos ideologías en diferentes países. Ambas son lo que Smith denomina "movimientos de salvación". Ambas se refieren al presente como una situación de opresión, en la que los individuos viven alienados (marxismo) o han perdido su identidad (nacionalismo). 
Nacionalismo y marxismo comparten el mito de una era final de justicia y libertad, aunque perciben el pasado en forma distinta. El nacionalismo lo ve como fuente de inspiración para restaurar la identidad nacional y liberar a la nación de sus opresores. El marxismo propugna una concepción dialéctica del desarrollo histórico, en la que el pasado se acepta con el fin de trascenderlo y avanzar a través de los estadios de la historia.

Otras características que ambos comparten: El estado-nación moderno es el escenario para sus luchas; dan lugar a movimientos sociales activos debido a su carácter "mesiánico"; aunque dan una importancia grande a las masas, la dirección del movimiento queda en manos de un grupo de intelectuales.

Las diferencias más profundas: el nacionalismo pone mayor énfasis en la cultura y el marxismo en las raíces económicas de cada fenómeno. Los marxistas consideran su enemigo al capitalismo sin tener en cuenta su nacionalidad. Ambos interpretan al pasado de forma distinta.

\section{Las paralelas se cruzan en el infinito}

"Las paralelas se cruzan en el infinito" dice la geometría y parecería que también es posible en el mundo de las ideologías. De hecho es una buena explicación sobre como dos ideologías aparentemente (o no tan aparentemente) opuestas llevadas a su máxima expresión suelen parecerse. Por supuesto que esto no es siempre así. Aunque tentador debemos reconocer que puede ser superficial este análisis. Sin embargo, con mucha cautela vamos a seguir por esta línea.

Tzevan Todorov, filósofo y lingüista búlgaro contemporáneo tienen en uno de sus últimos libros una aproximación al fenómeno del Estado totalitario a partir del estudio del estalinismo y el nazismo. A través de seis víctimas destacadas de los mismo. Estos son: Vassili Grossman, Margarete Buber-Neumann, David Rousset, Primo Levi, Romain Gary y Germaine Tillion. ${ }^{24}$

Tal vez no es necesario decir que el nazismo (Nacional-Socialismo) es la expresión extrema del nacionalismo tanto como el estalinismo lo es del marxismo. Deberíamos agregar que lamentablemente no son las únicas. Parecería que lo nuclear de su parecido está en que ambos se expresan en regímenes totalitarios. Por eso, y siguiendo nuevamente a Todorov, tratemos de desmenuzar cuales son los elementos básicos que lo definen. Y estos son: colectivismo, teología, clasismo, monismo, utopismo, milenarismo, despotismo y cientificis mo.

El estado totalitario se construye en función de la colectividad. El individuo sólo es valioso en función de un todo. Todas las facetas de la vida individual,- incluso aquellas más privativas del yo como pueden ser las creencias religiosas, los sentimientos y gustos-, se diluyen en la norma pública.

El estado pronto llega a convertirse en absoluto y necesita la adhesión "cuasireligiosa" de los ciudadanos. Se crea una liturgia nueva que sustituye la de las antiguas religiones. Nuevos dioses reemplazan a los anteriores y un nuevo culto a las personalidades de los líderes se afirma.

24 TODOROV, Tzvetan. Memoria del mal, tentación del bien. Indagación sobre el siglo XX. Barcelona, Ed. Península, 2002. 
El utopismo y milenarismo tienden a unirse en la propaganda que promete la felicidad plena, el paraíso en la tierra. Las utopías que proclaman tienen su origen en el milenarismo cristiano del s. XIII. Es fácil entender la visión mesiánica que engendran estos movimientos y el despotismo intrínseco.

El cientificismo otorga una base pseudo científica al totalitarismo. La propia ideología reviste caracteres "científicos" que le otorgan un plus de legitimidad. Suministra el único pensamiento racional adecuado para dominar el universo y construir una sociedad perfecta.

El último elemento que queda por analizar, el clasismo, es un contrasentido. Aunque proclama la igualdad la sociedad totalitaria se basa en profundas diferencias. Su sistema es una pirámide fuertemente estratificada basada en el ejercicio del poder. Es una sociedad vertical aunque prefiera definirse como horizontal e igualitaria.

Parecería que su más terrible consecuencia, la deshumanización del hombre,- la pérdida del valor intrínseco del ser humano-, también lo comparten. Y ambos llevándolo a lo más vil que ha conocido el siglo XX: los campos de concentración y el genocidio.

\section{La Teoría del Nacionalismo de Gellner}

Los escritos de Gellner ofrecen el mejor punto de partida para discutir el papel de la cultura en la creación del nacionalismo. Según él, la sociedad industrial se basa en un crecimiento económico constante; esto engendra movilidad social y ésta produce igualitarismo. El ndustrialismo implica una división del trabajo compleja y requiere un sistema educativo es pecializado y universal, capaz de proporcionar a los individuos herramientas para su trabajo y estas son una lengua común y una alfabetización estándar. Para sostener un sistema educativo cuya función es la producción de una "cultura estándar" se necesita un estado centralizado.

Propone dos definiciones provisionales:

1. Dos hombres son de la misma nación si y sólo si comparten la misma cultura., entendiendo cultura como un sistema de ideas y signos, de asociaciones y de pautas de conducta y comunicación.

2. Dos hombres son de la misma nación si y sólo si se reconocen como pertenecientes a la misma nación.

La primera sería cultural y la segunda voluntarista. Son buenas las dos pero ninguna es por sí suficiente.

La humanidad está entregada a la sociedad industrial y se convierte en una sociedad con un sistema productivo orientado a la acumulación de ciencia y tecnología. El nacionalismo es una consecuencia de la revolución industrial pero no la única. La historia actual tiende a combinar los efectos del nacionalis mo con las restantes consecuencias del industrialismo; pero aunque el nacionalismo es una consecuencia de la organización social industrial no es la única y sería bueno separarla de los otros procesos.

La interesantísima relación entre Reforma y nacionalis mo ilustra bien el problema. La insistencia de la primera en la alfabetización y el escrutinio, su hostilidad al clero monopólico, su individualismo, etc. son factores que según nuestro modelo anuncian el nacionalismo. El nacionalismo también está relacionado con el colonialismo, imperialismo y descolonización. 


\section{¿Qué es una nación? ${ }^{25}$}

En principio, para Gellner, habría dos candidaturas prometedoras para elaborar una teoría de la nacionalidad: voluntad y cultura. Ambas importantes y relevantes pero no suficientes.

La mayoría de los grupos que perduran se basan en una mezcla de lealtad e identificación (de adhesión voluntaria) e incentivos ajenos. Aún cuando la voluntad sea la base de una nación lo es de tantas otras cosas que no le permiten definir el concepto de nación de esta forma.

Actualmente los individuos viven inmersos en una cultura común, móvil y fluida que no permite usar este concepto tampoco.

Propone, pues, una tipología de los nacionalismos

Esta tipología se basa en varios factores. El primero es el poder. En una sociedad moderna no hay razón para plantearse la posibilidad de que no exista un estado centralizado. Siempre hay algunos que ejercen el poder y otros que no. Unos están más cerca de los puestos de mando que otros.

El siguiente elemento es el acceso a la educación. Es decir, el acceso a una serie de herramientas que le permitan desempeñarse competentemente en su medio cultural. A diferencia de lo que ocurre con el poder donde está bien definido los que tienen el poder y los que no, con la educación no pasa lo mismo. A partir de esto tenemos cuatro posibilidades:

Sólo los que tienen acceso al poder tienen acceso a la educación y se reservan el monopolio del acceso; que los que detentan el poder como los que no tengan acceso a la educación; que sólo los no detentadores puedan acceder a ella; finalmente, que ninguna de las partes tenga el acceso. ${ }^{26}$

Combinando los dos factores surge: igual acceso, igual carencia de acceso, y acceso inclinado a favor o en contra de los que detentan el poder.

Introducir un tercer elemento que para él es el más crucial desde el punto de vista del nacionalismo: identidad o diversidad de culturas.

La imposición de esta oposición binaria "unidad cultural/dualidad cultural" a la tipología que había establecido genera ocho posibles situaciones.

El autor, siendo socialista, critica la visión del marxismo por la cual le gusta pensar que los conflictos étnicos enmascaran el conflicto de clases y cree que sería mejor para la humanidad que esta máscara cayera y se libraría del prejuicio nacionalista. Lo que distingue este modelo del marxista es que en él no se menciona el control o propiedad del capital. Los únicos elementos que han servido como premisas han sido identidad de cultura, acceso al poder y acceso a la educación. El capital, la propiedad y la riqueza sencillamente se han ignorado de forma deliberada.

\footnotetext{
25 Acá hacemos referencia a la obra pionera de Renan (RENAN, Enest.¿Qué es una nación?. Madrid, Tecnos, 1985.), su conferencia en la So rbona el 11 de marzo de 1882, donde plantea a la nación como un acto de voluntad, un plebiscito diario, un contrato de los ciudadanos con el Estado. Es decir, lo que podríamos llamar el "modelo francés" en oposición al "modelo alemán":

26 La educación en manos de los que detentan el poder en el modelo del nacionalista civilista se convierte en una herramienta poderosa para igualar, integrar y unificar.
} 
El nacionalismo - el principio que predica que la base de la vida política ha de estar en la existencia de unidades culturales homogéneas y que debe existir obligatoriamente unidad cultural entre gobernantes y gobernados - no es algo natural como expresa la doctrina nacionalista. Sin embargo, como fenómeno- y no como doctrina presentada por los nacionalistas-, el nacionalismo es inherente a cierto conjunto de condiciones sociales; y estas condiciones son las de nuestro tiempo.

La idea clave es tan simple y tan fácil que podría ocurrírsele a cualquiera y por eso es que puede decir que siempre es natural.

Falsas teorías del nacionalismo:

1. El nacionalismo es natural, evidente y se auto genera. Su ausencia sólo puede deberse a una fuerte represión.

2. Es una consecuencia natural de ideas que nunca hubo necesidad de formular. La sociedad podría funcionar sin él aún en las sociedades industriales.

3. La "teoría del camino equivocado" que sustenta el marxismo: los marxistas fundamentalistas se complacen en pensar que el espíritu de la historia o la conciencia humana cometió una tremenda tontería. El mensaje que estaba destinado a despertar las conciencias a las clases, por un terrible error postal se entregó a las naciones.

4. Dioses oscuros: El nacionalismo es la resurrección de las fuerzas atávicas de la sangre o la tierra. Esta opinión es compartida con frecuencia tanto por los que están a favor como en contra del nacionalismo.

Ninguna de estas teorías le resulta remotamente defendible.

Las violaciones del principio nacionalista de congruencia entre estado y nación hieren profundamente al sentimiento nacionalista pero no todos lo hacen con la misma intensidad. El peor es la diferencia étnica entre dirigentes y dirigidos. Un grupo que tenga más de un estado asociado a su cultura , aunque en teoría está violando el principio nacional, ya tiene menos motivos de queja.

Gellner sostiene que la mayoría de los neozelandeses y la mayoría de los ciudadanos del Reino Unido son tan afines culturalmente que, sin asomo de duda, ambas unidades no se habrían separado si hubieran sido contiguas geográficamente. Nosotros pensamos que un ejemplo similar se puede encontrar entre Argentina y Uruguay, donde una mala política exterior y doméstica, la convirtieron en lo que podría considerarse como una misma nación en dos estados.

Por supuesto que estas ideas trajeron aparejadas muchas críticas. Desde aquellas que dicen que el modelo propuesto sólo puede aplicarse a Europa Occidental,- como postula Monts errat Guibernau ${ }^{27}$-, hasta algunas más complejas como las propuestas por Roman Szporluk.

Para él el mérito de Gellner fue el ser el primero en establecer conexiones entre el nacionalismo y el marxismo. La Revolución Industrial cambió la relación entre el hombre y el mundo que lo rodea. El nacionalismo trata sobre la industrialización. Para los marxistas el nacionalismo era una interpretación alternativa del mundo y un programa rival para su transformación.

De igual modo que antes que Marx hubo socialistas ."utópicos" también halló pensadores nacionalistas que podrían ser considerados "utópicos". Idealizaron el órden social del pasado rechazando la industrialización y el cambio. List puede ser considerado como el 
fundador del "nacionalismo científico". Su sistema podía ser considerado genérico porque podía ser usado por cualquier nación.

Si List no hubiera existido habría sido necesario inventarlo. "El Marx del nacionalismo, pude decir a mis estudiantes, "fue Friedrich Lis t." 28

Gellner tal vez hubiera dicho que el nacionalismo y el marxismo contemplan el mundo con un ojo abierto, el izquierdo o el derecho: consecuentemente el nacionalismo ve una parte del cuadro y el marxismo la otra.

\section{Ruritania ${ }^{29}$}

Gellner utiliza Ruritania,- un lugar tan mítico como la tierra de Utopía de Moro o la Atlantida de Platón-, para explicar de forma gráfica el proceso de formación de las naciones. Es tan interesante y está tan bien hecho que merece que lo incluya mos aquí. ${ }^{30}$

Los ruritanos eran un grupo de campesinos que hablaban un dialecto común y vivían en regiones no muy separadas entre sí en el imperio de Megalomanía. La aristocracia hablaba el lenguaje megalómano. La mayoría de los ruritanos pertenecían a una iglesia cuya liturgia era en su id ioma. Los sacerdotes hablaban una versión culta de este lenguaje.

En el pasado , éste pasó por grandes aflicciones, conmovedora y hermosamente plasmadas en sus endechas...que se han hecho muy conocidas para el público musical internacional a través de las partituras del gran compositor nacional ruritano L...La penosa opresión sufrida...dio lugar en el siglo XVIII a la resistencia dirigida por el famoso bandolero generoso ruritano $\mathrm{K}$, cuyas hazañas, se dice, aún están vivas en la memoria popular local, sin contar varias novelas y dos películas, una de ellas producida por el artista nacional Z, bajo los más altos auspicios, muy poco después de la proclamación de la República Popular Socialista de Ruritania ${ }^{31}$

En el siglo XIX Megalomanía se industrializó. Los habitantes de la atrasada Ruritania debieron trasladarse a las ciudades donde eran pésimamente tratados por no tener el mismo idioma y ser, en su mayoría, analfabetos. Un grupo de jóvenes educado por el clero logra insertarse en la administración del imperio ayudados, además, por no existir diferencias étnicas significativas. Estos intelectuales, con el tiempo, formaron un movimiento de reivindicación nacional al cual se unieron otros grupos. Finalmente, cuando el terreno internacional se hizo propicio lograron la independencia. Es claro que al ser una clase educada obtuvieron los mejores puestos en la administración del nuevo estado. Posiciones mucho mejores a las que hubieran obtenido en el imperio.

Es evidente que el "modelo ruritano" puede aplicarse a muchos países. Pero sólo a aquellos que han logrado su formación como estado nación desde abajo.

28 SZPORLUK, Roman. En: may, John A. Estado y Nación. Madrid, Cambridge Universtity Press, 2000. Pag. 55. 29Ruritania es un país imaginario, situado en Europa Central, donde se desarrolla la historia de la novela El prisionero de Zenda y Ruperto de Hentzau, de Anthony Hope.

30GELLNER, E. Nación y nacionalismo.Alianza, 1981. Cap. V.

31GELLNER, E. Op. Cit. Pag.84. 


\section{CAPITULO II \\ LA DIPLOMACIA CIVILISTA: EL CASO ARGENTINO}

Nosotros creemos que existe una relación directa entre las políticas domésticas de los estados y su diplomacia. Y tanto una como otra están determinadas por el imaginario que sus dirigentes tengan de si mismos como nación. La praxis polìtica está determinada por el ser nacional. Por eso una nación civilista, como es Argentina en esta etapa, no puede menos que desarrollar una política exterior civilista. Lo que implica y las características propias que representa es lo que desarrollaremos en este capítulo.

La Argentina que nace después de 1810 y 1816 no puede ser considerada una nación propiamente dicha. Por mucho tiempo el país va a ser un estado sin nación. Incluso, el estado como tal, va a carecer de muchas de sus atribuciones básicas. Se puede afirmar que las provincias argentinas, por décadas, carecieron de un estado centralizado y unificador, que tuviera el monopolio de la fuerza legítima y la acuñación de moneda. Por otra parte, tamp oco estaba clara la jurisdicción territorial ni definidas sus fronteras.

La necesidad de ser reconocida su independencia internacionalmente, - tanto por una cuestión de geopolítica como por la de tener la posibilidad de obtener empréstitos en el exterior-, hizo que comenzaran a utilizar todo el simbolismo de los estado-nación, inculcándolo en la población y creando una especie de ilusión que no tenía asidero en la realidad.

La Independencia quitó el poder unificador que representaba la corona española y trajo como consecuencia la guerra civil y las luchas con potencias extranjeras. El inmenso territorio implicaba una gran variedad de intereses regionales, muchas veces contrapuestos entre sí, que llevaron a la anarquía durante décadas. La unión nacional tenía un significado distinto para cada sector.

Todo esto tuvo como consecuencia que no existía una idea de pertenencia nacional. El vínculo con el "pago", el lugar donde se vivía, era el que marcaba las lealtades y el sentimiento de pertenencia. Ni siquiera estaba claro el concepto de "argentino". Según las investigaciones de Ángel Rosenblat este término fue hasta la década de 1820 sinónimo de "porteño". De acuerdo con José Chiaramo nte en aquellos primeros tiempos el nombre de "Argentina" sólo era aplicado a una jurisdicción mayor a la de Buenos Aires, sólo si ese territorio estaba bajo la égida esa ciudad. ${ }^{32}$

Durante los siglos XVII y XVIII se formó en toda Hispanoamérica una especie de "protonacionalidad" que estaba basada en un idioma común, una religión compartida, un concepto de "raza" que distinguía a los españoles y criollos de las "castas" (negros, indios, mestizos, mulatos,etc.) y, a partir de las reformas borbónicas que beneficiaban a los peninsulares en detrimento de los americanos, un enemigo común.

Con los procesos de independencia de los estados americanos fue necesario ir destruyendo esa identidad creando nuevas y justificando las nuevas autonomías aunque la separación entre recién creados países fuera notablemente artificial,- aún para los parámetros generales -. A lo largo de las décadas los nuevos estados emergentes fueron destruyendo 
esa protonacionalidad y creando una nueva que fueron imponiendo a la población mayormente por medio del sistema educativo. Una nueva identidad nacional se fue creando bas ada en la exaltación de las virtudes propias contrapuestas a los vicios de los vecinos. Esto sumado a una concepción territorialista de la soberanía desencadenó en muchos casos enfrentamientos armados por disputas fronterizas.

Es en este contexto que todo lo que tiene que ver con pérdidas/ganancias territoriales en cada uno de los países de la región se han convertido en temas sensibles no sólo en la opinión pública de las poblaciones en general sino, incluso, en las áreas académicas.

La creación en 1776 del virreinato del Río de la Plata se debió a motivos estratégicos, la necesidad de frenar el avance portugués hacia el sur. A partir de entonces las economías del Tucumán, Cuyo, Bolivia y Chile, se reorientaron hacia el Atlántico. Buenos Aires pasó a ocupar el lugar de Lima y se convirtió en una ciudad rica, con una clase de comerciantes muy poderosa.

1810 significó la disolución del poder unificante de la Corona y la explosión de fuerzas centrífugas producto de intereses políticos y económicos contrapuestos. Todo esto confluyó en conflictos armados crónicos entre caudillos.

Durante la época de Rosas se fue gestando un lento ordenamiento económico y social que fue llevando a un cambio de mentalidad entre los argentinos.

Sin embargo, sólo a partir de 1880 se puede hablar de un estado consolidado en lo territorial y con un mayor grado de estabilidad política que logra una verdadera integración en el mercado internacional tomando su puesto en la producción de materias primas. ${ }^{33}$

\section{El nacionalismo fundacional}

La llamada generación del 80 no sólo sentará las bases ideológicas sobre las que se fundará el país, por lo menos hasta 1910, sino que llevará a cabo la praxis de dichas ideas y fundará una nación "moderna",- en términos de la época-,.

Dentro de las problemáticas que deberá enfrentar los gobiernos uno de los más significativos es el de integrar Argentina al mercado mundial. Para esto debía resolver el problema de enormes extensiones de tierras despobladas, habitadas mayormente por aborígenes. El tema del desierto y su solución se convirtieron en materia de estrategia nacional. $\mathrm{Su}$ correlato, la necesidad de poblar esas bastas latitudes con población extranjera, generó enormes consecuencias.

33 Siguiendo a Aldo Ferrer podemos hablar de cuatro etapas en el desarrollo económico argentino. La primera abarca el siglo XVI a fines del XVIII. Sería la etapa de las economías regionales de subsistencia y se caracteriza por varios complejos económico-sociales en distintas regiones del país. Tenían baja productividad y lo hacían para el consumo interno.

La segunda abarca desde fines del siglo XVIII hasta 1860 y la denomina de transición. Surge la producción de cueros y otros productos de la ganadería para el mercado mundial.

La t ercer etapa, - que es la que nos interesa-, se define como economía primaria exportadora, se abre en 1860 y se cierra con la crisis de 1930. Se caracteriza por la exportación de productos agropecuarios, la enorme inmigración y la radicación de capitales extranjeros.

La cuarta etapa, de la cual no nos ocuparemos pues excede el marco de este trabajo, comienza en 1930 y lo denomina de economía semi-industrial.

FERRER, Aldo, La economía argentina. FCE, Argentina, decimosexta impresión, 1996. Págs. 13 y 14. 
En base a la formación ideológica y a las necesidades concretas del país, es que se opta por un modelo civilista de nación a partir del cual construir la nueva Argentina. Recordemos algunos de sus principios básicos:

El "nacionalismo civilista" o "nacionalismo jacobino" es un concepto que corresponde a la Ilustración y tiene un carácter artificial basado en un vínculo contractual. Según este concepto todos los nacionales de un país son ciudadanos. La ciudadanía iguala y unifica. Todos son iguales ante la ley sin importar su procedencia, lengua materna o religión. El estado se compromete a tratar a todos por igual: les brinda un sistema educativo en la lengua nacional (por lo general es un sistema escolar obligatorio en los primeros años), separa la Iglesia del Estado y tiende a ser laico.

Es en esta línea que el estado adopta una concepción civilista y amplia de la ciudadanía, otorgándosela a todos los hijos nacidos en territorio nacional. De acuerdo con este punto de vista, todo miembro de una nación quedaba convertido en ciudadano, dotado de todos los derechos y obligaciones que ello lleva aparejado. La nación era una comunidad de ciudadanos

El estado moderno, que recibió su forma sistemática en la era de la Revolución francesa, se define como un territorio (preferiblemente continuo) sobre el que se gobernaba la población de forma directa y no mediante intermediarios. Y se encontró con que debía tomar nota de la opinión de los súbditos o ciudadanos. En resumen, el estado gobernaba a un "pueblo" definido territorialmente.

El gobierno y el súbdito o ciudadano se veían relacionados en lo cotidiano como nunca antes se había dado. Con el tiempo los estados fueron necesitando de una especie de religión cívica, el "patriotismo" dado que cada vez más requerían de ellos. La nación se convertía en una elección política de sus miembros. Es el concepto francés de la nación como un plebiscito. La nacionalidad francesa era la ciudadanía francesa: la etnicidad, la historia, la lengua que se hablaba en el hogar no tenían nada que ver con la definición de "la nación”.

Los estados usarían la maquinaria para propagar la imagen de la nación. La escuela primaria fue vital en esto. Sin embargo, los mejores resultados se daban cuando se podía manipular un sentimiento nacionalista extraoficial ya existente.

Para los nacionalistas civilistas la condición previa a cualquier nación es el "país". El Estado nacional, que es salvaguarda de la nación, consolida el espacio nacional y regula la vida de los ciudadanos.

Una última característica de las naciones civiles es su empeño en imponer una cultura pública y una "religión civil". Así se explica la importancia de un sistema educativo generalizado, público y unificado. Una educación basada en la lengua común.

Para la minoría interior el precio a pagar es muy alto: una total asimilación y la perdida de la identidad étnica a cambio de los beneficios de la ciudadanía. No es simplemente una ideología de crisol. En la nación cívica el ideal fue la asimilación de la cultura mayoritaria a través de la aculturación. Era algo lógicamente exigido por la igualdad de todos los ciudadanos.

Un tema interesante, y para el cual sólo arrimaremos algunas respuestas, es si el modelo civilista de nación era el único camino viable para la formación de Argentina. Nos da la impresión que en el país, así como hubo una fuerte división geopolítica, económica, ideológica, también la hubo sobre modelo de país y modelo de formación nacional. Mientras en el interior se gestaba uno más genealógico, basado en una relativamente grande homogeneización racial,- el criollo,- religiosa e idiomática, en Buenos Aires se buscaba 
otro modelo de país con las características que ya vimos. La famosa dicotomía "bárbaros" enfrentados a "civilizados" era también la lucha de dos "países" por ser. Si lo que surge de la Generación del ' 80 es el modelo Civilista es porque es este el que vence y se impone pero no porque era la única altern ativa. De hecho el modelo "vencido" no desaparece y parece que dormita hasta la década del treinta del siglo XX y llega a su clímax con el Peronismo.

No podemos olvidar la variable inmigración si es que queremos estudiar el nacionalismo argentino o el concepto de identidad nacional.

\section{La inmigración}

Para mediados del siglo XIX se visualiza en Europa: que la población había crecido enormemente. La falta de trabajo, la crisis agraria, las persecuciones de tipo religioso o político, hicieron que esas personas buscaran nuevos horizontes en países con condiciones económicas mejores.

Entre 1880-1890 llegaron al país 1.000.000 de europeos, sin embargo esa masa de hombre no alcanzaba para satisfacer las demandas externas. Entre 1880-1914 llegaron cerca de 6.000.000 de nuevos habitantes los cuales se radicaron definitivamente cerca de 4.000.000. Argentina pasó de 1.800.000 hab. en 1869, donde el $12 \%$ eran inmigrantes a 7.800.000 en 1914, siendo el 30\% extranjeros. El estado nacional invirtió 5.000.000 de pesos oro para pagar los pasajes de 130.000 personas.

Aunque el gobierno prefería la inmigración de personas del norte de Europa,- ingleses, alemanes, franceses -, con mayores calificaciones en materia de estudios y oficios, esto no se logró. La gran masa de población va a venir del sur, en particular de España e Italia. De hecho, la mayoría de estos eran analfabetos y, políticamente hablando, con fuertes simpatías hacia el socialismos y el anarquismo.

La mayor parte de los inmigrantes se establecieron en la Pampa Húmeda (Buenos Aires, Santa Fe, Entre Ríos y Córdoba), pero las tierras sembradas fueron prácticamente las de Santa Fe,- donde se utilizó un sistema llamado Colonización -, porque en Buenos Aires la tierra ya estaba en manos de grandes terratenientes promotores de la gran campaña contra los indios, años atrás. ${ }^{34}$

Muchos de ellos alcanzaron a "hacerse la América" (arrendatarios, propietarios, colonos, comerciantes), sobretodos los que llegaron antes de 1880, porque venían con algún capital para iniciarse laboralmente, sin embargo la mayor parte de ellos engrosaron las masas de peones rurales y urbanos, es decir, no pudieron llegar a ser propietarios.

Para fines de 1890 el $90 \%$ de los extranjeros vivía en las ciudades del área pampeana, y la población urbana superó a la rural por primera vez. Buenos Aires y Rosario fueron las de mayor crecimiento.

\footnotetext{
34 Cuando en Argentina hablamos de colonización estamos haciendo referencia al establecimiento de campesinos agricultores en tierras públicas destinadas para este fin. Este fenómeno viene unido al de la inmigración. El sistema de colonización consistía básicamente en un contrato. Un promotor traía familias de Europa, las asentaba en terrenos públicos donados por el estado y le reembolsaban sus gastos los propios inmigrantes a plazos. Uno de los primeros y más exitosos de estos empresarios fue Aarón Castellanos fundador de la colonia Esperanza en Santa Fe. De hecho este sistema tuvo un gran alcance en esta provincia y en la de Entre Ríos. En menor medida en Buenos Aires.
} 
La inmigración para la generación de intelectuales que influyeron en la construcción de la Argentina como nación, tenía una doble finalidad. Por un lado la existencia de una gran cantidad de mano de obra que permitiría incorporar al sector productivo las enormes extensiones de tierras ganadas a partir de la "Campaña al Desierto" ${ }^{35}$. Por el otro, lograr un cambio cultural que hoy llamaríamos de mentalidades.

Alberdi, el gran propulsor de la inmigración, intenta lograr un trasplante cultural. Para él la cultura tradicional hispánica es atrasada e impide el cambio y la innovación. Para lograr un cambio significativo era necesario que este viniera de afuera a través de la población inmigrante. ${ }^{36}$ Por eso llegó a afirmar que "en América todo lo que no es europeo es bárbaro" y por eso es necesario fomentar activamente la inmigración europea y norteamericana. Sus ideas manifestadas mayormente en su libro las Bases impregna ideológicamente la redacción de la constitución de 1853.

Un concepto similar es el que plantea Sarmiento. Para él el gaucho,- heredero de la tradición española que ve al trabajo manual como deshonroso-, es en sus términos un "salvaje" improductivo. No siembra ni cosecha, vive en ranchos miserables y no tiene intenciones de progresar. El europeo, en cambio, tiene una ética del trabajo que lo lleva a intentar superarse y mejorar. Este tipo de población es "civilizada" y civilizadora y, por eso no solo hay que permitirla sino fomentarla.

Por lo demás, de la fusión de estas tres familias "(españoles, indios y negros) ha resultado un todo homogéneo, que se distingue por su amor a la ociosidad e incapacidad industrial, cuando la educación y las exigencias de una posición social no vienen a ponerle espuela y sacarla de su paso habitual. Mucho debe haber contribuido a producir este resultado desgraciado, la incorporación de indígenas que hizo la colonización. Las razas americanas viven en la ociosidad, y se muestran incapaces, aun por medio de la compulsión, para dedicarse a un trabajo duro y seguido. Esto sugirió la idea de introducir negros en América, que tan fatales resultados ha producido. Pero no se ha mostrado mejor dotada de acción la raza española, cuando se ha visto en los desiertos americanos abandonada a sus propios instintos.

Da compasión y vergüenza en la República Argentina comparar la colonia alemana o escocesa del sur de Buenos Aires y la villa que se forma en el interior: en la primera, las casitas son pintadas; el frente de la casa, siempre aseado, adornado de flores y arbustillos graciosos; el amueblado, sencillo, pero completo; la vajilla, de cobre o estaño, reluciente siempre; la cama, con cortinillas graciosas, y los habitantes, en un movimiento y acción continuos. Ordeñando vacas, fabricando mantequilla y quesos, han logrado algunas familias hacer fortunas colosales y retirarse a la ciudad, a gozar de las comodidades. ${ }^{37}$

\section{El estado y la integración}

En los nacionalismos "de arriba", como es el caso del argentino, el estado tiene un papel central. A él le corresponde homogeneizar a la sociedad y convertirla en una nación.

35 Se llamó "Campaña al Desierto" a los dos avances militares contra el indio. El primero en 1833 por Juan Manuel de Rosas que llegó hasta el Río Colorado. La segunda encabezada por el General Julio Argentino Roca en 1879, llegó hasta el Río Negro.

36 BOTANA, Natalio R. El Orden Conservador. Argentina, Hyspamérica, 1986.

37 SARMIENTO, Domingo F. Facundo. Capítulo I. Disponible en Internet. 
Detengamos un momento para explicar el concepto "de arriba" y a qué nos referimos con él. A partir de la década de 1950 y aún más en la de 1960, procesos como la descolonización y la creación de nuevos estados del "Tercer Mundo", conviviendo con un fuerte impulso industrializador tanto en el occidente capitalista como en el mundo socialista, llevó a muchos intelectuales de las ciencias sociales a plantearse el desarrollo económico como objeto de estudio. Y esto no sólo con un afán teórico- académico sino con un fin práctico y político. De este tenor son los famosos debates entre Sweezy y Dobb donde se busca encontrar la clave del "despegue económico" a partir de modelos históricos. ${ }^{38}$ Dentro de este contexto, el papel que jugó y que debería jugar el estado era fundamental. Hay que aclarar que esta discusión no era menor y, mucho menos, ingenua. En el contexto de la guerra fría, donde se dieron estos debates, tomar partido por un Estado que "desde arriba" fomentaba la industrialización,-esto es "planificaba"-, o un modelo donde el sector privado (el mercado) era protagonista, significaba alinearse con alguno de los dos poderes que se disputaban el planeta.

Despolitizando el concepto y sacándolo del contexto histórico que hemos descrito, es que utilizamos el término "desde arriba" o sea, "desde el Estado" o, "desde abajo" sinónimo de "desde el pueblo", como herramienta de análisis.

La generación del '80 tiene esto muy claro. La enorme extensión de tierras del país necesitaba la introducción de grandes cantidades de mano de obra. La inmigración se convirtió en estratégica para el desarrollo del país. A esa masa heterogénea de personas, con idiomas, religiones, costumbres, tan disímiles había que convertirlos en argentinos.

Es en esta línea que el estado adopta una concepción civilista y amplia de la ciudadanía, otorgándosela a todos los hijos de inmigrantes nacidos en territorio nacional. Sguiendo el trabajo clásico de Marshall sobre el tema vemos que esta se puede expresar en tres ámbitos: a) civil (libertad personal y de expresión, a la propiedad, acceso a la justicia), b) político (derecho a participar en el ejercicio del poder) y c) social (seguridad social, bienestar económico. Por supuesto que la clase dirigente sólo pensaba en el ámbito civil y con restricciones. Sin embargo, es justo decir, que esta "ciudadanía limitada" era en muchos casos más generosa que la que gozaban en sus países de origen. ${ }^{39}$

Siguiendo con el planteamiento de Alberdi debían coexistir dos tipos de república: la república abierta y la república restrictiva. La república abierta estaría regida por la libertad civil; en ella tienen cabida todos los ciudadanos, nacionales y extranjeros. Esto es lo que se consagra en la Constitución nacional. Sin embargo, no tienen poder político alguno. No pueden ser gobernantes; no son electores ni representantes. Esto se logra mediante los mecanismos de la representación indirecta y la clara distinción entre habitante y ciudadano. La legislación electoral era el camino concreto para lograrlo. ${ }^{40}$

Los tres pilares sobre los que se asentó la "máquina de la integración", para llamarla de algún modo, fue: La creación del Registro Civil, la ley de Educación y el Servicio Militar Obligatorio. Los dos primeros son fruto de la obra de gobierno de la primer presidencia de Julio Argentino Roca y el tercero de su segundo mandato.

38 SWEEZY, Paul M. Y OTROS. La Transición del Feudalismo al Capitalismo. Argentina, Ediciones la Cruz del Sur, 1974.

39 MARSHALL, T.H. y BOTTOMORE, Tom. Ciudadanía y clase social. Op.Cit.

40 BOTANA,N. El Orden Conservador Op.Cit. 
Todas estas leyes sirvieron para integrar a un estado heterogéneo en lo cultural y en lo étnico. El resultado, más de cien años después, es un país con un sentimiento nacionalista muy original y un sentido de tolerancia étnica grande.

\section{1-La Ley de Registro Civil}

Los antecedentes más lejanos del Registro Civil los encontramos en la práctica de los censos de algunas culturas de Oriente; y que ya en la Roma Antigua, existieron datos censales desde la época del emperador Servio Tulio, siendo implantadas las normas sobre filiación en el siglo II d. C. La obligatoriedad del registro se logró mediante decreto que imponía a los padres registrar el nacimiento de sus hijos.

Al pasar a la Edad Media, la expansión de la Iglesia católica y su auge en las distintas esferas de la vida social la llevaron a tener el control del registro de los nacimientos y matrimonios. Los primeros libros parroquiales en donde aparecen inscripciones se encuentran en Francia, a mediados de siglo XIV.

Al disponer la libertad de cultos para los protestantes en Francia en 1787, Luis XVI dio pie al establecimiento de un incipiente Registro Civil en el que los nacimientos, matrimonios y defunciones eran inscritos ante los oficiales de la justicia real. El Registro Civil para todos los ciudadanos comenzó en 1793 como fruto de la revolución francesa y es hijo de la misma ideología que sentó las bases del nacionalismo civilista o jacobino.

$\mathrm{Su}$ creación es consecuencia de la división entre Iglesia y Estado. En Argentina se buscaba fomentar la inmigración, - sobre todo aquella del norte de Europa que no era católica-, y lograr la integración y homogeneización.

2-La Ley 1420 de Educación Común, de la enseñanza gratuita, obligatoria y la ica para todos los habitantes de 6 y 14 años. En esa época el índice de analfabetismo era muy grande.

La Ley de Educación Común, n* 1420, fue sancionada el 8 de julio de 1884. Su importancia fue enorme en el orden de asimilar e instruir. Todos los niños entre los seis y los catorce años de edad estaban obligados por ley a asistir a la escuela. No importaba sus antecedentes familiares, todos recibían los mismos estándares educativos mínimos en el idioma nacional.

Algunos artículos son particularmente significativos.

Art. $2^{\circ}$ - La instrucción primaria debe ser obligatoria, gratuita, gradual, y dada conforme a los preceptos de la higiene.

Art. $6^{\circ}$ - El mínimum de instrucción obligatoria comprende las siguientes materias: lectura y escritura; ... ; geografía particular de la República y nociones de geografía universal; de historia particular de la República y nociones de historia general; idioma nacional; moral y urbanidad; nociones de higiene; ... y conocimiento de la Constitución Nacional.

Para las niñas era obligatorio, además, el conocimiento de labores de manos y nociones de economía doméstica. Para los varones el conocimiento de ejercicios y evoluciones militares más sencillas; y en las campañas, algo de agricultura y ganadería.

El objetivo de la educación era lograr que esos niños finalizaran conociendo la geografía y la historia nacional. Debían dominar el idioma, - que muchas veces no era el mismo que hablaban en sus hogares,- debían conocer las estructuras políticas a través del conocimiento de la Constitución y debían convertirse en ciudadanos útiles al desarrollo de la nación: las niñas siendo buenas amas de casa, los niños siendo buenos agricultores y ganaderos. 
Art. $8^{\circ}$ - La enseñanza religiosa sólo podrá ser dada en las escuelas públicas por los ministros autorizados de los diferentes cultos, a los niños de su respectiva comunión, y antes o después de las horas de clase.

Este punto facilitaba la inmigración. Le educación religiosa se impartía fuera del horario escolar. Esto hacía que los niños pudieran conservar sus propias creencias en materia de fe.

Art. 11.- Además de las escuelas comunes mencionadas se establecerán las siguientes escuelas especiales de enseñanza primaria:

Escuelas para adultos, en los cuarteles, guarniciones, buques de guerra, cárceles, fábricas y otros establecimientos donde pueda encontrarse ordinariamente reunido un número, cuando menos, de cuarenta adultos ineducados.

Escuelas ambulantes, en las campañas, donde, por hallarse muy diseminada la población no fuese posible establecer con ventaja escuelas fijas.

El sistema educativo se flexibilizó lo más posible para poder integrar al mayor número de personas.

Art. 15.- Anualmente se abrirá en cada consejo escolar, un libro de matrícula destinado a inscribir el nombre, edad, sexo, comunión de sus padres, domicilio y demás indicaciones necesarias acerca de cada niño en edad escolar existente en el distrito.

Art. 23.- El censo de la población escolar se practicará simu ltáneamente, cada dos años por lo menos, en todos los diversos distritos escolares, en la forma y por los medios que se creyeran más adecuados para obtener la exactitud posible.

Carlos Escudé analiza el tema del sistema educativo argentino y lo hace responsable de un adoctrinamiento sistemático de la población,- que pasa de generación en generación -, en lo que llama el "Dogma de la superioridad nacional". Aunque es cierto que el comienza a estudiar el proceso con las reformas instrumentadas en 1908 por José Ramos Mejía lo que postula podría comprender nuestro período de estudio. ${ }^{41}$

Según este autor, la población había sido sometida al adoctrinamiento en las ideas que decían que el país era grande y de enorme importancia, que no podía ser marginado fácilmente, y que no tenía por que temer a las posibles de las grandes potencias. Son estas cualidades de nación implantadas por décadas en el imaginario popular, sumado al fenómeno de gran movilidad social que caracterizó nuestra historia, lo que hizo que no supieran medirse correctamente las consecuencias de ciertas medidas desacertadas en política ext erior. Incluso de apoyos masivos e irracionales del grueso de la población en acontecimientos tan nefastos como la guerra de Malvinas.

3-Se creó el Estado Mayor del Ejército, y se organizó el mismo, culminando en la Ley de Servicio Militar Obligatorio en 1901

El proyecto de ley sobre el Servicio Militar obligatorio cumplía con un doble objetivo: por un lado modernizar el ejército y, por el otro, servir como un factor de cohesión nacional.

Para lograr el primer objetivo se buscaron utilizar los modelos prusiano y francés. A través del nuevo sistema de reclutamiento se lograba una base muy amplia de soldados. También se buscó la profesionalización y jerarquización de los oficiales 
En cuanto al segundo objetivo, este era clarísimo. El propio ministro de Guerra y autor del proyecto, el general Pablo Ricchieri hablaba del servicio militar obligatorio como un sistema que iba a " acelerar la fusión de los diversos y múltiples elementos étnicos que están constituyendo a nuestro país en forma de inmigraciones."

Como la escuela pública, la conscripción estaba llamada a cumplir un papel disciplinador, moralizador y nacionalizador de la población que habitaba estas tierras. Debía normalizar esa heterogénea masa de jóvenes de diferentes orígenes sociales, culturales y étnicos para integrarlos a la "Argentina moderna".

Junto con estas tres leyes de carácter positivo que buscaban la integración y homogeneización de la población, se sancionaron otras absolutamente represivas. Para aquellas personas que no podían, o no querían, integrarse al modelo nacional impuesto por el gobierno, el Estado sancionó la Ley de Residencia en 1902.

Artículo 1º : El Poder Ejecutivo podrá ordenar la salida del territorio de la Nación a todo extranjero que haya sido condenado o sea perseguido por los tribunales extranjeros por crímenes o delitos comunes.

Artículo 20: El Poder Ejecutivo podrá ordenar la salida de todo extranjero cuya conducta comprometa la seguridad nacional o perturbe el orden público.

Artículo 3: El Poder Ejecutivo podrá impedir la entrada al territorio de la república a todo extranjero cuyos antecedentes autoricen a incluirlo entre aquellos a que se refieren los artículos anteriores.

Artículo 4: El extranjero contra quien se haya decretado la expulsión, tendrá tres días para salir del país, pudiendo el Poder Ejecutivo, como medida de seguridad pública, ordenar su detención hasta el momento del embarque.

Todas estas leyes sirvieron para integrar a un estado heterogéneo en lo cultural y en lo étnico. El resultado, más de cien años después, es un país con un sentimiento nacionalista muy original y un sentido de tolerancia étnica grande.

La Argentina del período de "la organización nacional", es decir de 1880 a 1916, es una nación nueva basada en los principios de la nacionalidad civilista. Y este modelo que se da a nivel interno va a encontrar su correlato en la política exterior. La estrategia que llevará a cabo la Cancillería será una proyección de la política doméstica y servirá para concretar sus grandes lineamientos. La necesidad de crecimiento económico, incorporando el país en el sistema de división internacional del trabajo, como país productor de materia primas (en concreto carnes y cereales), obligaba a hacer producir las enormes extensiones de terreno semi-vacío representado por el desierto. Y este objetivo sólo era posible gracias al fomento de la inmigración como mano de obra abundante y barata, y la radicación de capitales extranjeros que se ocuparan de la infraestructura. En particular con los ferrocarriles.

A partir de estos grandes objetivos estratégicos es que la política exterior va a tener dos facetas, la mundial y la regional.

\section{A La política mundial:}

Esta faceta se refiere a la inserción de la Argentina en la economía y políticas mundiales. Es en este plano que la conciencia de nación que ha logrado ciertos logros significativos como son el crecimiento económico, una administración estatal eficiente según los cánones de la época, una fuerte inmigración con estándares de vida de la población recién llegada superior en muchos casos a los de sus países de origen, un sistema político que en 
lo formal era democrático determina pautas de comportamiento en política exterior. Es por esto que Argentina se va a parar frente al concierto internacional como "uno entre iguales" y buscará las relaciones bilaterales. Esto al punto de sentir un verdadero desdén hacia toda clase de conferencias internacionales.

Por otro lado hay que reconocer que es una política Atlántica que da la espalda a las demás relaciones. Su condición de socio comercial preferencial con la Gran Bretaña le dará el apoyo regional que potencie sus relaciones regionales. Incluso, como veremos más adelante, teniendo una posición de rivalidad hacia EEUU.

El marcado apego hacia la defensa del derecho internacional como una salvaguarda de las soberanías de los estado-nación y su permanente neutralidad a nivel global, son sólo reflejos de esta condición de país.

En la Memoria de la Legación de la República Argentina "presentado al Presidente Señor General Roca- sobre la reunión del Congreso Pan-Americano de Méjico”. Dice el delegado:

$1^{\circ}$ La reunión de este Congreso es importante para los pueblos unidos del Perú y Bolivia, y allí puede afirmarse el prestigio de la República Argentina. Si la Rep ${ }^{\circ}$ Argentina no trabaja con energía y decisión en dicho Congreso, para hacer triunfar la causa justa del Derecho americano, condenando la usurpación y la conquista más vale que no concurra.

65

Está próximo á reunirse un Congreso Internacional en Méjico, al que han sido invitados los gobiernos del Norte, Centro y Sud América, con tal motivo me permito dirigir a $\mathrm{VE}^{\circ}$ éstas líneas indicando los rumbos de la política $\mathrm{E}^{\circ}$ nos conviene imprimir en dicho Congreso para facilitar y contribuir á la paz sudamericana y á levantar aún más el prestigio, en este Continente, de nuestra política, y con ella, el de nuestra patria.

El gobierno Argentino ha aceptado la invitación que le ha sido dirigida no solamente con el objeto de contribuir por medio de su representación diplomática á estrechar sus relaciones con toda la América, sino para levantar allí su voz y sostener el rango que le corresponde ante los demás Estados del Continente".

La PazSept. $51900^{42}$

\section{A. La política regional:}

Aquí nos referimos específicamente a sus relaciones con el continente. Y es en esta área donde se manejará sistemáticamente con una política de prestigio

La relación entre la Argentina y los Estados Unidos ha sufrido a lo largo del tie mpo numerosos cambios. Para nuestro estudio hemos decidido tomar la etapa que va de 1880 a 1910 por considerarla fundamental en la formación de ambas naciones y el comienzo de una relación ambigua y muchas veces tensa entre ellas.

Nadie puede cuestionar el papel fundacional que jugó la llamada "Generación del '80" en la formación de la nacionalidad argentina. Antes de este período el país se vio s umido en una serie de conflictos internos y de experimentos gubernativos que le impidieron tener una proyección más allá de sus fronteras que superase lo estrictamente comercial o bélico. ${ }^{43}$ 
Algo similar ocurre con los Estados Unidos. La Guerra Civil que duró de 1861 a 1866, y los posteriores años de reconstrucción la obligaron a un cierto repliegue que llegará a su fin a fines del siglo XIX. ${ }^{44}$

Va a ser en este período donde los dos países van a surgir como estados nación fuertes con características similares, y otras muy propias, que los van a llevar a roces diplomáticos. Los más interesantes son aquellos relacionados con los congresos Panamericanos. Por esta razón es que los usaremos como ejemplos.

\section{Los antecedentes del panamericanismo}

Durante la década de 1880, un tema clave de la agenda política en las relaciones entre los gobiernos de Buenos Aires y Washington fue el esfuerzo puesto en práctica por la diplomacia norteamericana en pos de la unidad panamericana.

Simón Bolívar fue uno de los precursores más importantes en relación con la idea de una unión hispanoamericana. Por su propuesta e iniciativa se reunió en 1826 la primer conferencia hispanoamericana, el Congreso de Panamá. Luego hubo otras tres conferencias similares: el Primer Congreso de Lima (diciembre de 1847 a marzo de 1848); el Congreso Continental, celebrado en Santiago de Chile (septiembre de 1856); y el Segundo Congreso de Lima (noviembre de 1864 a marzo de 1865. Todas estas conferencias fueron esfuerzos de las naciones asistentes para hacer frente a amenazas externas. Hay que decir que Argentina no asistió a ninguna de estas reuniones.

El propósito fundamental de Estados Unidos fue el de buscar imponer su hegemonía sobre los países de la región. Tampoco descartaba un área de comercio más allá de Centroamérica (su histórico hinterland). Evidentemente ambos objetivos chocaban con los de Argentina y su aliado histórico la Gran Bretaña.

En consecuencia, el panamericanismo norteamericano de la década de 1880 fue inaceptable para la elite argentina, opuesta a un esquema de unidad regional cuyo centro estuviera en Washington y no en Buenos Aires.

En 1889 se celebró la Primera Conferencia Panamericana en la capital del norte. Las posibilidades potenciales de este primer congreso panamericano se redujeron a un duelo tenaz entre la iniciativa panamericana impulsada por los representantes norteamericanos (John B. Henderson, William Trescott, Andrew Carnegie y Clement Studebaker, entre otros) y la cerrada oposición de los delegados argentinos (Manuel Quintana y Roque Sáenz Peña). Vicente G. Quesada, que era ministro en Washington desde 1885, decidió no participar de la conferencia. El nudo del desacuerdo argentino-norteamericano estuvo en la mencionada propuesta del secretario Blaine para la creación de una unión aduanera panamericana, finalmente rechazada

Otro punto de discordia entre las delegaciones argentina y norteamericana en la Conferencia de Washington fue el vinculado con los procedimientos sobre arbitraje en conflictos regionales. Ambos países desearon en este punto un rol directivo. Mientras la representación argentina favoreció una forma moderada de arbitraje, que respetase la igualdad jurídica y la autonomía de los Estados, rechazando todo tipo de intervención, la norteameri-

44 Las anexiones forzosas que realizó sobre territorio mexicano lo englobamos en la política de expansión hacia el oeste y, si se quiere, forma parte de esa misma concepción colonial "doméstica". 
cana estuvo a favor de un sistema de arbitraje compulsivo, con un tribunal permanente y obediente a los dictados de las autoridades de Washington. La propuesta argentina, al plantear el respeto por la autonomía de los Estados, resultó ser más atractiva que la norteamericana para los pequeños países latinoamericanos, cuyo apoyo buscó la delegación encabezada por Sáenz Peña. Incluso se suscitó en este punto una curiosa convergencia de las posiciones argentina y brasileña.

El 19 de abril de 1890 concluyó la Conferencia de Washington. Con el cierre de la misma se terminaba también una década de la historia argentina marcada por las realizaciones y logros de la orgullosa "generación del ochenta". Los hombres de esta generación lograron la organización nacional, cerraron la cuestión capital, expandieron las fronteras hacia el sur tras la Conquista del Desierto y además, en política exterior, se animaron a desafiar a las autoridades de Estados Unidos. Si bien este desafío se reveló a largo plazo contrario a los intereses materiales argentinos, esto sólo apareció claramente a partir de 1914. En las décadas de 1890-1900 y 1900 a 1914, la economía argentina vivió sumida en un espejismo de grandeza que ocultó su vulnerabilidad estructural ${ }^{45}$

La posición argentina en la Conferencia Panamericana de 1889, oponiéndose sistemáticamente a la cada vez mayor influencia de Estados Unidos, estaba basada en la visión que la clase gobernante tenía de su país. El éxito del modelo económico, los progresos en el orden cultural, la convertían en una nación superior al resto de América Latina y de espaldas a esta. Con una íntima relación con Europa y con un sentimiento de competencia y desconfianza hacia la potencia emergente en el norte.

El panorama continental para fines del siglo XIX nos presenta dos estados ricos, con fuertes procesos inmigratorios, con nacionalismos formados desde el estado y con una visión en el imaginario de sus respectivas elites de países con futuros prometedores.

En cuanto a sus políticas exteriores los dos estados jugarán roles distintos. Estados Unidos buscará extender su influencia más allá de su hinterland histórico, América Central. Argentina, de espaldas a una América Latina que desprecia, se articulará con los intereses regionales de su socia comercial y aliada política, Gran Bretaña. Para esta última, era de vital importancia frenar las pretensiones expansionistas de Washington y, de este modo, mantener América del Sur bajo sus alas.

Era lógico que esta situación chocas e en el Primer Congreso Panamericano convocado y realizado en el país del norte. La diplomacia argentina, con éxito pudo poner freno.al menos momentáneamente mientras Inglaterra siguió siendo potencia mundial-, a los objetivos norteamericanos.

\section{Doctrina Drago}

Hacia fines de 1902, Venezuela se vio amenazada por las fuerzas navales de Gran Bretaña, Alemania e Italia. Su objetivo era lograr el cobro compulsivo de la deuda que el gobierno venezolano mantenía con estos países. Aunque esa intervención violaba los principios de la Doctrina Monroe ("América para los americanos”), el gobierno norteamericano lo justificó con el llamado "primer Corolario Roosevelt", que limitaba la doctrina a la adquisición de territorios y respaldaba la intervención europea para lograr el cobro de deudas. 
En este contexto, Luis Maria Drago, ministro de relaciones exteriores argentino entre agosto de 1902 y julio de 1903, presentó una nota ante el gobierno de Washington. Esto será conocido más tarde como "Doctrina Drago" y sostiene que "la deuda pública no puede dar lugar a la intervención armada, ni menos a la ocupación material del suelo de las naciones americanas por una potencia europea" ${ }^{46}$

La postura del canciller argentino constituyó un respaldo al texto de la Doctrina Monroe y una fuerte crítica a las prácticas intervensionistas en la región. Paradójicamente, debido al fuerte respaldo que la doctrina Drago hace a la Monroe, las políticas exteriores argentinas y norteamericanas se alejaron.

En la opinión de algunos autores, el "Corolario Roosevelt" formó parte de una ideología imperial del gobierno norteamericano que extendió la visión de Destino Manifiesto desde la zona del Caribe hacia las naciones de habla hispana a lo largo del hemisferio. Mientras EEUU adoptó la forma de control directo en la cuenca del caribe, la estrategia utilizada para el Cono Sur fue la de la "diplomacia de control".

Esta doctrina tiene como antecedente otra planteada por otro jurista argentino, la Doctrina Calvo. Según esta los pleitos jurídicos con ciudadanos extranjeros debían neces ariamente ser solucionados por tribunales locales evitando la intervención diplomática del país de pertenencia. Su pensamiento tuvo una enorme influencia en los países de América Latina y fue incluida en la mayoría de sus constituciones. ${ }^{47}$

Carlos Calvo nació en Montevideo el 12 de febrero de 1824, pero se trasladó a Buenos Aires donde estudió Derecho. Se hizo ciudadano argentino y empezó su actividad como diplomático representando al país como vicecónsul en Montevideo de 1852 a 1858, Paraguay, Inglaterra y Francia, entre otros.

Su obra fundamental y en la cual expone su pensamiento es Derecho internacional teórico y práctico $^{48}$, publicado por primera vez en castellano en 1868 y traducida al francés en su versión final de seis tomos. En ella basa su principio en las ideas de la soberanía nacional, igualdad entre ciudadanos nacionales y extranjeros, y la jurisdicción territorial. Según él:

1/ Los estados soberanos están, y deben estarlo, de toda interferencia extranjera de cualquier tipo.

2 /Los ciudadanos extranjeros tienen los mismos derechos que los ciudadanos nacionales. En caso de reclamaciones deberán hacerlo ante los juzgados nacionales y absteniéndose de la intervención diplomática de sus países de origen.

Fruto de la interpretación posterior de esta doctrina surge la llamada "Cláusula Calvo" según la cual se introducen estos principios en los contratos comerciales obligándose las partes a respetar estos principios.

$\mathrm{Si}$ analizamos lo expuesto por el canciller argentino vemos que se ajusta absolutamente a los lineamientos básicos de la política exterior del país. La defensa irrevocable del

$46 \mathrm{El}$ texto completo de la carta puede leerse en el APENDICE DOCUMENTAL.

47 TAMBURINI, Francesco. HISTORIA Y DESTINO DE LA "DOCTRINA CALVO": ¿ACTUALIDAD U OBSOLESCENCIA DEL PENSAMIENTO DE CARLOS CALVO?. . Rev. estud. hist-juríd.. [online]. 2002, no.24 [citado 30 Julio 2005], p.81-101. Disponible en la World Wide Web: <http://www.scielo.cl/scielo.php?script=sci_arttext\&pid=S0716-54552002002400005\&lng=es\&nrm=iso>. ISSN 0716-5455

48 CALVO,C. Le droit international théorique et pratique précédé d'un exposé historique des progrès de la science du droit des gens. París, Rousseau., 1896, pp. 350 - 351. 
derecho internacional, la igualdad soberana de los estados y, por lo tanto, su derecho inherente a la neutralidad. De esta forma Argentina se convierte en, - una vez más-, oponente de los intereses de Estados Unidos sobre la región y, en cierta forma, en adalid de las reivindicaciones regionales. Esto último al apoyar a estados objetivamente con menores atributos colocándose en una situación que muestra gráficamente su diplomacia de prestigio.

Las convicciones de una nación civilista basada en una forma contractual donde ser privilegia el marco jurídico se proyecta hacia la política exterior del estado. Y, al mismo tiempo, la defensa a rajatabla de esos principios en el exterior significa una defensa y res-

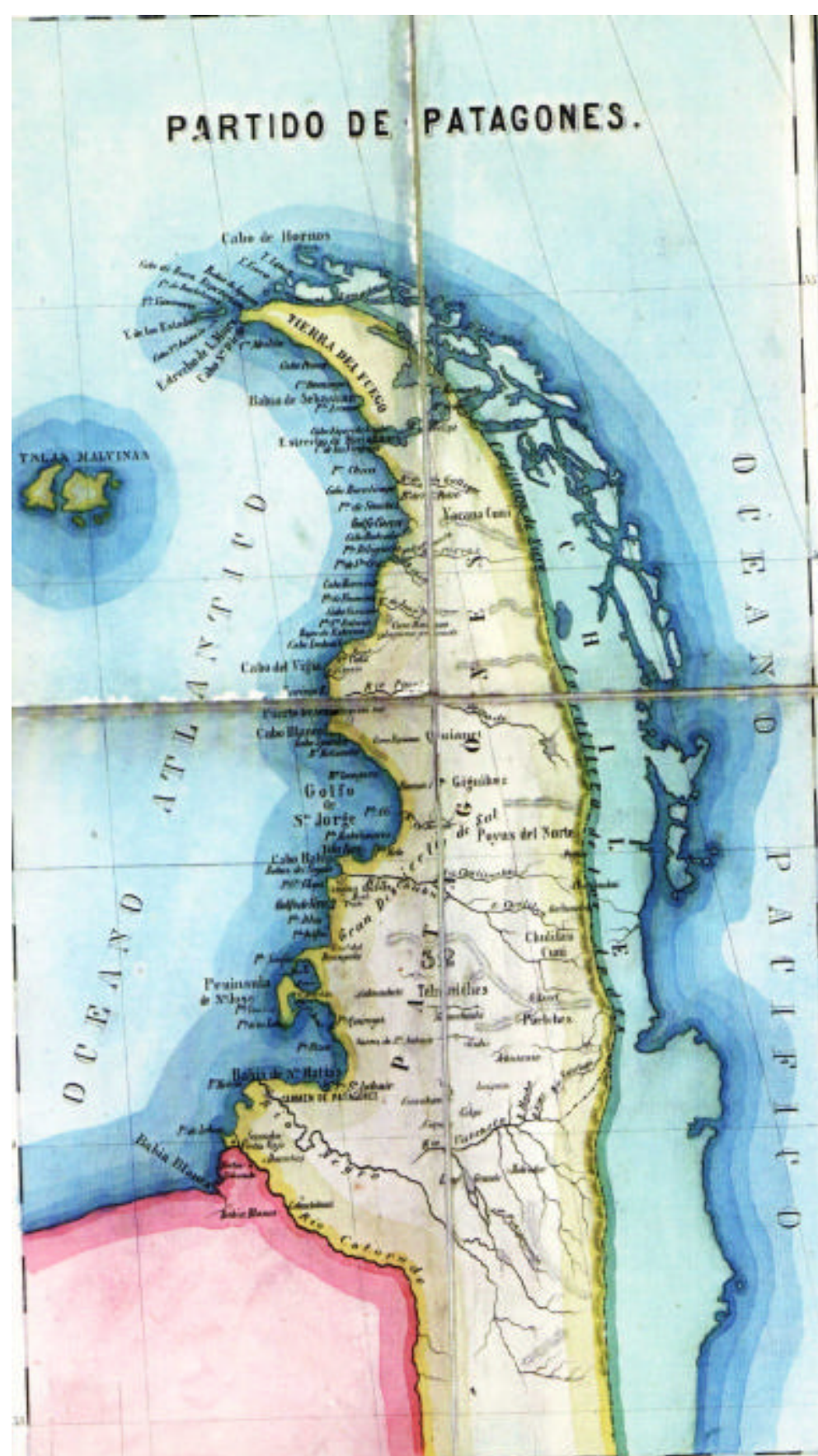
guardo del modelo de organización del país. Es decir, la política exterior refuerza la política doméstica. Y esto no solo como una forma de "propaganda" hacia la población o de reforzamiento de la conciencia de prestigio nacional, sino en términos prácticos gubernativos. Tengamos en cuenta que Argentina también era un deudor moroso de naciones europeas y que defendiendo a Venezuela, en cierta forma, se protege a sí misma de acciones similares.

Por otro

lado la inmigración, - tema capital como ya hemos visto-, es favorecida al proyectar hacia el interior de la opinión pública local una imagen de país "justo y poderoso que sale a enfrentarse a las 
naciones invasoras con las armas de la ley". Esto seria muy atractivo, junto con las posibilidades de desarrollo económico y de libertades culturales-religiosas, y seguramente favorecería las redes informales de inmigración.

Argentina, 1868 



\section{CAPITULO III IRLANDA: NACIONALISMO ROMANTICO}

En el capítulo 1 hemos hablado de lo que algunos autores llaman el "nacionalismo genealógico"49 y que nosotros llamamos "nacionalismo romántico". Es el concepto surgido a partir de este movimiento filosófico-cultural en Europa en la década de 1830. Para estos intelectuales había que volver a los sentimientos, a las raíces más puras del ser nacional. La esencia del Romanticismo era la exaltación de los instintos y emociones en oposición al racionalismo exagerado de la Ilustración. Incluía otros elementos como el amor a la naturaleza, la informalidad, el amor sentimental. En Alemania el fenómeno se transforma en el Idealismo Romántico de filósofos como Hegel y Kant y presentó el contexto ideológico para las reivindicaciones nacionales.

El Idealismo Romántico debe su nombre a la combinación de la teoría romántica con la concepción idealista del universo. Creían que el hombre carece de importancia si no forma parte de un grupo social. Por lo tanto, se debía procurar el bien del grupo primero y así el individuo podría alcanzar tamb ién beneficios. La sociedad y el estado son organismos sociales, producto de la evolución natural. Surge de la idea herderiana de Volksgeist_o "espíritu del pueblo" que concibe a la nación como una entidad objetiva independiente de la voluntad de sus miemb ros.

El concepto de Volksgeist, es decir, de genio nacional, aparece en 1774 con Herder. Para él todas las naciones de la tierra tienen un modo de ser único e irrepetible y valores universales como el Bien, Verdad o Belleza quedan en segundo plano. Es innegable las potencialidades totalitarias que tiene. El estado y su voluntad están por encima de los individuos. El genio nacional suprime al individuo y a la humanidad. La negación del individuo engendra un poder sin límites. Y así la idea del Volksgeist se transforma en el explosivo de los tie mpos modernos.

Los nacionalismos étnicos se proponen crear naciones a partir de etnias que se perciben pre-existentes. Fundamental para esta concepción es la importancia que se da a la genealogía. La nación étnica tiene su poder y legitimidad en la voluntad de la mayoría de sus miembros y no sólo de las elites. El objetivo es la comunidad y no el individuo. Se pone énfasis en la cultura del pueblo, su lengua nacional y pasan a ser instrumentos en la lucha contra los opresores. Son armas de combate y en su nombre se libran las batallas. Esta fue la herencia de Herder y sus seguidores.

Nosotros entendemos que Irlanda y su nacionalismo cumple con los requisitos para ser considerado un nacionalismo de esta clase.

La política internacional de Irlanda tiene algunos puntos básicos derivados de sus características nacionales. Uno de ellos, muy importante, es la defensa del derecho internacional y el manejo dentro de esas reglas. De este modo se busca controlar al más poderoso a favor del más débil. Y, además, este marco les permite a los países pequeños un margen de maniobras mayor. Esto también se aplica a la labor de los diplomáticos. Es por eso que se los puede ver como los más entusiastas participantes de toda clase de foros donde las deci-

49PALTI, Elías. La nación como problema. Op.Cit.. 
siones se toman en forma colectiva,- el ejercicio de unas relaciones internacionales multilaterales donde países pequeños consiguen mayores logros a través de su asociación ${ }^{-{ }^{50}}$.

Los primeros diplomáticos irlandeses no lo eran de carrera, sino personas que eran elegidas por saber algún idioma, o tener alguna habilidad que fuese considerada útil para la actividad. De 1919 a 1922 se denominó al área Departament of Foring Affaires, luego cambió de nombre al de Departament of External Affairs y mantuvo ese nombre hasta 1971. Su objetivo primero y casi excluyente, era lograr el reconocimiento internacional a la independencia del país y para lograrlo se envió representantes a todo el mundo.

Uno de los mayores logros los obtiene al lograr el 6 de diciemb re de 1922, la incorporación a la Sociedad de las Naciones. De este modo obtiene la capacidad para abrir representaciones diplomáticas en otros Estados, negociar y firmar tratados, y poder emitir pasaportes para sus ciudadanos.

Irlanda fue uno de los país es pequeños, - tanto por su territorio como por su población-, que logran su independencia luego de la Primer guerra Mundial. Y, como dice Cerard Keown, dio fruto la política seguida hasta el cansancio de participar en numerosas conferencias internacionales,- aún cuando el país no tenía un interés substancial en los temas que trataba,- y firmando acuerdos que ni siquiera podría quebrar. ${ }^{51} \mathrm{Y}$, como ejemplo, mencionamos su apoyo a la Corte Internacional de Justicia en 1929 y el pacto Kellog-Briand ${ }^{52}$.

El otro aspecto importante es la búsqueda de objetivos utilizando medios no estrictamente diplomáticos. O, dicho de otro modo, la utilización de canales informales de negociación. los cuales fueron claves en política internacional. En concreto nos referimos a las vinculaciones con las "diásporas", las cuales no solo aportaron en su momento dinero, hombres y armas, sino incluso manejo de influencias. Entendemos por diplomacia las actividades y negociaciones llevadas a cabo primaria, pero no excluyentemente, por diplomáticos profesionales que actúan en beneficio de estados soberanos. Sin embargo, más allá del sistema formal de representación de los estados soberanos que existen actualmente en el mundo, existe un cada vez mayor número de ONGs, agencias, asociaciones, individuos que tienen representación similar a la diplomática y que buscan su reconocimiento de los estados. Esto puede ser explicado en parte por la emergencia de una sociedad civil global inter actuante. Por eso la gran pregunta es quien puede ser diplomático hay en día. La respuesta: potencialmente casi todos.

Esto que se vislumbra como una realidad emergente de unas pocas décadas atrás, puede ser estudiado en la Irlanda pre y post proceso de independencia.

Analizando este proceso vamos a analizar dos aspectos concretos: el uso de una diplomacia multilateral y el papel desempeñado por las poblaciones emigradas en el apoyo a la independencia. Pero para entender este proceso comencemos entendiendo al objeto de estudio: Irlanda.

50 En 1969, durante la coyuntura política denominada “ The Troubles”,- período de enfrentamiento entre católicos y Protestantes que comienza en 1969 y finaliza con el "Good Friday Agreement" de 1998-, ante el aumento de la escalada de violencia, el gobierno irlandés apeló ante el Consejo de Seguridad de Naciones Unidas para pedir un alto al fuego y la solución pacífica del conflicto. Aunque no obtuvo los resultados esperados.

51 KEOWN, Gerard. En: KENNEDY, Michael y MORRISON SKELLY, Joseph. Irish Foreing Policy, 1916-66. Inglaterra, Four Courts Press, 2000.

52 El pacto Kellog-Briand del 27 de agosto de 1928 en París, fue firmado por 15 países. Proscribe y prohíbe la guerra como instrumento de política nacional 


\section{Breve Historia de Irlanda.}

Antes de continuar nos parece apropiado hacer una pequeña introducción sobre la historia de Irlanda. No pretende agotar el tema y entendemos que no es exhaustiva. Tampoco pretende serlo. La idea es introducirnos en el marco histórico-cultural que estamos estudiando.

La proximidad geográfica de Gran Bretaña ha marcado en gran medida la historia de Irlanda.Cazadores, agricultores, y luego tribus que trabajaban cerámica y metales, habitaron la isla desde aproximadamente el año 4.000 a. de C. Alrededor del siglo VI a. de C., empezaron a llegar oleadas de invasores celtas desde la Europa continental.Fue la última de estas sucesivas olas de invasiones la de los "Gael”, gaélicos, que llegó a Irlanda probablemente antes del nacimiento de Cristo. Su lengua fue la lengua de la mayoría del pueblo irlandés desde entonces hasta mediados del siglo XIX.

En la Edad Media, en el siglo V, Irlanda fue cristianizada por San Patricio y otros monjes, y como resultado florecieron el arte y la cultura irlandesa a la que ya se ha hecho referencia más arriba. En los siglos IX y X, Irlanda fue invadida por los vikingos, que eran comerciantes y que hicieron progresar a Dublín y a otras ciudades. Brian Boru, Gran Rey de Irlanda, los venció en Clontarf en el año 1014.En el siglo XII llegaron los normandos, que antes se habían establecido en Gran Bretaña, e Irlanda quedó bajo el poder del rey de Inglaterra. Pero con el tiempo los normandos se hicieron "más irlandeses que los irlandeses", adoptando su lengua, el gaélico irlandés, y sus costumbres.

Por eso en el siglo XVI, Enrique VIII y luego su hija Isabel I, enviaron a Irlanda pobladores de Gran Bretaña (las llamadas "plantations"), pues temían que su influencia allí estuviera al borde del colapso. Esto se llevó a cabo de la forma más tiránica y cruel posible: despojaban a los irlandeses de sus tierras productivas, para poner en ellas a los escoceses o ingleses, y los irlandeses eran enviados a tierras pobres, debiendo pagar más impuestos por ellas. Para empeorar la situación, se sumó a todo ello la diferencia religiosa, pues con Enrique VIII Inglaterra se había convertido al protestantismo. Finalmente y después de muchas revueltas, el último reducto gaélico, el Ulster, cayó en manos de la corona. El clima de violencia se incrementó más aún con la llegada de Oliver Cromwell, quien siguió con la política de despojo de tierras a los hacendados irlandeses o ingleses católicos.

Los protestantes ingleses monopolizaron así el poder político y la propiedad de la tierra, llegando a considerarse a sí mismos como "la nación irlandesa" y al comenzar el siglo XVIII dictaron las llamadas "Penal Laws" (Leyes Penales) que prohibían a un católico tener un puesto oficial, integrar el parlamento, votar, servir en el ejército o la marina, ejercer la profesión de abogado y comprar tierra. Tampoco podía un católico, por ley, rentar tierra por más de 31 años, ni dejar en herencia de acuerdo con su voluntad, lo que él poseyera; una vez fallecido su tierra debía ser entregada a su primogénito varón, a menos que uno de ellos se hubiese convertido al protestantismo, en cuyo caso heredaba todo.

Por ello, comenzó en esa época una sostenida emigración de irlandeses mayormente católicos, especialmente al nuevo mundo. Sin embargo, hubo en este siglo un gran desarrollo económico, el ganado vacuno y la lana irlandeses eran los mejores de Europa. Los industriales ingleses lograron obtener del parlamento inglés leyes que prohibieron la exportación de lana manufacturada de Irlanda y que sólo permitían que su lana virgen se exportara únicamente a Inglaterra, pagando altísimos impuestos aduaneros. De esta manera la flo reciente industria irlandesa fue arruinada, en detrimento incluso de los intereses de 
algunos protestantes, que integraban el Parlamento Inglés y que también apoyaron las ideas que propiciaban la independencia de Inglaterra.

La revolución norteamericana, y luego la francesa, ayudaron a crear en Irlanda el clima necesario para buscar la independencia, lo que desembocó en la formación de la "Sociedad de Irlandeses Unidos". En 1798 los United Irishmen (Irlandeses Unidos) protagonizaron una insurrección en Irlanda, con el objeto de establecer una república irlandesa independiente. La rebelión fue sofocada y el gobierno británico reaccionó con gran severidad. Dictó el "Acta de Unión" de 1800, y se disolvió el parlamento irlandés. Los miembros de este parlamento oriundos de Irlanda, debieron ir a Westminster para integrar el parlamento en Gran Bretaña. Con el tiempo, fueron dejándose a un lado las severas restricciones contra los católicos.

Es entonces cuando surge la figura más popular en el país, Daniel O’Connell, abogado católico de Kerry, llamado "The Liberator" (El Libertador) porque liberó a la masa irlandesa de la irrelevancia política, gracias a su talento en la oratoria, su gran inteligencia y su prudente conducción. Ganó finalmente un asiento en el Parlamento de Westminster, convirtiendo por primera vez a la opinión popular irlandesa en una fuerza dentro de la política británica.

En el siglo XIX, mientras Gran Bretaña se industrializaba y se urbanizaba creciendo económicamente, Irlanda (excluyendo al Ulster que era ya un reducto inglés protestante), se fue empobreciendo por la desindustrialización obligada, quedando en especial su población rural, cada vez más numerosa y pobre, sin otro alimento que la papa. A partir de 1840, como resultado del fracaso sucesivo de varias cosechas por un hongo, tuvo lugar en Irlanda una terrible hambruna, conocida como "The Great Famine" que produjo que casi un millón de personas muriera y otro millón emigrara. En diez años, de 1846 a 1856, la población disminuyó de ocho a seis millones y siguió disminuyendo posteriormente ya que no se aportó solución alguna desde Gran Bretaña, de la que Irlanda dependía absolutamente. Para esa época, y en concordancia con lo que se estaba dando en el resto de Europa, se creó en 1848 la Liga de la Joven Irlanda y en 1861 la de los fenianos, partidarios de la acción violenta para lograr la separación de Irlanda del Reino Unido.

A principios del siglo XX surgieron el partido político "Sinn Féin", nombre gaélico que significa "nosotros mismos", y el "Irish Citizen Army" (Ejército de Ciudadanos Irlandeses) que era socialista y separatista. En 1912 se trató otra vez de conseguir el "Home Rule" en Westminster, y en consecuencia los del Ulster, acérrimos unionistas protestantes, formaron el grupo armado "Ulster Volunteers" (Voluntarios del Ulster). Ambos grupos se preparaban en una atmósfera militarizada. Sólo el estallido de la primera guerra mundial demoró las hostilidades. Pero en la Pascua de 1916, un grupo creado en respuesta a la formación de los "Ulster Volunteers", los "The Irish Volunteers" (Voluntarios Irlandeses) liderados por Patrick Pearse, poeta, y el "Irish Citizen Army", proclamaron una república en Dublín, tomaron el Correo Central y provocaron una insurrección armada que fue aplastada. Sus líderes fueron ejecutados tiempo después.

Esto exaltó los ánimos del pueblo, que en 1918 votó por los candidatos del "Sinn Féin" para el Parlamento Británico. Estos decidieron, bajo el liderazgo de Éamon de Valera, constituirse en Dublín como el primer "Dail Eireann" (gaélico irlandés que significa "Parlamento Irlandés", y que aún hoy se usa para designar esa institución).

La respuesta británica para tratar de aplastar al "Sinn Féin", fue la "Guerra de Independencia" de 1919-21. Michael Collins dirigió las fuerzas irlandesas. En diciembre de 1921 se firmó un tratado por el cual veintiséis condados formarían el "Estado Libre Irlan- 
dés". En 1920, ya se les había concedido a seis condados del Ulster su propio parlamento en Belfast, y habían quedado entonces como parte del Reino Unido. El establecimiento del "Estado Libre Irlandés" originó una guerra civil entre el nuevo gobierno y los que no aceptaron el tratado. De Valera fue uno de ellos, y por lo tanto fue Collins quien viajó a Gran Bretaña para firmarlo. A pesar de su lucha y sus desvelos, Collins fue muerto por otro irlandés en una emboscada.

El primer gobierno del nuevo estado fue encabezado por Cosgrave, pero aún Irlanda no era libre. El partido "Fianna Fáil" fundado por de Valera dominó la política entre los años 30 y 70 . Entre 1932 y 1938 tuvo lugar la denominada "guerra económica", originada en las disputas causadas por los continuos pagos sobre la tierra exigidos por Gran Bretaña, que no podía resignarse a "perder" los beneficios económicos. En 1937, a instancias de de Valera, se aprobó una nueva Constitución, que declaraba a Irlanda estado soberano, independiente y democrático. Irlanda se mantuvo neutral durante la Segunda Guerra Mundial. Pero recién en 1948, el "Acta de la República de Irlanda" cortó definitivamente las últimas ataduras constitucionales con Gran Bretaña.

Irlanda fue admitida en las Naciones Unidas en 1955 y en la Unión Europea en 1973, año en que de Valera dejó la presidencia. El discurso predominante de la política irlandesa ha sido preconizar la unión con Irlanda del Norte, a pesar de la rígida postura inglesa.

A principios de diciembre de 1999, merced a lo acordado entre la República de Irlanda, Irlanda del Norte y Gran Bretaña, entró en funcionamiento en Belfast el primer gobierno independiente de Irlanda del Norte, poniendo fin al poder británico en la isla. Se iniciaron además tratativas tendientes a lograr una paz definitiva, a través del desarme de los grupos guerrilleros pertenecientes a Irlanda del Norte y a la República de Irlanda.

El artículo 4 de la Constitución, estableció que el nombre del país es Eire, en gaélico, o Ireland en inglés. La bandera nacional es tricolor: verde, blanco y naranja. La primera vez que se la usó fue como emblema del movimiento de la Joven Irlanda, en 1848. El verde representa los antiguos elementos gaélicos y Anglo-normandos, el naranja a los protestantes llevados por Guillermo de Orange ${ }^{53}$. El blanco busca unir a los dos fuertes grupos (católicos y protestantes) en uno. Esta bandera recién toma connotaciones de símbolo nacional cuando se izó en el edificio del Correo en Dublín durante la sublevación de Pascua de 1916.

La ley básica del nuevo estado es su constitución adoptada por referéndum en 1937. Es la sucesora de la Constitution of Dáil Eireann (1919) y la Constitución del Irish Free State (1922). La autoridad de los tres poderes (legislativo, ejecutivo y judicial) deriva de Dios hacia el pueblo.

Establece los derechos básicos de los ciudadanos: personales, familiares, a la educación, a la propiedad privada y religiosos. En cuanto a la educación, el estado reconoce la primacía de la familia en este campo. El estado sólo ayuda a las familias en esto. Se garantiza la libertad de conciencia y de practicar cualquier culto mientras no esté reñido con el orden y la moral.

53 Hijo de Guillermo de Orange-Nassau y de María, hija a su vez de Carlos I de Inglaterra.14 de noviembre de 1650 nació en La Haya, Holanda. En 1689, después de destronar a Jacobo II en la llamada "Revolución gloriosa", fue coronado rey de Inglaterra, Escocia e Irlanda. Esto gracias al apoya de los protestantes. Orange significa naranja. 
En cuanto a su organización política Irlanda es una democracia parlamentaria. El Parlamento Nacional (Oireachtas) está integrado por un Presidente y dos cámaras: la Cámara de Representantes y el Senado. Este último se compone de sesenta miembros: once designados por el Primer Ministro, seis electos por dos universidades.

Según la Constitución, el Presidente de Irlanda es elegido por voto directo de los ciudadanos. Cualquier persona mayor a treinta y cinco años es elegible para el cargo. Su cargo dura siete años y puede ser re-elegido sólo una vez. Es cabeza del estado pero no tiene funciones ejecutivas. No existe la figura del vice-presidente.

El poder ejecutivo está representado por el Consejo de Estado no debe tener menos de siete miembros y no más de quince. El Taoiseach o Primer Ministro es designado por el presidente por indicación del Parlamento. Por lo general es el líder del partido político con mayor número de escaños . Dentro de estos ministerios el que más nos interesa, por razones obvias, es el de Relaciones Internacionales. Su función primaria es la de promover y proteger los intereses irlandeses en el extranjero. Es, además, el canal de comunicación entre el Gobierno y los gobernantes de otras naciones. Es el responsable por la representación diplomática en el exterior.

Los partidos políticos más importantes son: el Fianna Fáil, Fine Gael, Laborista, Demócratas Progresistas, Partido Verde, Socialismo y Sinn Féin. Todos estaos tienen representación en el Parlamento.

El Fianna Fáil, partido Republicano, fue fundado por Eamon de Valera en 1926. Su objetivo era asegurar la paz y conseguir la unidad e independencia de Irlanda. Desarrollar la vida nacional de acuerdo con las tradiciones y el lenguaje autóctono. Este partido contribuyó consolidar la independencia del país, promulgó la constitución de 1937, mantuvo la neutralidad durante la Segunda Guerra Mundial, asentó las bases de la industria, creó programas de asistencia social, estableció la educación secundaria gratuita y negoció la participación en el Mercado Común Europeo.

El Sinn Féin es el Partido Republicano Irlandés fundado en 1905. Sus objetivos son la reunificación del país, independencia política y soberanía nacional. El líder del partido es Gerry Adams.

\section{Diplomacia y diásporas}

Los asuntos diplomáticos actuales han permitido el surgimiento de nuevos actores. A medida que las fronteras de los estados parecen diluirse van creciendo nuevas posibilidades. No es que los estado-nación dejen de ser los protagonistas sino que van permitiendo y dando espacio a otros. Sin embargo, esto que ahora se ve facilitado por las telecomunicaciones, la economía y cultura global ha tenido precedentes importantes. Este es el caso particular de las diásporas con sus estados madres y el papel que jugaron para consolidar sus objetivos.

Hay autores que hablan de la resolución de conflictos en un territorio nacional estudiándolo como un "juego de tres niveles" y otros que hablan incluso de un cuarto nivel, donde la diáspora se convierte en la "variable de ajuste". ${ }^{54} \mathrm{~A}$ estas actividades Ivo D. Duchacek las llama "para-diplomacia", y consiste en la relación de estos grupos con estados

54 HOCKING, Brian. Localizing Foreing Policy: Non-Central Governments and Multiplayer Diplomacy. Londres/Nueva York, Macmillan and St. Martin’s Press, 1993. 
extranjeros tanto en el ámbito comercial, como industrial y cultural. Muchas veces estos nuevos "sujetos" comienzan a tener discursos e intereses distintos a los del gobierno central (esto puede ocurrir con cierta frecuencia), e incluso con sus "naciones de origen", aunque esto es menos frecuente. ${ }^{55}$

Los grupos de inmigrantes y sus descendientes, tratan de mantener sus costumbres, lengua, religión en los países de acogida. Para esto son importantes las redes institucionales que crean y que dan un marco de contención y facilitan estos objetivos. Su función es mantener los lazos existentes con su lugar de origen y lo logran de modo más eficiente que lo que puede hacerlo el simple individuo. Al mismo tiempo se logra una relación de beneficios mutuos entre los líderes de estos grupos y los sectores no emigrados. Los primeros logran prestigio dentro de su comunidad por la cercanía a los grupos nacionales y estos últimos logran apoyo para su causa de un modo como no podrían obtener en su país.

Estas diásporas no-estatales y sus agentes pueden actuar como terceras partes en los conflictos entre sus nacionalidades y sus gobiernos centrales. Y son más efectivas cuanto mayor éxito tengan en involucrar a su favor a los estados que las contienen. Cuanto más numerosa, rica, poderosa e influyente sea este grupo mayor va a ser la posibilidad de lograr esto.

Entendemos por diplomacia las actividades y negociaciones llevadas a cabo primaria, pero no excluyentemente, por diplomáticos profesionales que actúan en beneficio de estados soberanos. Sin embargo, más allá del sistema formal de representación de los estados soberanos que existen actualmente en el mundo, existe un cada vez mayor número de ONGs, agencias, asociaciones, individuos que tienen representación similar a la diplomática y que buscan su reconocimiento de los estados. Esto puede ser explicado en parte por la emergencia de una sociedad civil global interactuante. Por eso la gran pregunta es quien puede ser diplomático hay en día. La respuesta: potencialmente casi todos. Esto que se vislumbra como una realidad emergente de unas pocas décadas atrás, puede ser estudiado en la Irlanda pre y post proceso de independencia.

Analizando este proceso vamos a analizar dos aspectos concretos: el uso de una diplomacia multilateral y el papel desempeñado por las poblaciones emigradas en el apoyo a la independencia.

El concepto de diáspora está profundamente unido al del nacionalismo de corte romántico y al modelo de política exterior que se genera a partir de él. Toda la retórica discursiva del gobierno comienza a centrarse en conceptos tales como madre patria, donde la raza es más importante y va más allá del Estado.

El apoyo de las comunidades en el extranjero al proceso de independencia de Irlanda:

Ya hemos mencionado que Irlanda fue mayormente una nación expulsora de población tanto libre como forzada. Motivos económicos, políticos o religiosos motivaron el éxodo de grandes cantidades de población. La Gran Hambruna significó un acelerador de enormes proporciones a este proceso. En cuanto a la emigración forzada nos referimos específicamente a los convictos,- muchas veces sólo por crímenes menores- enviados a los penales en Australia y a los enviados en régimen de servidumbre a las plantaciones en el Caribe. Esto significó el nacimiento de una "nación de diáspora" unida profundamente al

55 En este sentido es interesante el estudio de Gloria Totoricaguena para el caso de los vascos. En: TOTORICAGUENA, Gloria Nationalism and Ethnic Politics. EEUU, Taylor and Francis Inc., 2005Nationalism and Ethnic Politics. EEUU, Taylor and Francis Inc., 2005. 
suelo natal y que no perdió mayormente esos vínculos. Dentro de estos grupos nos vamos a referir a dos como casos testigos: los Hiberno-argentinos y los Irlando-americanos .

\section{a- Los Hiberno-argentinos:}

La inmigración de irlandeses al país pasó por varias etapas. Ya desde la época colonial hubo familias que se instalaron en el Río de la Plata. Asimismo, las invasiones inglesas dejaron en nuestro territorio prisioneros de este origen que, con el tiempo, se fueron integrando casándose y formando sus propias familias.

Después de la Independencia esta inmigración continuó. La mayor cantidad de inmigrantes de Irlanda estuvo relacionada a cadenas migratorias por relaciones de familiares, amigos y vecinos. Estas cadenas comenzaron principalmente con ex prisioneros y desertores de las invasiones inglesas 1806-07 (en el caso de Westmeath, Longford y Offaly), y por el asentamiento de comerciantes en Buenos Aires (en el caso de Wexford y Dublin).

Korol y Sabato consideran que había muchas desventajas en la elección de la Argentina como país para emigrar: Por una parte, una lengua diferente, costumbres desconocidas, y una cultura totalmente ajena a la propia aparecen como problemas adicionales a los que el traslado y el desarraigo imponen de hecho al que decide emigrar. Por otra parte, la distancia que separa a Irlanda de nuestro país se convierte en obstáculo insalvable para los sectores más pobres, que generalmente no pueden llegar más allá de Inglaterra, o con mucha suerte consiguen un pasaje para América del Norte. Finalmente, la infraestructura que se crea para fomentar y facilitar la emigración desde Irlanda hacia países de raíz anglosajona no puede compararse con la precaria organización que promueve el traslado de irlandeses hacia el Plata.

En general -explican- es la relación más o menos casual del futuro migrante con el núcleo de irlandeses que reside en Buenos Aires uno de los factores determinantes en su decisión de trasladarse al Plata. Esa relación se denomina "cadena migratoria" y -según John Mc Donald- se la puede definir "como el movimiento por el cual los migrantes futuros, toman conocimiento de las oportunidades laborales existentes, reciben los medios para trasladarse y resuelven su alojamiento y su empleo inicial, por medio de sus relaciones sociales primarias con migrantes anteriores" ${ }^{56}$.

El total de inmigrantes a la Argentina puede estimarse en unos 40 o 45 mil. ${ }^{57}$ De estos casi la mitad regresó a Irlanda o se dirigió a otros destinos como Estados Unidos. La mayoría de la información que tenemos a este respecto se la debemos al trabajo de investigación realizado por Coghlan. Su trabajo se basa en aquellos que dejaron descendencia para desarrollar un catálogo genealógico.

De 1919 a 1923. Irlanda mantuvo una presencia diplomática en América Latina. Particularmente en Argentina y Chile. Estas personas enviadas por el Sinn Féin, no tenían una acreditación oficial ante sus gobiernos pero sí ante las comunidades irlandesas en sus respectivos países. Estos representantes fueron Eamon Bulfin para el primero y Frank Eagan para el segundo. Esto muestra el temprano interés por mantener contacto con las diásporas de estos países.

56 MAC DONALD, John: citado por Nélida Boulgourdjian-Toufeksian, en: Los armenios en Buenos Aires. La reconstrucción de la identidad (1900-1950). Buenos Aires, Centro Armenio, 1997.

57 Segón cifras de MCKENNA, Patrick. Nineteenth Century of the Irish in Argentina. En: MURRAY, Edmundo. Devenir Irlandés. Buenos Aires, EUDEBA,2004. 
Durante las negociaciones llevadas a cabo entre Eamon DeValera y el Primer Ministro Británico Lloyd George, se convocó el primer congreso internacional irlandés como una forma de demostrar al mundo lo que estaba aconteciendo en el país. El mismo sería en Paris en 1922 y su organizador fue e ideólogo principal fue Thomas Hughes Kelly de Nueva York. ${ }^{58}$

Para poder prepararlo y con la finalidad de unificar estrategias es que fue necesario como paso previo organizar las comunidades irlandesas en los distintos países donde se encontraban. Por esta razón el gobierno envió durante 1921 misiones especiales a América del Sur, Sudáfrica, Australia, Nueva Zelanda, Rusia y Estados Unidos. En este contexto es que llega a Buenos Aires Laurence Ginnell como representante de la República de Irlanda para cooperar con Eamon Bulfin quien ya estaba trabajando en el tema. ${ }^{59}$

Finalmente, el 29 de noviembre de 1921, se llevó a cabo en Buenos Aires el primer congreso de la raza irlandesa. Más de 50 organizaciones mandaron sus representantes y fundaron una nueva Federación. El número no es un dato menor. Marca la gran cantidad de inmigrantes irlandeses, su dispersión y también, en cierta forma, su fragmentación organizativa. ${ }^{60}$ Allí se eligieron cinco delegados para ir a la reunión en Francia.

Para ilustrar lo dicho nos gustaría traer a colación a un hiberno-argentino quien hizo ondear la bandera tricolor sobre el edificio del correo en el alzamiento de Pascua de 1916, él es Eamon Bulfin.

Eamon Bulfin nació en Buenos Aires en 1892, hijo de William Bulfin, quien emigró a la Argentina a la edad de 20 años. En el país se convirtió en escritor, periodista, editor y dueño del "The Southern Cross". Desde su periódico ayudó propagandisticamente y económicamente con la causa republicana. Regresa a Irlanda en 1909 junto a su familia y fallece allí un año después.

En 1916 Eamon participa activamente en el levantamiento y fue él en persona quien colocó la bandera en el techo del correo. Finalizada la rebelión fue sentenciado a muerte por una corte marcial inglesa, sin embargo el hecho de ser ciudadano argentino le salvó la vida. Fue deportado a Argentina y, años más tarde, fue nombrado por Eamon de Valera cónsul en 1919. Su labor consistió en buscar apoyo dentro de la colectividad irlandesa y la opinión pública argentina juntando fondos y armamento para la causa. Finalmente en 1922 pudo regresar a Irlanda donde se estableció y falleció en 1968.

Analizado con frialdad se puede decir que la experiencia en Argentina no fue tan exitosa como la de Estados unidos. Los motivos son varios: la distancia sumado a las enormes dificultades para mantener una comunicación fluida fue un obstáculo enorme, las divisiones dentro de la comunidad irlandesa en el país.

58 BARRY, Carolina. La Primera Convención de la Raza Irlandesa en Sudamérica. En:

'The Southern Cross' Vol. 129, 5883 (January 2004), p. 3.

59 Otra misión importante que tenía era lanzar el "Bono Irlandés". Ginnell y varios en Irlanda tenían grandes expectativas de los irlandeses de Argentina, porque tenían fama de ricos hacendados con mucho capit al disponible y muy generosos con las distintas causas irlandesas. Esta "fama" era totalmente equivocada (la gran mayoría eran peones, capataces y empleados administrativos y sólo una minúscula minoría era propietaria de grandes estancias)

60 Simplemente como dato ilustrativo y para entender este fenómeno, existe un refrán irlandés que dice:’Dos irlandeses tres opiniones". Aunque no representa un estudio científico acabado, nadie puede dudar de lo gráficos que pueden ser los dichos populares. 


\section{b. Los irlando-americanos:}

La inmigración irlandesa a los Estados Unidos fue siempre un grupo fuerte y numeroso con un liderazgo marcado con fuertes tendencias nacionalistas. A este grupo se lo conoció paulatinamente como "Irish-American" ${ }^{61}$.

El nacionalismo irlandés en Estados Unidos pasó por tres etapas:

2. Se basó fundamentalmente en el factor étnico como "nación en el exilio" o "nación de diáspora". Continuaron manteniendo las características básicas tanto políticas, como culturales o religiosas. Incluso sus líderes seguían siendo los mismos que habían encabezado los movimientos anti-británicos en Irlanda. El trabajo en función de apoyar y sostener las reivindicaciones nacionalistas fueron fuertes y constantes.

3. Este período se caracterizó por la paulatina nacionalización de los inmigrantes y su conversión en ciudadanos americanos. Es el comienzo de los "irlando-americanos". El nacionalismo tiende a ir perdiendo fuerza a medida que se van integrando a la sociedad de acogida con su nueva problemática.

4. El nacionalismo dentro de la colectividad irlando-americana es cada vez menor y cada vez más marginal. Llegando a convertirse en una especie de sentimiento nostálgico que se manifiesta en fechas especiales como puede ser el Día de San Patricio. Mucho de esta fase tiene que ver con la presidencia de J.F. Kennedy y el prestigio que llegaron a tener por este motivo,- mayormente,- en la sociedad civil estadounidense.

En relación a los grupos y asociaciones que formaron hay que decir que los de la primer etapa fueron los más concientemente defensores de la independencia irlandesa. Sus mie mbros eran mayormente inmigrados de primera generación y asilados políticos . Estos últimos responsables de las actividades más violentas contra el gobierno de Londres.

Es necesario aclarar que durante el siglo XVIII y comienzos del XIX la llegada de irlandeses no fue muy significativa. Sólo era un pequeño y escasamente influyente sector.

Según los datos estadís ticos para 1790 sólo había un poco más de 40.000 católicos irlandeses en las ex colonias. Las asociaciones de esta primera época eran de socorros mutuos con características principalmente religiosas. La primera de ellas fue la "Sociedad Irlandesa de Caridad" fundada en Boston en 1737. Finalizando el siglo las asociaciones tendieron a unirse alrededor del factor nacional apelando a la tradición celta y comenzaron a denominarse "Hibernian". ${ }^{62}$

La segunda etapa quedó marcada por los rasgos de la "Hermandad Feniana" creada en 1858, también conocida como "Hermandad Revolucionaria irlandesa", y la más radical "Clan na Gael” en 1867.

61 Norteamericanos de ascendencia irlandesa.

62 Los Scot-Irish, son irlandeses presbiterianos llegados a Estados Unidos desde muy temprano. Con el tiempo se constituyeron en una fuerza política importante. El Senador Joseph R. McCarthy y el Presidente Ronald Reagan, son dos buenos ejemplos de ello en el siglo XX. 
Las agrupaciones se basaban en las características étnicas de los "irlandoamericanos" y acentuaban el nacionalismo americano. Por ejemplo: la " Asociación Americana para el reconocimiento de la República de Irlanda", "Los amigos de la neutralidad irlandesa en América", el "Comité americano para los estudios irlandeses".

Como dijimos anteriormente la variable religiosa fue importante en el desarrollo del nacionalismo irlandés en Estados Unidos. La inmigración constituyó un pequeño grupo católico distinto y diferenciado del núcleo anglo-sajón protestante que habitó el país desde sus orígenes. Estos primeros núcleos católicos se establecieron en principio cerca de Baltimor y Nueva York y, posteriormente, en Boston y Filadelfia. Pronto los católicos eran en su gran mayoría irlandeses aunque también existían grupos menores de alemanes o polacos. Hay que decir que la religión jugó un papel importante uniendo a la colectividad diferenciándola del resto y ayudando a la buena aceptación del nacionalismo.

El número de católicos antes de la Guerra de Independencia era mínimo. Tanto es así que de todos los irlandeses que firmaron la Declaración de Independencia eran protestantes salvo uno. Estos católicos venían de sectores agrícolas pobres de Irlanda y no contaban con muchas influencias. Sin embargo, pudieron desarrollar sus instituciones de forma temprana y sin demasiados inconvenientes. Hay registros que documentan la celebración de San Patricio en 1762 en Nueva York y en 1779 el primer desfile. Es decir, ya en épocas muy tempranas desenvolvieron sus actividades religiosas sin problemas. Aunque hay que destacar que la inmigración también incluía a Presbiterianos, Bautistas y Metodistas .

El nacionalismo tuvo un desarrollo paralelo en Irlanda misma y en la comunidad de emigrados en Estados Unidos. El país se convirtió en lugar de asilo para muchos mie mbros y líderes de los movimientos nacionalistas. En especial esto ocurrió después del fallido intento de los "Jóvenes irlandeses" en 1848. A partir de allí los emigrados por motivos políticos creció enormemente. Estos grupos pronto comenzaron a actuar y tuvieron una acogida favorable ya que existía una comunidad numerosa que se sentía diferente por lo racial y religioso.

En 1858 se fundó en Dublín la “ Hermandad irlandesa republicana” por la iniciativa de los inmigrantes estadounidenses. Y pronto se formó una asociación hermana de esta y con el mismo nombre en Nueva York. Este manojo de grupos con orientación feniana pronto tendieron a radicalizarse. Algunos, incluso llegaron a ser ilegales. Por esta razón y para eludir la proscripción es que se fundó en 1867 el "Clan na Gael". Estos grupos radicales controlaban el diario “ Irish Nation” y "United Irishman”. El nacionalismo moderado publicaba el "Pilot" en Boston y el "Irish World" en Nueva York.

Recapitulando, hay que remarcar el papel importantísimo que jugó la colectividad irlandesa y la posición privilegiada de que gozaba en la mente de los principales dirigentes en Irlanda. Para tener una idea de la dimensión de este fenómeno hay que recordar que desde junio de 1919 a diciembre de 1920, el presidente del Dáil Ëireann, Eamon de Valera, encabezó una gira por Estados Unidos para juntar fondos, concientizar y afianzar vínculos con la poderosa comunidad irlandesa en América y para difundir su posición en la opinión pública en general y en la de los políticos en particular. Con la idea de evitar las divisiones internas fundó la "Asociación para el reconocimiento de la República de Irlanda". Y durante 1922 se enviaron delegados de primer nivel con la misma finalidad. Además, la primer legación diplomática fue la de Estados Unidos en 1924. 


\section{POBLACHI HA H ERAEAME.

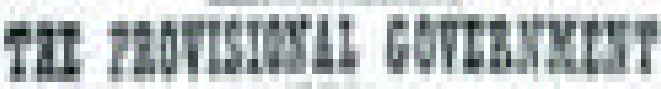 16.

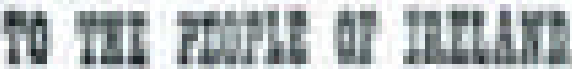

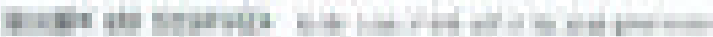

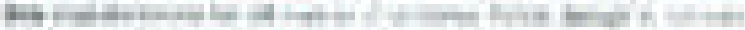

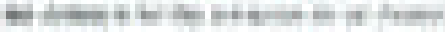

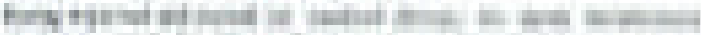

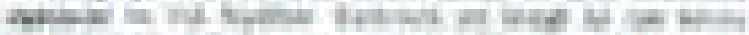

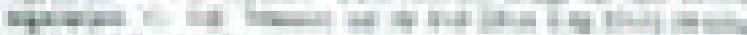

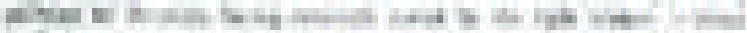

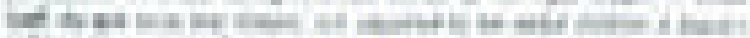

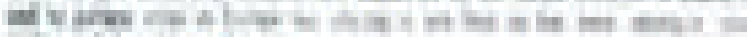

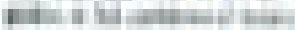

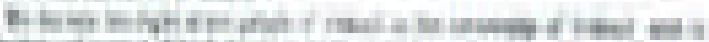

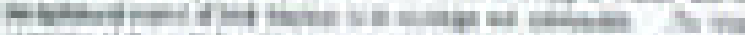

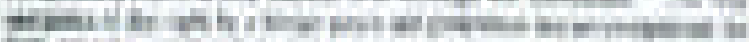

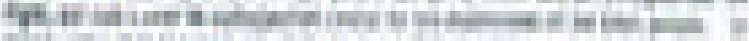

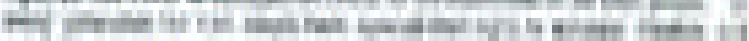

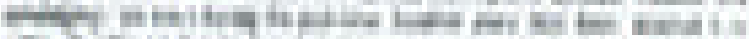

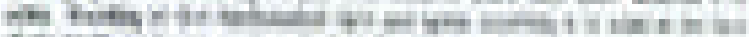

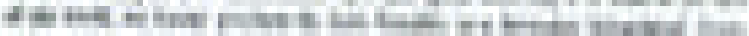

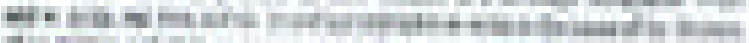

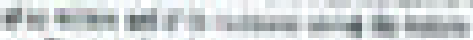

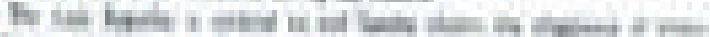

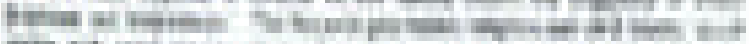

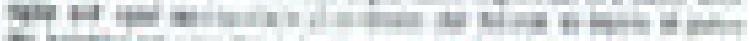

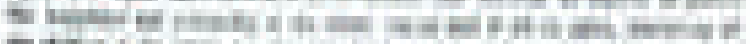

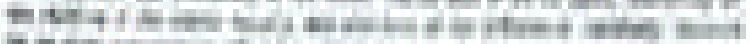

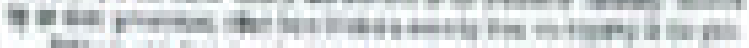

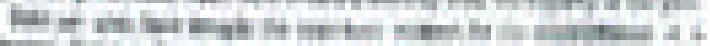

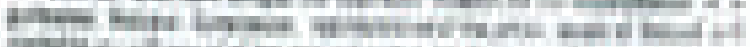

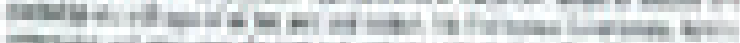

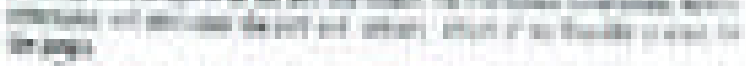

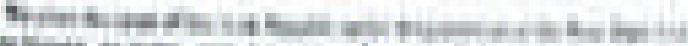

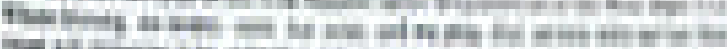

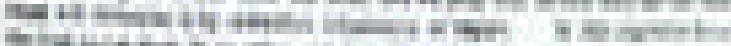

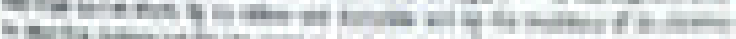

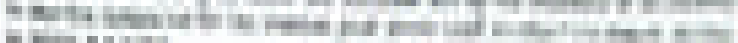
athorith

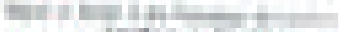

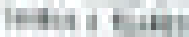

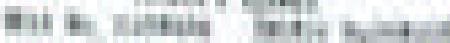

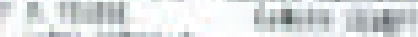

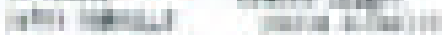

Proclama del levantamiento de Pascua de 1916 


\section{CAPITULO IV POLÍTICA EXTERIOR DE ARGENTINA E IRLANDA: COMPARACIÓN}

Existen muy pocos trabajos que estudien las políticas exteriores comparada. Esto se da principalmente porque no existe un marco teórico adecuado para ellos. Es en esta línea que haremos un repaso de los autores que lo han intentado en nuestra región.

Uno de los primeros trabajos fue el de Carlos Pérez Llana quien en su trabajo de 1975 realiza un estudio comparativo de las políticas exteriores de Argentina, Brasil y México. Aunque hay que reconocer que no fue el objetivo central. ${ }^{63}$

Algo se avanzó con la creación a fines de los 70 del Programa de Estudios Conjuntos sobre las Relaciones Internacionales en América Latina (RIAL). En 1981 comenzó con la elaboración de trabajos comparativos en la región y con los primeros atisbos metodológicos. En el marco de la IV Reunión Anual de Centros Miembros del RIAL, Juan Carlos Puig presentó un documento de trabajo que proponía algunas pautas para estos trabajos ${ }^{64}$ Para este autor no existía una teoría de las relaciones internacionales que fuere suficientemente explicativa de la realidad del sistema internacional. Ni el paradigma atomista-hegemónico (concepción estado-céntrica), ni las explicaciones sustentadas en el Derecho Internacional (juricistas) eran suficientemente comprensivas como para dar una visión acabada de la realidad. Por supuesto tampoco el enfoque realista, centrándose desde las potencias, podía hacerlo.

Una segunda etapa de aportes lo constituyó el Programa de Seguimiento de las Políticas Exteriores Latinoamericanas (PROSPEL), del Centro de Estudios de la Realidad Contemporánea (Santiago de Chile). Este centro tenía una publicación llamada Anuarios que comenzaron en 1985 y llegaron hasta comienzos de los 90 . En ellos se estudiaba la las políticas exteriores de los países latinoamericanos y se analizaba algunos aspectos de las agendas donde convergían varios de estos países. Aunque no fue estrictamente un análisis comparativo, sí sistematizó y agrupó la información como para tener los elementos básicos necesarios para los futuros estudios con este enfoque.

En esta línea, aunque limitado al tema de las "relaciones con Estados Unidos", un Grupo trabajó, en el marco del RIAL, dirigido por Mónica Hirst, siete países (Argentina, Brasil, Chile, Colombia, Cuba, México y Perú) sobre la base de factores comunes.

Una nueva visión contemporánea de la historia de las relaciones internacionales, se basa en la aplicación de nuevos abordajes y de las fuentes como metodología para acceder a un nuevo objeto de estudio: el de las percepciones. Esta idea se basa en que se puede comprender la política exterior de mejor manera si se profundiza sobre la imagen del "otro". En América Latina se comenzó con estudios de esta clase a mediados de 1980. Nosotros entendemos que este enfoque, aunque sumamente interesante y novedoso, no sería posible aplicarlo a nuestro análisis debido a la diferencia del marco temporal que utilizamos. Si

63 PEREZ LLANA, Carlos. ¿Potencias intermedias o países mayores? La política exterior de Argentina, Brasil y México. 1975.

64 PUIG, Juan Carlos. (comp.) América Latina: Políticas Exteriores Comparadas.Bs.As., Grupo Editor Latinoamericano, 1984. 
bien vamos a comparar las etapas fundacionales de la República Argentina y de la República de Irlanda como estados-nación, y es en este contexto que nos permitimos realizar una comparación no basada en la contemporaneidad sino en "categorías" de desarrollo como estado.

Tomando el modelo de Tomassini con las modificaciones hechas por Raúl BernalMeza para su estudio comparativo sobre las políticas exteriores de Argentina y Brasil es que hemos decidido darle el marco metodológico a nuestro trabajo. ${ }^{65}$

Siguiendo este marco metodológico, son tres las grandes cuestiones que definen y diferencian la política exterior de los países:

1. la agenda internacional, o sea, los intereses que los países persiguen en su accionar externo.

2. los objetivos, la posición que ese país desea alcanzar o el estado de cosas que pretende lograr a través de la satisfacción de sus intereses.

3. el estilo que caracteriza la formulación y aplicación de esa política.

\section{1.a. Relación con Inglaterra:}

Es innegable que tanto para el caso de la política exterior de Argentina como para la de Irlanda la relación con Inglaterra ha sido de tal magnitud que fácilmente se puede ver en ella a la variable divisoria de la política diplomática de estos dos países.

La relación privilegiada de socio comercial de Argentina con la Gran Bretaña ha sido ampliamente estudiada. Esto demuestra el papel de suma importancia que tuvo en el desarrollo histórico del país. La consolidación del estado-nación, que comenzó hacia 1860 y que terminó de concretarse en la década de 1880, tuvo su basamento en la consolidación del sistema económico y su inserción en el sistema capitalista global como país agroexportador. Fue esa coyuntura económica la que le permitió un gran desarrollo dentro de la división internacional del trabajo. A partir de esta inserción es que Argentina e Inglaterra tendrán una relación simbiótica- funcional donde la primera irá perdiendo autonomía frente a la segunda.

El Estado desarrolló una política exterior destinada a dar garantías a las inversiones, europeas en general y británicas en particular, a asegurar su financiación externa y a consolidar los mercados europeas para la producción agrícola. En este contexto las relaciones económicas llegaron a tener un carácter casi esencial en el funcionamiento del país, sin embargo las relaciones estrictamente políticas se caracterizaron por un bajo perfil británico.

Este bajo perfil debió ponerse a prueba en dos ocasiones, la primera fue en 1880 cuando naves de la armada argentina confiscaron la carga del buque inglés S.S. Plato. En esta ocasión tanto el embajador británico en el país como la actitud tomada por el Foreing Office, fue de absoluta no intervención. En lugar de una intromisión directa, incluso con el envío de tropas, se prefirió una política de negociación que no "ofendiera" el orgullo de las autoridades argentinas y que permitiera continuar con el intercambio comercial pacífico.

El segundo incidente fue el estallido de la crisis de 1890 y las severas políticas impuestas por Pellegrini. Algunas de estas medidas, como la adopción de un impuesto del 2\% sobre los depósitos en bancos extranjeros y del 7\% a los beneficios de las compañías ex-

65 BERNAL-MEZA, Raúl. América Latina en el mundo. El pensamiento latinoamericano y la teoría de las relaciones internacionales. Bs As., Grupo Editor Latinoamericano S.R.L., 2005 
tranjeras, afectaron indudablemente a algunas compañías británicas. A pesar de las presiones desarrolladas en Londres para lograr una intervención directa de la corona que revirtiera estas medidas, el gobierno se mantuvo ausente y mantuvo su política prescindente.

Sin embargo, hay que decir que esta conexión hegemónica con Gran Bretaña (basada en la inversión en ferrocarriles, frigoríficos y del sector financiero), fueron llevando a una progresiva pérdida de autonomía.

En relación con el caso de Irlanda su condición de territorio ocupado desde el siglo XII por Inglaterra marca una relación de dependencia que se mantuvo hasta lograr su independencia. Recién en diciembre de 1921 se firmó un tratado por el cual veintiséis condados formarían el "Estado Libre Irlandés". En 1920, ya se les había concedido a seis condados del Ulster su propio parlamento en Belfast, y habían quedado entonces como parte del Reino Unido. El establecimiento del "Estado Libre Irlandés" originó una guerra civil entre el nuevo gobierno y los que no aceptaron el tratado.

El primer gobierno del nuevo estado fue encabezado por Cosgrave, pero aún Irlanda no era libre. El partido "Fianna Fáil" fundado por de Valera dominó la política entre los años 30 y 70. Entre 1932 y 1938 tuvo lugar la denominada "guerra económica", originada en las disputas causadas por los continuos pagos sobre la tierra exigidos por Gran Bretaña, que no podía resignarse a "perder" los beneficios económicos. En 1937, a instancias de de Valera, se aprobó una nueva Constitución, que declaraba a Irlanda estado soberano, independiente y democrático. Irlanda se mantuvo neutral durante la Segunda Guerra Mundial. Pero recién en 1948, el "Acta de la República de Irlanda" cortó definitivamente las últimas ataduras constitucionales con Gran Bretaña.

Irlanda fue admitida en las Naciones Unidas en 1955 y en la Unión Europea en 1973, año en que de Valera dejó la presidencia. La tónica predominante de la política irlandesa ha sido preconizar la unión con Irlanda del Norte, a pesar de la rígida postura inglesa.

A principios de diciembre de 1999, merced a lo acordado entre la República de Irlanda, Irlanda del Norte y Gran Bretaña, entró en funcionamiento en Belfast el primer gobierno independiente de Irlanda del Norte, poniendo fin al poder británico en la isla. Se iniciaron además tratativas tendientes a lograr una paz definitiva, a través del desarme de los grupos guerrilleros pertenecientes a Irlanda del Norte y a la República de Irlanda. Por eso, tanto por acción como por reacción, la política exterior de Irlanda estuvo decidida desde Londres, hasta 1949, sus salida del Commonwealth. ${ }^{66}$

Siguiendo la teoría de Puig, quien comenzó a estudiar el funcionamiento del régimen internacional tomando como eje la autonomía y sus gradaciones, y usando sus cuatro estadíos principales: dependencia para-colonial, dependencia nacional, autonomía hetero-

66 CommonwealthMancomunidad Británica de Naciones (en inglés, Commonwealth of Nations, antiguamente British Commonwealth of Nations) es una organización compuesta en la actualidad por 53 países independientes que, con la excepción de Mozambique, comparten lazos históricos con el Reino Unido. Su principal objetivo es la cooperación internacional en el ámbito político y económico y desde 1950 su membresía no implica sumisión alguna hacia la corona británica. El monarca británico es la cabeza de la organización y, según sus principios, "símbolo de la libre asociación de sus miembros".

La organización tiene sus orígenes en la Conferencia Imperial de 1920, cuando el gobierno británico reconoció ciertos derechos de autodeterminación de sus colonias e inició los trabajos que culminaron con el Estatuto de Westminister en 1931, que dieron origen a la Mancomunidad (en ese entonces consistente en un puñado de ex colonias aún leales a la monarquía). 
doxa y autonomía secesionista, es fácil ubicar a los dos estados-nación en este esquema. A Irlanda, al menos hasta 1948, se la puede describir como de dependencia para-colonial, Argentina en la etapa del modelo agro-exportador que estudiamos (1880-1916) también podría entrar en la misma categoría. Por supuesto que con diferencias mayormente formales que los colocan en los opuestos del mismo espectro. Con lo cual nosotros creemos que, al menos en este aspecto, la diferencia entre los dos países es sólo una diferencia de grado.

\section{b. Relaciones bilaterales/multilaterales:}

Sabemos que la diplomacia puede tener dos modalidades: la bilateral que tiene lugar entre dos estados (mayormente) y la multilateralque tiene lugar entre 2 o más Estados o bien entre uno de estos y otros sujetos de derecho internacional. Puede ser igualmente temporal, por medio de las conferencias internacionales, o permanentes por medio de las delegaciones o misiones permanentes. Tiene una forma de ejecución también muy característica: la multilateral que es la denominada diplomacia de conferencia que se institucionalizó a escala global con el tratado de Versalles y la Sociedad de Naciones, aunque ya existía desde antes. $^{67}$

La Argentina de la década de 1880 es un estado-nación integrado y ordenado, con una fuerte inmigración, económicamente rica y con una relación de privilegio con su socia comercial: Inglaterra, potencia aún dominante en esa época. Es por esta razón que dentro del concierto internacional se va a mostrar como "uno entre iguales" manteniendo una relación bilateral con el resto de los países, en particular con aquellos hacia los que siente una inocultable admiración cultural: los europeos del norte.

Asimismo, mantendrá la defensa irrestricta del derecho internacional, la salvaguarda de las soberanías de los estado-nación y una permanente política de neutralidad.

En relación con el espacio latinoamericano guardará cierta ambigüedad basada en una distancia y despreocupación por la vinculación a la región y, al mismo tiempo, una política de prestigio basada en la defensa y salvaguarda de los interesas de estos países frente a la intromisión de potencias europeas o de Estados Unidos.

Por otro lado existió un menosprecio hacia las conferencias internacionales y una abierta oposición hacia las decisiones que en ella se tomaban. Esto particularmente verás cuando debía enfrentarse a los intereses hegemónicos de Estados Unidos, como hemos visto ampliamente desarrollado en el capítulo 2 de esta tesis.

Es indudable que la situación de la nación irlandesa era distinta y, por lo tanto también lo era su política exterior. Su situación como país pequeño lo llevó a una fuerte defensa del derecho internacional,- como forma de protección-, y a la participación decidida y constante en todos los foros internacionales donde le era posible participar. Lo va a hacer en la Sociedad de las Naciones (1923), en las Naciones Unidas (1955) y en la Unión Europea (1973). Lo que demuestra una estrategia de acción sistemática.

Mientras Argentina usará una política bilateral de prestigio que se fundamentaba en una política doméstica de un estado fuerte con un modelo de nacionalismo civilista, Irlanda debió buscar la mejor estrategia en política exterior que le permitiera compensar un

67 Congreso de Viena conferencia internacional convocada, con el objeto de restablecer las fronteras de Europa tras la derrota de Napoleón I. La reunión se llevó acabo del 1 de octubre de 1814 al 9 de junio de 1815 y las decisiones que allí se tomaron de forma multilateral marcaron el equilibrio de poderes de la mayor parte del siglo XIX. 
estado nuevo salido de las reivindicaciones de un nacionalismo identitario, a través de su uso de la diplomacia multinacional.

\section{c. Relación con Estados Unidos de América:}

Durante la década de 1880, un tema clave de la agenda política en las relaciones entre los gobiernos de Buenos Aires y Washington fue el esfuerzo puesto en práctica por la diplomacia norteamericana en pos de la unidad panamericana. Mientras Estados Unidos buscaba imponer su hegemonía en los países de Sudamérica, Argentina se convertía en su principal oponente. Esta rivalidad se desarrolló en todas y cada una de las Conferencias Panamericanas.

Uno de los puntos mayormente discutidos fue el del arbitraje sugerido por el país del norte y que chocaba con los principios profundamente arraigados en la diplomacia nacional sobre igualdad soberana y no intervención de países extranjeros.

La posición argentina en la Conferencia Panamericana de 1889, oponiéndose sistemáticamente a la cada vez mayor influencia de Estados Unidos, estaba basada en la visión que la clase gobernante tenía de su país. El éxito del modelo económico, los progresos en el orden cultural, la convertían en una nación superior al resto de América Latina y de espaldas a esta. Con una íntima relación con Europa y con un sentimiento de competencia y desconfianza hacia la potencia emergente en el norte.

El panorama continental para fines del siglo XIX permitió que dos países ricos, con nacionalismos formados desde el estado, con procesos inmigratorios fuertes, se enfrentaran. Mientras EEUU tendrá una política exterior expansionista, Argentina pondrá todos sus recursos para contenerlo.

Cuando hacia fines de 1902, Venezuela se vio amenazada por las fuerzas navales de Gran Bretaña, Alemania e Italia con el fin de lograr el pago de la deuda Estados Unidos no utilizó los principios de la Doctrina Monroe ("América para los americanos"), con el fin de proteger a su vecino sino, por el contrario creó el llamado "primer Corolario Roosevelt" para limitar la doctrina y no intervenir. En este contexto, el Canciller argentino presenta su después llamada "Doctrina Drago", donde sostiene que la deuda de ningún país puede dar lugar a la intervención armada.

La postura del canciller argentino constituyó un respaldo al texto de la Doctrina Monroe y una fuerte crítica a las prácticas intervensionistas en la región. Paradójicamente, debido al fuerte respaldo que la doctrina Drago hace a la Monroe, las políticas exteriores argentinas y norteamericanas se alejaron.

En la opinión de algunos autores, el "Corolario Roosevelt" formó parte de una ideología imperial del gobierno norteamericano que extendió la visión de Destino Manifiesto desde la zona del Caribe hacia las naciones de habla hispana a lo largo del hemisferio. Mientras EEUU adoptó la forma de control directo en la cuenca del caribe, la estrategia utilizada para el Cono Sur fue la de la "diplomacia de control". Mientras que Argentina se le opondrá utilizando los principios del derecho internacional.

La relación de Irlanda con Estados Unidos va a ser mayormente buena. Esto gracias al trabajo de concientización de la opinión pública y del mundo político que van a realizar primeramente los grupos organizados de la Diáspora y luego los principales mie mbros del gobierno en persona. La primera embajada se abrió en Washington en 1924 y dos años después se firma el acta de reciprocidad. En 1928 la primer visita de estado irlandesa va a ser a este país. 


\section{Los objetivos:}

Durante los primeros cuarenta años posteriores a su independencia Argentina debe mantener una política exterior netamente defensiva y su principal objetivo fue la búsqueda del reconocimiento diplomático de su existencia. Además debió esforzarse por consolidar sus fronteras externas y tratar de minimizar lo más posible la intromisión de otros países en los asuntos internos. Tengamos en cuenta que durante el siglo XIX la intervención político militar de Europa y Estados Unidos en los asuntos internos Latinoamérica nos era frecuente.

Recién a fines del siglo, con todo lo que ya hemos visto sobre la consolidación nacional, es que se comienza con una política exterior coherente con lineamientos propios. Ya hemos visto como las elites que gobernaban el país apostaron a insertar al país dentro de la división internacional como un país productor de alimentos. El proceso de crecimiento económico era un pre requisito para lograr los demás objetivos nacionales. Es por esta razón que la diplomacia se convirtió en la típica de un "estado comerciante" ("trading state"), siendo instrumento de la inserción económica buscando abrir nuevos mercados a la producción local, promover la inversión extranjera, la obtención de créditos internacionales y favorecer el arribo de inmigración. ${ }^{68}$

Un análisis de la estructura organizativa de la diplomacia confirma esto. Para 1910, los medios eran relativamente modestos (había representación diplomática en diecinueve países y un personal de aproximadamente ses enta y siete personas), mientras que el cuerpo consular, que se ocupaba de los temas económicos, era equivalente en tamaño e importancia al de las principales potencias de la época, salvo lógicamente Gran Bretaña y Francia.

Irlanda tiene en esta etapa un sólo gran objetivo: el reconocimiento internacional de su soberanía. El envío de representantes a todas partes del mundo, participando en todos los foros posibles, utilizando las diásporas eran medios para lograrlo De hecho, junto con la proclamación de independencia se redacta un manifiesto dirigido a todos los países del mundo instándolos a apoyar su existencia.

The Nation of Ireland having proclaimed her national independence, calls through her elected representatives in Parliament assembled in the Irish Capital on January $21^{\text {st }}, 1919$, upon every free nation to support the Irish Republic by recognising Ireland's national status and her right to its vindication at the Peace Congress. ${ }^{69}$

\section{3. el estilo}

Frente a los objetivos de política exterior antes expuestos la Argentina tomó un estilo de "no compromiso" a nivel mundial cuyos lineamientos básicos eran:

- Mantener buenas relaciones con los países más avanzados como un instrumento para resguardar la inserción económica internacional del país.

68 DE LA BALZE, Felipe A.M. La política exterior en tres “tiempos". Los fundamentos de la "nueva política exterior”. En: Felipe A. M. de la Balze y Eduardo ROCA (comp.) Argentina y EE.UU. Fundamentos de una nueva alianza, Buenos Aires, ABRA-CARI, 1997.

69 Versión completa en nuestro Apéndice documental. 
- No establecer alianzas políticas formales que pudieran llevarla a conflictos de los cuales no era parte y que perjudicaría su posición comercial.

- Buscar la neutralidad y la defensa del derecho internacional como resguardo de estos objetivos.

Es decir, se buscó mantener un perfil de neutralidad y una defensa explícita del derecho internacional.

Por el contrario, a nivel de política regional,- es decir en el continente Americano-, la Argentina instrumenta un estilo más agresivo basado en una tradicional política de prestigio e intentaba ejercer un cierto liderazgo en la región. Para esto sostuvo una férrea oposición a la hegemonía de Estados Unidos en la región y participó como "árbitro", "garante" o "amistoso componedor" en la resolución de los conflictos interregionales.

En resumen: la clave del estilo de la política exterior consistió en fundar la independencia política y el prestigio internacional del país sobre el éxito económico, la estabilidad institucional, la cantidad y variedad de intercambio comercial y una sistemática no intromisión en los asuntos de otros países aunque, simultáneamente, oponiéndose a Brasil y Estados Unidos en la lucha por el liderazgo regional.

Un análisis superficial de la política exterior e internacional de la Argentina parecería demostrar su permanente incoherencia. En el siglo XIX era un país dependiente de Europa, y particularmente de Gran Bretaña, pero no obstante desafiaba a los europeos con las armas en las manos (1840 y 1849) o en fieras controversias diplomáticas...mantenía vinculaciones políticas esporádicas en América latina, pero defendía ardorosamente a Venezuela contra la intervención europea (en 1902, cuando el canciller Luis María Drago enunció su doctrina). ${ }^{70}$

Irlanda debe crear una organización burocrática dedicada a las relaciones exteriores prácticamente de la nada. Los primeros funcionarios van a ser pocos y van a ser elegidos más por habilidades personales o por sus propios contacto más que por una carrera específica $\mathrm{n}$ el área y una formación profesional en el tema. Es por eso que el estilo difícilmente considerado agresivo. Más bien va a ser un estilo más discreto.

Estas apreciaciones que hace Puig sobre lo que habitualmente se escucha, -tanto en los ámbitos académicos como del público en general-, sobre las aparentes paradojas de la política exterior del país son reales. Sin embargo, nosotros entendemos que no surgen de un estudio objetivo de la realidad histórica y se debe principalmente a confundir objetivos de la diplomacia con estilos.

\section{Diferencias estructurales a partir del nacionalismo}

El nacionalismo, como lo hemos entendido a lo largo de este trabajo, es la doctrina social y política a partir de la cual se conforman los grupos humanos llamados nación. Esto implica que no necesariamente estado y nación coinciden pero en la mayoría de los casos el primero será motivo de reivindicación del segundo. ${ }^{71}$

70 PUIG, Juan Carlos. Política Internacional Argentina. Buenos Aires, GEL, 1988.

71 Parecería que el pueblo Gitano es la única nación que no reclama, por no interesarle, un hogar nacional. Se dice que los gitanos se diseminaron por el mundo procedentes de la región del Panyab (India y Pakistán). Sin embargo esto se basa en un análisis lingüístico (su idioma, el romaní, es hermano del sánscrito), que no toma en cuenta 
A partir de la interrelación que se genera entre ambos hemos propuesto una clasificación. Según esta si el Estado es el formador desde arriba de un estado-nación homogéneo, basado en el contrato entre ciudadanos y gobernantes, unificados en el vínculo igualitario de la ciudadanía, con fuerte presencia de adoctrinamiento estatal a través,- principalmente, de la escuela, el Registro Civil y el servicio militar obligatorio-,. a esta categoría la llamamos: nacionalismo civilista.

Cuando el sentido de formación es el inverso, es decir de abajo hacia arriba, cuando lo que une es la conciencia de pertenencia basada en raza, idioma, religión, etc., lo llamamos: nacionalismo romántico. Genera lmente son naciones sin estado que reclaman por vías pacíficas o violentas su "hogar nacional".

El poder político ha sido asociado al gobierno y al estado. El Estado se ha convertido en el lugar del poder. Siguiendo a la definición clásica de Weber, es un poder basado en el monopolio del uso de la violencia legítima. Esta situación comienza a gestarse en occidente a partir del Renacimiento y son su racionalización específica.

Desde finales del siglo XVII se desencadenan una serie de episodios revolucionarios que dan lugar a cartas constitucionales y declaraciones de derechos (Revolución Gloriosa en Inglaterra, 1688; declaración de la Independencia norteamericana, 1776; Revolución francesa, 1789; Declaración de los Derechos del Hombre, 1791) que instituyen al Estado sobre las bases de libertad, igualdad política, propiedad privada, tc. Los textos teóricos que dan marco ideológico a lo que nace son los clásicos Leviathan de Hobbes en 1651, los Dos tratados sobre el Gobierno de Locke, 1689 y el Contrato social de Rousseau en 1762.

El ciudadano renuncia a parte de sus derechos individuales en favor del Estado (Leviathan), que se convierte en un poder absoluto, consensuado y legitimado. Cuya función es defender los derechos fundamentales. Estos son según el ideario burgués, la seguridad, la libertad y el órden para Hobbes y la vida, la libertad y propiedad privada para Locke. De esta forma el Estado es una creación humana y legitima las formas de Monarquías Absolutas (Hobbes) o Parlamentarias (Locke). La propuesta de Rousseau avala la fórmula revolucionaria y republicana. Esto lo hace planteando la necesidad de un contrato social que garantice la igualdad (formal) de los hombres y la satisfacción de sus necesidades a través de un gobierno que ejecute la voluntad general del pueblo.

En la concepción clásica de Marx (1852), después desarrollada por Lenin, el Estado no es neutro, se vincula a la clase dominante y garantiza el proceso de dominación. Visiones más contemporáneas como las de Gramsci (1929) y Poutlanzas (1972) dan un enfoque un poco más complejo pero basado en los mismos principios. En el ala más izquierda de este pensamiento teóricos clásicos del anarquismo del siglo XIX, como Proudhom y Kropotkin se plantean el modo de descentralizar y desconcentrar el poder que tiene el Estado.

La naciones, están constituidas por el concepto gramsciano del "complejo Estado/sociedad civil". Mientras que para el nacionalismo civilista la variable Estado es la de

otras variables cultur ales para determinar el real origen de este pueblo. Con todo, es creencia generalizada que en algún momento de la historia los gitanos abandonaron la India para poblar otros lugares.

Lo cierto es que, aunque es posible que provengan de la India, no está claro si antes de llegar a aquel país tenían un origen distinto. Actualmente no hay teoría científica que demuestre absolutamente un origen cierto del pueblo gitano. Y, aunque se han establecido en muchos países, han conservado su idioma, costumbres y homogeneización racial. El hecho de ser semi-nómades parece ser la causa de no buscar una reivindicación estatual u hogar nacional. 
mayor peso, pasa lo contrario con el nacionalismo romántico. Este marco teórico de análisis nos permitirá avanzar en el tema.

El concepto gramsciano del "complejo Estado/sociedad civil" , que fue incorporado a la teoría de las relaciones internacionales por el norteamericano Robert W. Cox, y que nos recuerda que los diversos Estados están condicionados de muy diferentes maneras por sus respectivas sociedades civiles. De tal modo, visto en el largo plazo, el actor (o unidad) "nacional" que realmente interactúa en el orden interestatal con sus políticas exteriores no es simplemente el estado, sino el complejo Estado/sociedad civil, que imprime a cada actor una lógica y una dinámica diferente a la de los demás actores o unidades.

Cada país registra una relación entre el Estado y la sociedad civil que le es propia y que lo diferencia de todos los demás. Sistemas políticos, estructuras sociales y culturas políticas determinan enormes diferencias en, por ejemplo, la medida en que el Estado puede imponerle sacrificios a la ciudadanía. También determinan diferencias significativas respecto a la mismísima definición de conceptos aparentemente universales como el de "interés", que se vuelve etnocéntrico en tanto la valoración de un mismo costo o beneficio cambiará en función de factores políticos, sociales y culturales que son particulares a cada sociedad civil y que tienen una fuerte incidencia sobre el Estado, ya sea por las presiones de la sociedad civil (el caso, digamos, de las verdaderas democracias), o porque la ausencia de presiones genera una enorme autonomía al gobernante.

Por otra parte, incluso cuando la sociedad civil tiene un enorme peso sobre las decisiones del Estado, puede haber grandes diferencias cualitativas en el tipo de influencia que ésta ejerce debido a la intervención de variables culturales. La influencia de la sociedad civil sobre el Estado, por ejemplo, no siempre conduce a una administración más "racional" de la política exterior en términos del balance de costos y beneficios. Las estructuras sociales, los sistemas políticos y las culturas obran como condicionantes de primer orden en la percepción y valoración de hasta los parámetros más "objetivos".

Dentro de este esquema, Argentina con un nacionalismo civilista, lleva a cabo una política exterior basada en los intereses de su clase gobernante. Con un aparato burocrático importante que forma profesionales en la materia. Esto, lógicamente, a partir del presupuesto del Estado, o sea el estado invierte en la formación del personal diplomático. Y donde es muy difícil imponerle grandes sacrificios.

Esto último lo podemos ver con dos ejemplos de nuestra historia . Por un lado la Guerra de Malvinas, donde se le pidió a la sociedad desde el gobierno todos los sacrificios que un conflicto bélico conlleva. Donde este fue aceptado, aún con ciego entusiasmo. Pero donde hubo que apelar a la prosa más pura del nacionalismo para lograrlo. ${ }^{72}$

En sentido contrario, es llamativo como una crisis económica,- ejemplos hay muchos en nuestra historia reciente-, moviliza el pedido de cambio de ciudadanía y la emigración cuando el ciudadano entiende que el Estado no cumplió con su parte del contrato civil $\mathrm{y}$, por lo tanto, el individuo queda liberado de cumplir su parte.

Lo opuesto puede decirse sobre el nacionalismo romántico irlandés. Aquí vemos un Estado nuevo, pequeño y relativamente débil que debe improvisar un servicio exterior a partir de la buena voluntad de personas poco preparadas para ese fin. Y teniendo que recu-

72 Aunque no compartimos por entero, es interesante el análisis que sobre esto propone Escudé. Ver: ESCUDE. Carlos. Un enigma: la "irracionalidad" argentina frente a la Segunda Guerra Mundial. Buenos Aires,Universidad Torcuato Di Tella. Disponible en internet. 
rrir a estrategias informales ( el uso de la diáspora y su para-diplomacia) e interviniendo en foros numerosos a favor de su causa.

Recapitulando, la diferencia entre las políticas exteriores de Argentina e Irlanda son de distinta naturaleza. De agenda, de objetivos y de estilo.

De agenda, la relación particular que ambos países tienen con Inglaterra conlleva una relación distinta con Estados unidos. Mientras Argentina se apoyará en su alianza con el Reino Unido para oponerse a su rival del norte, Irlanda logrará allí un apoyo más o menos formal a su causa en oposición a su antigua Metrópoli. De objetivos: mayormente económicos para nuestro país, de reconocimiento internacional para la isla. Asimismo, estilos diferentes a partir de su accionar diplomático.

Pero estas diferencias se basan en la relación particular que se da en cada una de ellas del complejo gramsciano "Estado/sociedad civil" y que conforman su modelo de nacionalismo. Va a ser justamente ese modelo el que determine su diplomacia y las diferencias que de allí surgen. 


\section{CONCLUSION}

Existe una relación entre las políticas domésticas de los países y sus relaciones internacionales. Es una especie de feedback, donde se retroalimentación mutuamente estas dos "esferas". Los intereses internos influyen en las decisiones que se toman en el concierto internacional así como lo que ocurre en el exterior define, en mayor o menor medida según el grado de permeabilidad o de dependencia, lo que pase a nivel interno en los estados.

El Nacionalismo como teoría formativa de los países nos permite abordar estas relaciones internas. Los modelos de formación nacional tienen características propias y repetidas en cuanto a su papel internacional. A partir de estos podemos pensar en paradigmas (modelos de estudio) que nos permitan comprender el accionar global.

Por ejemplo, si pensamos que A es un nacionalismo Romántico, por lo tanto tendrá un accionar $a$ en materia diplomática. Si, por el contrario, B es un nacionalismo civilista su política exterior será $b$. Como esto no se da nunca en estado puro (hablamos de ciencias sociales y no de laboratorios), lo interesante será estudiar las distintas combinaciones que se gestarán en la realidad y en los distintos contextos históricos.

El nacionalismo, como lo hemos entendido a lo largo de este trabajo, es la doctrina social y política a partir de la cual se conforman los grupos humanos llamados nación. Esto implica que no necesariamente estado y nación coinciden pero en la mayoría de los casos el primero será motivo de reivindicación del segundo.

Si el Estado es el formador desde arriba de un estado-nación homogéneo, basado en el contrato entre ciudadanos y gobernantes, unificados en el vínculo igualitario de la ciudadanía, con fuerte presencia de adoctrinamiento estatal a través,- principalmente, de la escuela, el Registro Civil y el servicio militar obligatorio, a esta categoría la llamamos: nacionalis mo civilista.

Cuando el sentido de formación es el inverso, es decir de abajo hacia arriba, cuando lo que une es la conciencia de pertenencia basada en raza, idioma, religión, etc., lo llamamos: nacionalismo romántico. Generalmente son naciones sin estado que reclaman por vías pacíficas o violentas su "hogar nacional".

Utilizamos el concepto gramsciano del "complejo Estado/sociedad civil" , que fue incorporado a la teoría de las relaciones internacionales por el norteamericano Robert W. Cox, y que nos recuerda que los diversos Estados están condicionados de muy diferentes maneras por sus respectivas sociedades civiles. De tal modo, visto en el largo plazo, el actor (o unidad) "nacional" que realmente interactúa en el orden interestatal con sus políticas exteriores no es simplemente el estado, sino el complejo Estado/sociedad civil, que imprime a cada actor una lógica y una dinámica diferente a la de los demás actores o unidades.

Sobre la base de esto podemos afirmar que A (o los piases donde mayormente imperen la característica propia de los nacionalismos de abajo), tendrán una presencia mayor de la sociedad civil y su accionar en política exterior será marcada por esta. Teniendo esto presente podemos decir que a se caracteriza por la defensa del derecho internacional y el manejo dentro de esas reglas. De este modo se busca controlar al más poderoso a favor del más débil. Y, además, este marco les permite a los países pequeños un margen de maniobras mayor. Esto también se aplica a la labor de los diplomáticos. Es por eso que se los puede ver como los más entusiastas participantes de toda clase de foros donde las decisiones se toman en forma colectiva,- el ejercicio de unas relaciones internacionales multilaterales donde países pequeños consiguen mayores logros a través de su asociación -. 
El otro aspecto importante es la búsqueda de objetivos utilizando medios no estrictamente diplomáticos. O, dicho de otro modo, la utilización de canales informales de negociación. los cuales fueron claves en política internacional. En concreto nos referimos a las vinculaciones con las "diásporas", las cuales no solo aportaron en su momento dinero, hombres y armas, sino incluso manejo de influencias. Entendemos por diplomacia las actividades y negociaciones llevadas a cabo primaria, pero no excluyentemente, por diplomáticos profesionales que actúan en beneficio de estados soberanos. Sin embargo, más allá del sistema formal de representación de los estados soberanos que existen actualmente en el mundo, existe un cada vez mayor número de ONGs, agencias, asociaciones, individuos que tienen representación similar a la diplomática y que buscan su reconocimiento de los estados. Esto puede ser explicado en parte por la emergencia de una sociedad civil global inter actuante. Por eso la gran pregunta es quien puede ser diplomático hay en día. La respuesta: potencialmente casi todos.

Si por lo contrario analizamos países B podemos ver diferencias notables. El accionar de B, al que llamaremos b, será caracterizado por lo que podríamos llamar una Diplomacia Civilista: basada en las relaciones bilaterales y en la diplomacia de prestigio.

A y su accionar a, tanto como B y su respectivo accionar b lo hemos analizado para los casos de Argentina e Irlanda en sus etapas fundacionales como estados- nación. La variable temporal no es menor y el ubicar el estudio dentro de un contexto determinado permite focalizar el estudio y las comparaciones.

Siguiendo el marco metodológico propuesto por Raúl Bernal-Meza ${ }^{73}$, hemos hecho la comparación basados en las grandes cuestiones que definen y diferencian la política ext erior de los países:

1. la agenda internacional, o sea, los intereses que los países persiguen en su accionar externo.

2. los objetivos, la posición que ese país desea alcanzar o el estado de cosas que pretende lograr a través de la satisfacción de sus intereses.

3. el estilo que caracteriza la formulación y aplicación de esa política.

\section{Aquí estudiamos principalmente la relación bilateral de los dos países con Inglaterra y con los Estados Unidos.}

Es innegable que tanto para el caso de la política exterior de Argentina como para la de Irlanda la relación con Inglaterra ha sido de tal magnitud que fácilmente se puede ver en ella a la variable divisoria de la política diplomática de estos dos países.

Entre Argentina y el Reino Unido existió una relación privilegiada de socio comercial. La coyuntura económica la que le permitió un gran desarrollo dentro de la división internacional del trabajo. A partir de esta inserción es que Argentina e Inglaterra tendrán una relación simbiótica- funcional donde la primera irá perdiendo autonomía frente a la segunda. En relación con el caso de Irlanda su condición de territorio ocupado desde el siglo XII por Inglaterra marca una relación de dependencia que se mantuvo hasta lograr su independencia. Recién en diciembre de 1921 se firmó un tratado por el cual veintiséis condados

73 BERNAL-MEZA, Raúl. América Latina en el mundo. Op.Cit. 
formarían el "Estado Libre Irlandés". En 1920, ya se les había concedido a seis condados del Ulster su propio parlamento en Belfast, y habían quedado entonces como parte del Reino Unido. El establecimiento del "Estado Libre Irlandés" originó una guerra civil entre el nuevo gobierno y los que no aceptaron el tratado.

El primer gobierno del nuevo estado fue encabezado por Cosgrave, pero aún Irlanda no era libre. El partido "Fianna Fáil" fundado por de Valera dominó la política entre los años 30 y 70. En 1937, a instancias de de Valera, se aprobó una nueva Constitución, que declaraba a Irlanda estado soberano, independiente y democrático. Irlanda se mantuvo neutral durante la Segunda Guerra Mundial. Pero recién en 1948, el "Acta de la República de Irlanda" cortó definitivamente las últimas ataduras constitucionales con Gran Bretaña.

En relación con los Estados Unidos durante la década de 1880, un tema clave de la agenda política en las relaciones entre los gobiernos de Buenos Aires y Washington fue el esfuerzo puesto en práctica por la diplomacia norteamericana en pos de la unidad panamericana. Mientras Estados Unidos buscaba imponer su hegemonía en los países de Sudamérica, Argentina se convertía en su principal oponente. Esta rivalidad se desarrolló en todas y cada una de las Conferencias Panamericanas.

La relación de Irlanda con estados Unidos va a ser mayormente buena. Esto gracias al trabajo de concientización de la opinión pública y del mundo político que van a realizar primeramente los grupos organizados de la Diáspora y luego los principales mie mbros del gobierno en persona. La primera embajada se abrió en Washington en 1924 y dos años después se firma el acta de reciprocidad. En 1928 la primera visita de estado irlandesa va a ser a este país.

\section{Los objetivos:}

Durante los primeros cuarenta años posteriores a su independencia Argentina debe mantener una política exterior netamente defensiva y su principal objetivo fue la búsqueda del reconocimiento diplomático de su existencia. Además debió esforzarse por consolidar sus fronteras externas y tratar de minimizar lo más posible la intromisión de otros países en los asuntos internos. Tengamos en cuenta que durante el siglo XIX la intervención político militar de Europa y Estados Unidos en los asuntos internos latinoamericanos era frecuente.

Recién a fines del siglo, con todo lo que ya hemos visto sobre la consolidación nacional, es que se comienza con una política exterior coherente con lineamientos propios. Ya hemos visto como las elites que gobernaban el país apostaron a insertar al país dentro de la división internacional como un país productor de alimentos. El proceso de crecimiento económico era un pre requisito para lograr los demás objetivos nacionales. Es por esta razón que la diplomacia se convirtió en la típica de un "estado comerciante" ("trading state"), siendo instrumento de la inserción económica buscando abrir nuevos mercados a la producción local, promover la inversión extranjera, la obtención de créditos internacionales y favorecer el arribo de inmigración.

Un análisis de la estructura organizativa de la diplomacia confirma esto. Para 1910, los medios eran relativamente modestos (había representación diplomática en diecinueve países y un personal de aproximadamente sesenta y siete personas), mientras que el cuerpo consular, que se ocupaba de los temas económicos, era equivalente en tamaño e importancia al de las principales potencias de la época, salvo lógicamente Gran Bretaña y Francia. 
Irlanda tiene en esta etapa un sólo gran objetivo: el reconocimiento internacional de su soberanía. El envío de representantes a todas partes del mundo, participando en todos los foros posibles, utilizando las diás poras eran medios para lograrlo De hecho, junto con la proclamación de independencia se redacta un manifiesto dirigido a todos los países del mundo instándolos a apoyar su existencia.

\section{3. el estilo}

Frente a los objetivos de política exterior antes expuestos la Argentina tomó un estilo de "no compromiso" a nivel mundial cuyos lineamientos básicos eran:

- Mantener buenas relaciones con los países más avanzados como un instrumento para resguardar la inserción económica internacional del país.

- No establecer alianzas políticas formales que pudieran llevarla a conflictos de los cuales no era parte y que perjudicaría su posición comercial.

- Buscar la neutralidad y la defensa del derecho internacional como reguardo de estos objetivos.

Es decir, se buscó mantener un perfil de neutralidad y una defensa explícita del derecho internacional.

Por el contrario, a nivel de política regional, - es decir en el continente Americano-, la Argentina instrumenta un estilo más agresivo basado en una tradicional política de prestigio e intentaba ejercer un cierto liderazgo en la región. Para esto sostuvo una férrea oposición a la hegemonía de Estados Unidos en la región y participó como "árbitro", "garante" o "amistoso componedor" en la resolución de los conflictos interregionales.

En resumen: la clave del estilo de la política exterior consistió en fundar la independencia política y el prestigio internacional del país sobre el éxito económico, la estabilidad institucional, la cantidad y variedad de intercambio comercial y una sistemática no intromisión en los asuntos de otros países aunque, simultáneamente, oponiéndose a Brasil y Estados Unidos en la lucha por el liderazgo regional.

Un análisis superficial de la política exterior e internacional de la Argentina parecería demostrar su permanente incoherencia. En el siglo XIX era un país dependiente de Europa, y particularmente de Gran Bretaña, pero no obstante desafiaba a los europeos con las armas en las manos (1840 y 1849) o en fieras controversias diplomáticas...mantenía vinculaciones políticas esporádicas en América latina, pero defendía ardorosamente a Venezuela contra la intervención europea (en 1902, cuando el canciller Luis María Drago enunció su doctrina). ${ }^{74}$

La diplomacia irlandesa, por el contrario, debe crear un aparato burocrátic o casi de la nada. El personal va a ser poco y escasamente preparado. Por eso el estilo puede ser considerado más informal que el argentino.

Así las diferencias en las agendas, objetivos y estilos de Política Ext erior están más relacionadas con su "modelo nacional" que lo que habitualmente se piensa y es esto lo que tratamos de estudiar en este trabajo. 


\section{ANEXO Identidad Nacional}

Los estados-nación que surgen en América Latina después de los procesos de independencia, están construidos a partir de la concepción civilista de nación. Se basan en el contrato social y están inspirados en los principios de la Revolución francesa. Son, de hecho estados sin nación y, como tales, sin identidades propias.

Los países que van surgiendo en la región se vieron frente al doble desafío de crear y defender estados emancipados y generar naciones leales a los mismos. Esto presentó la gran dificultad de crear una nueva fórmula ideológica-política que pudiera legitimar una estructura de poder en lugares que habían sido parte de la gran estructura imperial española. Roto el nexo colonial hubo que reemplazarlo en un sentido tan radical que incluso ya no era monárquico sino republicano.

Desde el punto de vista teórico y siguiendo las ideas de Germán Carrera Damas ${ }^{75}$, vemos que en la formulación de cualquier conciencia nacional se distinguen dos fases, la de definición negativa y la de definición positiva. La primera es el punto de partida de todo proceso de formación de conciencia nacional y se basa en la formación de una conciencia americana. Esta se definió en oposición a la peninsular, español, europeo, y marcaba una diferencia que se enriquecía a medida que las sociedades iban fortaleciendo una conciencia criolla. Esta situación se exacerbó a fines del siglo XVIII a partir de una nueva oleada de inmigración peninsular propiciada por las políticas borbónicas.

Luego se subió otro escalón al irse formando conciencias regionales también basadas en un carácter negativo. Por ejemplo la contraposición entre el reino de México independiente y las áreas centroamericanas del antiguo Virreinato; a las que desembocaron en 1830 en el desmembramiento de la República de Colombia, que dió origen a Venezuela, Colombia y Ecuador; pero también las que condujeron a la formación de Bolivia y de la República Oriental del Uruguay, entre otras.

La fase de definición positiva se caracteriza por basarse en el principio jurídico del uti possidetis juris, que fue invocado como criterio de delimitación política y administrativa al desintegrarse el imperio. Sin embargo, por mucho tiempo el sentido de pertenencia nacional fue muy difuso, principalmente en las áreas fronterizas. La falta de un estado que pudiese integrar las distintas regiones e imponer un proyecto nacional, dificultó enormemente la formación positiva de la conciencia nacional.

El esfuerzo por crear un marco ideológico que justificara y legitimizara el corte con España comienza antes de la independencia. Ya está presente en los precursores de la emancipación. Uno de los grandes representantes de es to es Simón Bolívar, quien se aboca desde el pensamiento y desde la práxis a transformar el dominio colonial en una nación.

"Disuelta la Nación Española" por la ausencia de un gobierno central legítimo, los pueblos, convertidos en verdaderas ciudades -Estado, son el punto de partida para construir la nación. Esto no podrá hacerse más que por pactos y consensos.

75 CARRERA DAMAS, Germán. Del Estado Colonial al Estado Independiente Nacional. En: Vázquez, J. Z. / M. Miño Grijalva, eds.: Historia general de América Lat ina,VI: La construcción de las naciones latinoamericanas, 1820-1870. 
Miranda propone como solución la creación de naciones sobre los territorios delimitados por los pueblos aborígenes que los habitaron. La división estaría justificada por una realidad pre-existente y legitimada por ser la anterior a la dominación española. Sin embargo, después de siglos de control y cambio por parte de la Corona, era muy poco lo que realmente quedaba y era muy difícil crear diferencias nacionales en base a ese criterio. Pero Bolívar, mucho más realista, supo darse cuenta que era imposible volver los pasos de la historia y recuperar lo que ya no existía. Y postuló sus ideas en la famosa "Carta de Jama ica", del 6 de septiembre de 1815.

Yo considero el estado actual de la América como cuando, desplomado el imperio romano, cada desmembración formó un sistema político...con esta notable diferencia: que aquellos miembros dispersos volvían a restablecer sus antiguas naciones...más nosotros, que apenas conservamos vestigios de lo que en otro tiempo fue y que, por otra parte, no somos indios... ${ }^{76}$

Es decir, no podía pensarse en restablecer. Entre otras razones porque no había una clara y distintiva identidad. No eran indios, ni europeos, sino algo intermedio. Por eso la respuesta mirandina al problema era a todas luces inaplicable. Así se perfila la decisión bolivariana de renunciar a la Nación única,- la continental-, derivada de la "conservación" automática para buscar lo verdaderamente realizable. En síntesis, fue evidente para él, y luego para otros, que era necesario "destruir la Patria Grande" para poder construir la "Patria chica”.

Y en todas partes, desde el Río de la Plata a México, al hundimiento de la Gran Nación le siguió la aparición de las naciones locales: ya en forma concreta de estados provinciales, como en el Río de la Plata o México, o en forma de caudillismo regional como en Venezuela y las mismas Provincias Unidas.

\section{El caso argentino}

El estudio de la formación de la conciencia nacional argentina comienza con Angel Rosenblat a partir de sus artículos en el diario La Nación de 1940 y concluyendo con su ensayo de 1964 El Nombre de la Argentina. Sin embargo, los trabajos de José Carlos Chiaramonte van a tener más difusión y aceptación, convirtiéndose en precursores. Aunque hay que reconocer que se conoce aún más la obra de Nicolás Shumway, La invención de la Argentina. ${ }^{77}$

Todos estos autores coinciden que para 1810, cuando se estableció en Buenos Aires el primer gobierno patrio el mismo sólo tenía un área de soberanía real muy reducida. La mayor parte del territorio eran vastas extensiones de tierras desiertas habitadas por tribus indígenas. Las ciudades del interior formaban islas y la dificultad de comunicación las llevaba a un aislamiento muy similar a la autarquía. Por otro lado la jurisdicción propia del vi-

76 BOLIVAR; Simón. Carta de Jamaica, 6 de septiembre de 1815. En: Escritos Fundamentales. Caracas, Monte Avila, 1998.

77 Hilda Sabato hace una crítica muy interesante del libro de Shumway donde destapa lo superficial de algunos aspectos del análisis, junto a cierta subjetividad llevada casi al maniqueísmo. En: BOLETIN DEL INSTITUTO DE HISTORIA ARGENTINA Y AMERICANA DER. EMILIO RAVIGANANI. N*10. Buenos Aires, FCE, 1994. 
rreinato del Río de la plata no era clara y las diferencias con los vecinos nuevos países no se hicieron esperar.

Por otro lado, la población en general fue formando una identidad común distinta de la inglesa, portuguesa o francesa. Esta identidad se basaba en el mismo origen español, una lengua en común y una religión compartida. Por eso se puede hablar de una protonacionalidad hispanoamericana. A esto hay que sumarle las reformas borbónicas de 1778 que crearon un sentimiento común de recelo entre los españoles nativos, que gozaban de mayores privilegios, y los criollos blancos y mestizos. Esto sumó un elemento más de cohesión: un enemigo común, el peninsular. Por esto no podemos hablar para aquella época de "argentino" como concepto identitario opuesto a "paraguayo", "chileno", etc. Incluso se puede decir que un porteño tenía más en común con un uruguayo que con un correntino, por ejemplo.

La pérdida del factor unificador que significaba la Corona llevó a una cierta anarquía que era necesario revertir creando unidades políticas gobernables. Esas unidades requerían de una identidad exclusiva e inequívoca que garantizara la lealtad de los ciudadanos. Para lograrlo se recurrió a la potenciación de las diferencias entre vecinos y a basarse en un concepto territorialista de soberanía. La delimitación de fronteras fue instrumento de construcción identitaria.

Es fácil entender que semejante estrategia política trajera aparejados más desencuentros que encuentros. Los problemas fronterizos en la región se sucedieron casi ininterrumpidamente durante el siglo XIX y su resolución llevó, en muchos casos, a guerras fratricidas y a conflictos que abarcan siglos de duración y llegan a nuestros días.

Para el caso argentino, donde la inmigración fue una variable de suma importancia a partir de las últimas décadas del siglo XIX, la idea de una identidad nacional basada en un "crisol de razas" difícilmente incluyó a los migrantes de países fronterizos a los cuales se los veía como de segunda categoría. Esto en particular para el caso de la ciudad y provincia de Buenos Aires.

Las crisis económicas de la región crearon una competencia entre nativos y extranjeros, -ya mayormente latinoamericanos a fines del siglo XX-, que exacerbó las diferencias y los choques. Esto particularmente en los sectores más humildes de la población local que eran los que se veían a sí mismo como potencialmente más perjudicado

A partir de la década del ochenta del siglo pasado, el cambio de mentalidad de los gobernantes fue llevando a la búsqueda de una integración política, social y económica cuyo modelo es la Unión Europea. Para el caso del cono sur, el MERCOSUR marca un avance significativo. Es de esperar que este cambio que se da a nivel gobiernos vaya "derramándose" a los sectores medios y bajos de la población creando una mejor convivencia basada en el diálogo y el entendimiento mutuo. 



\section{APENDICE DOCUMENTAL}

\section{DOCTRINA DRAGO ${ }^{78}$}

Buenos Aires, 29 de dicie mbre de 1902

Señor ministro:

He recibido el telegrama de V.E. de fecha 20 del corriente, relativo a los sucesos últimamente ocurridos entre el gobierno de la República de Venezuela y los de la Gran Bretaña y Alemania.

Según los informes de V.E. el origen del conflicto debe atribuirse en parte a perjuicios sufridos por súbditos de las naciones reclamantes durante las revoluciones y guerras que recientemente han tenido lugar en el territorio de aquella república -y en parte también a que a ciertos servicios de la deuda externa del Estado no han sido satisfechos en la oportunidad debida. Prescindiendo del primer género de reclamaciones, para cuya adecuada apreciación habría que atender siempre las leyes de los respectivos países, este gobierno ha estimado de oportunidad transmitir a V.E. algunas consideraciones relativas al cobro compulsivo de la deuda pública, tales como las han sugerido los hechos ocurridos.

Desde luego se advierte, a este respecto, que el capitalista que suministra su dinero a un Estado extranjero, tiene siempre en cuenta cuáles son los recursos del país en que va a actuar y la mayor o menor probabilidad de que los compromisos contraídos se cumplan sin tropiezo. Todos los gobiernos gozan por ello de diferente crédito, según su grado de civilización y cultura y su conducta en los negocios, y estas circunstancias se miden y se pesan antes de contraer ningún empréstito, haciendo más o menos onerosas sus condiciones, con arreglo a los datos precisos que en ese sentido tienen perfectamente registrados los banqueros. Luego, el acreedor sabe que contrata con una entidad soberana y es condición inherente de toda soberanía que no puedan iniciarse ni cumplirse procedimientos ejecutivos contra ella, ya que ese modo de cobro comprometería su existencia misma haciendo desaparecer la independencia y la acción del respectivo gobierno. Entre los principios fundamentales del derecho público internacional que la humanidad ha consagrado, es uno de los más preciosos el que determina que todos los Estados, cualquiera que sea la fuerza de que dispongan, son entidades de derecho, perfectamente iguales entre sí y recíprocamente acreedoras por ello a las mismas consideraciones y respeto. El reconocimiento de la deuda, la liquidación de su importe, pueden y deben ser hechos por la Nación, sin menoscabo de sus derechos primordiales como entidad soberana, pero el cobro compulsivo e inmediato, en un momento dado, por medio de la fuerza, no traería otra cosa que la ruina de las naciones más débiles y la absorción de su gobierno con todas las facultades que le son inherentes por los fuertes de la tierra. Otros son los principios proclamados en este continente de América. "Los contratos entre una Nación y los individuos particulares son obligatorios según la conciencia del soberano, y no pueden ser objeto de fuerza compulsiva.", decía el ilustre Hamilton. " No confieren derecho alguno de acción fuera de la voluntad soberana".

78 En todos los casos hemos respetado la ortografía y la diagramación de la época. 
Los Estados Unidos - continuaba- han ido muy lejos en este sentido. La enmienda undécima de su Constitución estableció, en efecto, con el asentimiento unánime del pueblo que el poder judicial de la Nación no se extiende a ningún pleito de ley o de equidad seguido contra uno de loe Estados Unidos por ciudadanos de otro Estado, o por ciudadanos o súbditos de un Estado extranjero. La República Argentina ha hecho demandables a sus provincias y aun ha consagrado el principio de que la nación misma puede ser llevada a juicio ante la Suprema Corte por los contratos que celebra con los particulares. Lo que no ha establecido, lo que no podría de ninguna manera admitir, es que, una vez determinado por sentencia el monto de lo que pudiera adeudar, se le prive de la facultad de elegir el modo y la oportunidad de pago, en el que tiene tanto o más interés que el acreedor mismo, porque en ello están comprometidos el crédito y el honor colectivos. No es ésta de ninguna manera la defensa de la mala fe, del desorden y de la insolvencia deliberada y voluntaria. Es simplemente amparar el decoro de la entidad pública internacional que no puede ser arrastrada así a la guerra, con perjuicio de los altos fines que determinan la existencia y la libertad de las naciones. El reconocimiento de la deuda pública, la obligación definida de pagarla no es, por otra parte, una declaración sin valor porque el cobro no pueda llevarse a la práctica por el camino de la violencia. El Estado persiste en su capacidad de tal y más tarde o más temprano las situaciones oscuras se resuelven, crecen los recursos, las aspiraciones comunes de equidad y de justicia prevalecen y se satisfacen los más retardados compromisos. El fallo, entonces, que declara la obligación de pagar la deuda, ya sea dictado por los tribunales del país o por los de arbitraje internacional, los cuales expresan el anhelo permanente de la justicia como fundamento de las relaciones políticas de los pueblos, constituye un título indiscutible que no puede compararse al derecho incierto de aquel cuyos créditos no son reconocidos y se ve impulsado a apelar a la acción para que ellos le sean satisfechos.

Siendo estos sentimientos de justicia, de lealtad y de honor, los que animan al pueblo argentino, y han inspirado en todo tiempo en política, V.E. comprenderá que se haya sentido alarmado al saber que la falta de pago de los servicios de la deuda pública de Venezuela se indica como una de las causas determinantes del apresamiento de su flota, del bombardeo de uno de sus puertos y del bloqueo de guerra rigurosamente establecido por sus costas. Si es estos procedimientos fueran definitivamente adoptados, establecerían un precedente peligroso para la seguridad y la paz de las naciones de esta parte de América. El cobro militar de los empréstitos supone la ocupación territorial para hacerlo efectivo, y la ocupación territorial significa la supresión o subordinación de los gobiernos locales en los países que se extiende. Tal situación aparece contrariando visiblemente los principios muchas veces proclamados por las naciones de América y muy particularmente la doctrina de Monroe, con tanto celo sostenida y defendida en todo tiempo por los Estados Unidos, doctrina de la República Argentina ha adherido antes de ahora. Dentro de los principios que enuncia el memorable mensaje del 2 de diciembre de 1823, se contienen dos grandes declaraciones que particularmente se refieren a estas repúblicas, a saber: "Los continentes americanos no podrán en adelante servir de campo para la colonización futura de las naciones europeas, y reconocida como lo ha sido la independencia de los gobiernos de América, no podrá mirarse la interposición de parte de ningún poder europeo, con el propósito de oprimirlos o controlarlos de cualquier manera, sino como la manifestación de sentimientos poco amigables para los Estados Unidos."

La abstención de nuevos dominios coloniales en los territorios de este continente, ha sido muchas veces aceptada por los hombres públicos de Inglaterra. A su simpatía puede decirse que se debió el gran éxito que la doctrina de Monroe alcanzó apenas promulgada. 
Pero en los últimos tiempos se ha observado una tendencia marcada en los publicistas y en las manifestaciones diversas de la opinión europea, que señalan estos países como campos adecuados para las futuras expansiones territoriales. Pensadores de la más alta jerarquía han indicado la conveniencia de orientar en esta dirección los grandes esfuerzos que las principales potencias de Europa han aplicado a la conquista de regiones estériles, con un clima inclemente, en las más apartadas latitudes del mundo. Son muchos ya los escritores europeos que designan los territorios de Sudamérica con sus grandes riquezas, con un cielo feliz y su suelo propicio para todas las producciones, como el teatro obligado donde las grandes potencias, que tienen ya preparados los instrumentos y las armas de la conquista, han de disputarse el predominio en el curso de este siglo. La tendencia humana expansiva, caldeada así por las sugestiones de la opinión y de la prensa, puede, en cualquier momento, tomar una dirección agresiva, aun contra la voluntad de las actuales clases gobernantes. Y no se negará que el camino más sencillo para las apropiaciones y la fácil suplantación de las autoridades locales por los gobiernos europeos, es precisamente el de las intervenciones, como con muchos ejemplos podría demostrarse. No pretendemos de ninguna manera que las naciones sudamericanas queden por ningún concepto exentas de las responsabilidades de todo orden que las violencias del derecho internacional compartan con los pueblos civilizados. No pretendemos ni podemos pretender que estos países ocupen una situación excepcional en sus relaciones con las potencias europeas, que tienen el derecho indudable de proteger a sus súbditos tan ampliamente como en cualquier otra parte del globo, contra las persecuciones o las injusticias de que pudieran ser víctimas . Lo único que la República Argentina sostiene y lo que vería con gran satisfacción consagrado con motivo de los sucesos de Venezuela por una nación que, como los Estados Unidos, goza de tan grande autoridad y poderío, es el principio ya aceptado de que no puede haber expansión territorial europea en América, ni opresión de los pueblos de este continente, porque una desgraciada situación financiera pudiese llevar a alguno de ellos a diferir el cumplimiento de sus compromisos. En una palabra, el principio que quisiera ver reconocido es el de que la deuda pública no puede dar lugar a la intervención armada, ni menos a la ocupación material del suelo de las naciones americanas por una potencia europea. El desprestigio y el descrédito de los Estados que dejan de satisfacer los derechos de sus legítimos acreedores, traen consigo dificultades de tal magnitud que no hay necesidad de que la intervención extranjera agrave con la opresión las calamidades transitorias de la insolvencia. La República Argentina podría citar su propio ejemplo, para demostrar lo innecesario de las intervenciones armadas en estos casos. El servicio de la deuda inglesa de 1824 fue reasumido espontáneamente por ella, después de una interrupción de treinta años, ocasionada por la anarquía y las convulsiones que conmovieron profundamente el país en ese período de tiempo, y se pagaron escrupulosamente todos los atrasos y todos los intereses, sin que los acreedores hicieran gestión alguna para ello.

Más tarde una serie de acontecimientos y contrastes financieros, completamente fuera del control de sus hombres gobernantes, la pusieron, por un momento, en situación de suspender de nuevo temporalmente el servicio de la deuda externa. Tuvo, empero, el propósito firme y decidido de reasumir los pagos inmediatamente que las circunstancias se lo permitieran y así lo hizo, en efecto, algún tiempo después, a costa de grandes sacrificios, pero por su propia y espontánea voluntad y sin la intervención ni las conminaciones de ninguna potencia extranjera. Y ha sido por sus procedimientos perfectamente escrupulosos, regulares y honestos, por su alto sentimiento de equidad y de justicia plenamente evidenciado, que las dificultades sufridas en vez de disminuir han acrecentado su crédito en los mer- 
cados europeos. Puede afirmarse con entera certidumbre que tan halagador resultado no se habría obtenido si los acreedores hubieran creído conveniente intervenir de un modo violento en el período de crisis de las finanzas, que así se han repuesto por su sola virtud. No tememos no podemos temer que se repitan circunstancias semejantes.

En el momento presente no nos mueve, pues, ningún sentimiento egoísta ni buscamos el propio provecho al manifestar deseo de que la deuda pública de los Estados no sirva de motivo para una agresión militar de estos países. No abrigamos tampoco respecto de las naciones europeas ningún sentimiento de hostilidad. Ante, por el contrario, mantenemos con todas ellas las más cordiales relaciones desde nuestra emancipación, muy particularmente con Inglaterra, a la cual hemos dado recientemente la mayor prueba de confianza que nos inspiran su justicia y su ecuanimidad entregando a su fallo la más importante de nuestras cuestiones internacionales, que ella acaba de resolver fijando nuestros límites con Chile después de una controversia de más de sesenta años. Sabemos que donde la Inglaterra va, la acompaña la civilización y se extienden los beneficios de libertad política y civil. Por eso la estimamos, lo que no quiere decir que adhiriéramos con igual simpatía a su política en el caso probable de que ella tendiera a oprimir las nacionalidades de este continente, que luchan por su progreso, que ya han vencido las dificultades mayores y triunfarán en definitiva para honor de las instituciones democráticas. Largo es, quizás, el camino que todavía deberán recorrer las naciones sudamericanas. Pero tienen fe bastante y la suficiente energía y virtud para llegar a su desenvolvimiento pleno, apoyándose las unas en las otras.

$\mathrm{Y}$ es por ese sentimiento de confraternidad continental, por la fuerza que siempre deriva del apoyo moral de todo un pueblo, que me dirijo al señor ministro, cumpliendo instrucciones del excelentísimo señor Presidente de la República para que transmita al gobierno de los Estados Unidos nuestra manera de considerar los sucesos en cuyo desenvolvimiento ulterior va a tomar una parte tan importante, a fin de que se sirva tenerla como la expresión sincera de los sentimientos de una nación que tiene fe en sus destinos y la tiene en los de todo este continente, a cuya cabeza marchan los Estados unidos, actualizando ideales y suministrando ejemplos.

Quiera el señor ministro aceptar las seguridades de mi consideración distinguida. 


\section{Declaration of independence}

Dublin, 21 January 1919

Whereaes the Irish people is by right a free people:

And Whereas for seven hundred yeasr the Irish people has never ceased to repudiate and has repeatedly protested in arms against foreing usurpation:

And Whereas English rule in this country is, and always has been, based upon force and fraud and maintained by military occupation against the declared will of the people:

And Whereas the Irish Republic was proclaimed in Dublin on Easter Monday, 1916, by the Irish Republican Army acting on behalf of the Irish people:

And Whereas the Irish people is resolved to secure and maintain its complete independence in orden to promote the common weal, to re-establish justice, to provide for future defence, to insure peace at home and goodwill with all nations and to constitute a national polity based upon the people's will with equal right and equal opportunity for every citizen.

And Whereas at the threshold of a new era in history the Irish electorate has in the General Election of December, 1918, seized the first occasion to declare by an overwhelming majority its firm allegiance to the Irish Republic:

Now, Therefore, we, the elected Representatives of the ancient Irish people in National Parliament assembled,do, in the name of the Irish nation, ratify the establishment of the Irish Republic and pledge ourselves and our people to make this declaration effective by every means at our command:

We ordain that the elected Representatives of the Irish people alone have power to make laws binding on the people of Ireland, and that the Irish Parliament is the only Parliament to wich that people will give its allegiance:

We solemnly declare foreing government in Ireland to be an invasion of our national right wich we will never tolerate, and we demand the evacuation of our country by the English Garrison:

We claim for our national independence the recognition and support of every free nation in the word, and we proclaim the independence to be condition precedent to international peace hereafter:

In the name of the Irish people we humbly commit our destinity to Almighty God who gave our fathers the courage and determination to persevere through long centuries of a ruthless tyranny, and strong in the justice of the cause wich they have handed down to use, we ask His divine blessing on this the last stage of the struggle we have pledged ourselves to carry trough to Freedom. 


\section{Message to the Free Nations of the World}

Dublin, 21 January,1919

To the Nations of the World!

Greeting.

The Nation of Ireland having proclaimed her national independence, calls through her elected representatives in Parliament assembled in the Irish Capital on January $21^{\text {st }}, 1919$, upon every free nation to support the Irish Republic by recognising Ireland's national status and her right to its vindication at the Peace Congress.

Nationally, the race, the language, the customs and traditions of Ireland are radically distinct from the English. Ireland is one of the most ancient nations in Europe, and she has preserved her national integrity, vigorous and intact, through seven centuries of foreing oppression: she has never relinquished her national rights, and throughout the long era of English usurpation she has in every generation defiantly proclaimed her inalienable right of nationhood down to her last glorious resort to arms in 1916.

Internationally, Ireland is the gateway of the Atlantic. Ireland is the last outpost of Europe towards the West: Ireland is the point upon wich great trade routes between East and West converge: her independence is demanded by the Freedom of the Seas: her great harbours must be open to all nations, instead of being the monopoly of England. To-day these harbours are empty and idle solely because English policy is determined to retain Ireland as a barren bulwark for English aggrandisement, and the unique geographical position of this island, far from being a benefit and safeguard to Europe and America, is subjected to the purposes of England's policy of world domination.

Ireland to-day reassert her historic nationhood the more confidently before the new world emerging from the War, because she belives in freedom and justice as the fundamental principles of international law, because she belives in a frank co-operation between the peoples for equal rights against the vested privileges of ancient tyrannies, because the permanent peace of Europe can never be secured by perpetuating military dominion for the profit of empire but only by establishing the control of government in every land upon the basis of the free will of a free people, and the existing state of war, between Ireland and England, can never be ended until Ireland is definitely evacuated by the armed forces of England.

For these among other reasons, Ireland- resolutely and irrevocably determinated at the dawn of the promised era of self-determination and liberty that she will suffer foreing dominion no longer- calls upon every free nation to uphold her national claim to complete independence as an Irish Republic against the arrogant pretensions of England founded in fraud and sustained only by an overwhelming military occupation, and demands to be confronted publicly with England at the Congress of the Nations, inorden that the civilised world having judged between English wrong and Irish right may guarantee to Ireland its permanent support for the maintenance of her national independence. 


\section{BIBLIOGRAFIA}

AMORES, Juan Bosco. Iberoamérica en el siglo XIX : nacionalismo y dependencia. Pamplona, EUNATE, 1995.

ANDERSON, Benedict. Comunidades Imaginarias. Argentina, FCE, 1993.

BARBERO, María Inés y ROLDAN, Darío. Inmigración y educación (1880-1910): ¿La escuela como agente de integración?. Cuadernos de historia regional, vol. III, Agosto 1987, no. 9. Luján, Bs.As.: Universidad de Luján 1987.

BARRY, Carolina. La Primera Convención de la Raza Irlandesa en Sudamérica. En: 'The Southern Cross' Vol. 129, 5883 (January 2004)

BERNAL-MEZA, Raúl. América Latina en el mundo. El pensamiento latinoamericano y la teoría de las relaciones internacionales. Bs As., Grupo Editor Latinoamericano S.R.L., 2005.

BOBBIO, Norberto, METTEUCCI, Incola y PASQUINO, Gianfranco. Diccionario de Política. México, Siglo XXI, 1997. Décima edición.

BOLETIN DEL INSTITUTO DE HISTORIA ARGENTINA Y AMERICANA DR. EMILIO RAVIGNANI. N* 10. Buenos Aires, FCE, 1994.

BOLIVAR; Simón. Escritos Fundamentales. Caracas, Monte Avila, 1998.

BOULGOURDJIAN-TOUFEKSIAN. Ed. Los armenios en Buenos Aires. La reconstrucción de la identidad (1900-1950). Buenos Aires, Centro Armenio, 1997.

BOTANA, Natalio R. El Orden Conservador. Argentina, Hyspamérica, 1986.

BUISSON, Inge, et al., eds. Problemas de la formación del estado y de la nación en Hispanoamérica (By O. Carlos Stoetzer), XXXV, 4, 1985, 462-464.

CALVO,C. Le droit international théorique et pratique précédé d'un exposé historique des progrès de la science du droit des gens. París, Rousseau., 1896

CISNEROS, Andrés. Argentina: historia de un éxito. En: Política Exterior argentina (1989-1999. Buenos Aires, GEL, 1998.

CHIARAMONTE, José Carlos. Nacionalismo y liberalismo económicos en la Argentina, 1860-1880.Buenos Aires, Solar-Hachette, 1971.

CLIFFORD, Angela. August 1969: Ireland`s Only Appeal to The United Nations. Belfast, Belfast Magazine, marzo de 2006.

CLIFFORD, Brendan. Aspects of The Movement of United Irishmen. Belfast, Athol Books, 1991.

D`HONDT, Jacques. De Hegel a Marx. Buenos Aires, Amorrortu editores, 1974

DE LA BALZE, Felipe A.M y Eduardo ROCA (comp.) Argentina y EE.UU. Fundame ntos de una nueva alianza, Buenos Aires, ABRA-CARI, 1997.

DE LANEY, Jeane. National Identity, Nationhood, and Immigration in Argentina: 1810-1930. Stanford Electronic Humanities Review, Vol. 5/2, 1997. <http://www.stanford.edu/group/SHR/5-2/delaney.html> [10 July 2003].

DEVOTO, Fernando. Historia de la inmigración en la Argentina. Buenos Aires.Sudamericana. 2003.

ESCUDE, Carlos Aspectos Ocultos de la Educación en la Argentina: Políticas de Inversión y Productividad Educativa, 1900-1975. Buenos Aires, El Coloquio, 1975. 
ESCUDE, Carlos. El fracaso del proyecto argentino: educación e ideología. Buenos Aires: Instituto Torcuato di Tella/Conicet 1990.

ESCUDE. Carlos. Un enigma: la "irracionalidad" argentina frente a la Segunda Guerra Mundial. Buenos Aires,Universidad Torcuato Di Tella. Disponible en internet.

FERNS, H.S. Las relaciones angloargentinas, 1880-1910. En: Gustavo Ferrari y Ezequiel Gallo (comp.), La Argentina del Ochenta al Centenario. Buenos Aires. Sudamericana,

FERNÁNDEZ BRAVO,Alvaro. La invención de la nación. Manantial,2000.

FERRER, Aldo, La economía argentina. FCE, Argentina, decimosexta impresión, 1996.

FIGARI, Guillermo. Pasado, presente y futro de la política exterior argentina. Buenos Aires, Biblos, 1993.

FINKIELKRAUT, Alain. La derrota del pensamiento. Anagrama, 1987.

GÉLLER, Ernest. Nación y nacionalismo.Alianza, 1981

GUIBERNAU, Montserrat. Los nacionalismos. España, Ariel, 1996

JOHN A. Estado y Nación. Madrid, Cambridge Universtity Press, 2000.

JOHN (ed.), The Land that England Lost: Argentina and Britain, a Special Relationship. London: British Academic Press 1992.

HALL, John A.Estado y nación. Cambridge University Press, 2000.

HOBSBAWM, ERIC. Naciones y Nacionalismo desde 1780. Barcelona, Ed. Crítica, 1995.

HOCKING, Brian. Localizing Foreing Policy: Non-Central Governments and Multiplayer Diplomacy. Londres/Nueva York, Macmillan and St. Martin's Press, 1993.

KAHN, Hans._Historia del Nacionalismo, Fondo de Cultura Económica,1984.

KENNEDY, Michael y MORRISON SKELLY, Joseph. Irish Foreing Policy, 1916-66. Inglaterra, Four Courts Press, 2000.

KOROL, Juan \& SABATO, Hilda. Cómo fue la inmigración Irlandesa en Argentina. Buenos Aires: Plus Ultra 1981.

MC NALL BURNS, Edward. Civilizaciones de occidente. Buenos Aires, Siglo Veinte, 1988. Tomo 2,

MARSHALL, T.H. y BOTTOMORE, Tom. Ciudadanía y clase social. Madrid, Alianza Editorial, 1998.

MARX, Carlos y ENGELS, Federico. El Manifiesto Comunista. Disponible en internet MILLER, David. Sobre la Nacionalidad. Barcelona, Piados, 1997.

MURRAY, Edmundo. Devenir Irlandés. Buenos Aires, EUDEBA,2004.

PALTI, Elías. La nación como problema. Argentina, Fondo de Cultura Económica, 2002. PEREZ LLANA, Carlos. ¿Potencias intermedias o países mayores? La política exterior de Argentina, Brasil y México. 1975.

PUIG, Juan Carlos. (comp.) América Latina: Políticas Exteriores Comparadas.Bs.As., Grupo Editor Latinoamericano, 1984.

PUIG, Juan Carlos. Política Internacional Argentina. Buenos Aires, GEL, 1988.

RENAN, Ernest. Qué es una nación?. Madrid, Tecnos, 1985.

REVISTA DE OCCIDENTE. N*161, octubre de 1994.

S/A. Características Migratorias de la Población en el IV censo general de la nación del año 1947. Argentina, INDEC, 1999. 
SARMIENTO, Domingo F. Facundo. Capítulo I. Disponible en Internet.

SABATO, Hilda ed., Ciudadanía política y formación de las naciones. Perspectivas. históricas de América Latina .México, Fondo de Cultura Económica, 1999, SHUMWAY, Nicolás. La invención de la Argentina: historia de una idea. Buenos Aires: Emecé, 2002.

SWEEZY, Paul M. Y OTROS. La Transición del Feudalismo al Capitalismo. Argentina, Ediciones la Cruz del Sur, 1974.

TAMBURINI, Francesco. HISTORIA Y DESTINO DE LA "DOCTRINA CALVO": ¿ACTUALIDAD U OBSOLESCENCIA DEL PENSAMIENTO DE

CARLOS CALVO?. . Rev. estud. hist.-juríd.. [online]. 2002, no.24 [citado 30 Julio 2005], p.81-101. Disponible en la World Wide Web:

$<$ http://www.scielo.cl/scielo.php?script=sci_arttext\&pid=S0716$54552002002400005 \& \operatorname{lng}=\mathrm{es} \& n r m=\mathrm{iso}>$. ISSN 0716-5455

TODOROV, Tzvetan. Memoria del mal, tentación del bien. Indagación sobre el siglo XX. Barcelona, Ed. Península, 2002.

TOTORICAGUENA, Gloria Nationalism and Ethnic Politics. EEUU, Taylor and Francis Inc., 2005.

VAZQUEZ, J. Z. / M. Miño Grijalva, eds.: Historia general de América Latina,VI: La construcción de las naciones latinoamericanas, 1820-1870. 